\title{
THE INFLUENCE OF BANDS OF AMERICA ON ONE HIGH SCHOOL MARCHING BAND: A SINGLE CASE STUDY
}

A Dissertation presented to the Faculty of the Graduate School at the University of Missouri

In Partial Fulfillment

of the Requirements for the Degree

Doctor of Philosophy

by

Stephen C. Eubanks

Dr. Brian Silvey,

Dissertation Supervisor

May 2016 


\section{Copyright by}

Stephen C. Eubanks

2016 
The undersigned, appointed by the dean of the Graduate School, have examined the dissertation entitled

\section{THE INFLUENCE OF BANDS OF AMERICA ON ONE HIGH SCHOOL MARCHING BAND: A SINGLE CASE STUDY}

presented by Stephen C. Eubanks, a candidate for the degree of doctor of philosophy, and hereby certify that, in their opinion, it is worthy of acceptance.

Professor Brian A. Silvey

Professor Wendy L. Sims

Professor Antonio J. Castro

Professor Kathleen Unrath

Professor D. Bradley Snow 


\section{DEDICATION}

This dissertation is lovingly dedicated to my mother, Eva D. Eubanks, who passed away during the first year of my doctoral program at the University of Missouri. 


\section{ACKNOWLEDGEMENTS}

I would like to thank Dr. Brian Silvey for his guidance and support as my advisor throughout my doctoral studies. His hours of dedication and words of encouragement for this dissertation have helped guide me toward the world of academic research. He was also gracious enough to include me in a research project, classroom teaching, and ensemble conducting. These experiences have proven invaluable in preparing me for my 'second career' as a university professor.

I would like to express my sincere thanks to Dr. Wendy Sims for her words of support and wisdom as I have pursued my $\mathrm{PhD}$. Her encouragement provided the impetus to begin and continue this quite rigorous program at the University of Missouri. Her example not only as a researcher and teacher, but also as a person has been one that I will value my entire life.

I would also like to thank Dr. Brad Snow for making me feel more like a colleague than a student during my tenure at the University of Missouri. The teaching opportunities he afforded me with Marching Mizzou, the University Band, and the Wind Ensemble will serve me well as I begin working at the university level. His thorough knowledge of the wind band and its literature has made me want to continue to learn.

I would like to offer a special note of thanks to Dr. Tony Castro and Dr. Kathleen Unrath for their assistance in the final preparation of this dissertation. Their insight and guidance into qualitative research have been truly helpful and most appreciated.

I wish to acknowledge all of my professors who stood by my side during the illness and death of my mother. Their willingness to be flexible with my academic responsibilities demonstrates why the University of Missouri is such a great institution. 
I would like to offer a special note of thanks to the administration of Camdenton High School, along with the marching band staff, the students and parents of the Camdenton High School Pride of the Lake Marching Band. Without them, this dissertation would not have been possible. 


\section{TABLE OF CONTENTS}

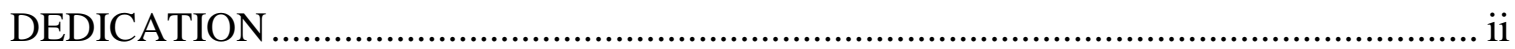

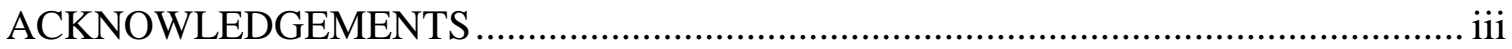

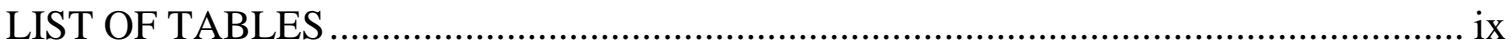

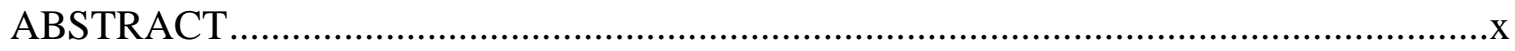

Chapter

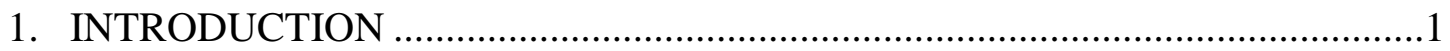

The High School Marching Band Tradition ......................................................1

The Value of the High School Marching Band .................................................

Competition and the High School Marching Band .........................................4

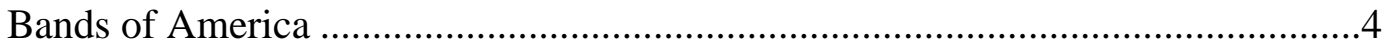

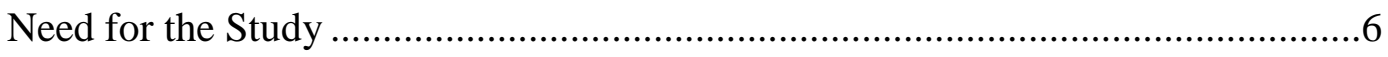

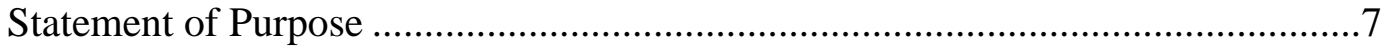

Camdenton High School Marching Band Show -2015 ...................................

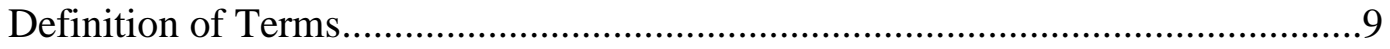

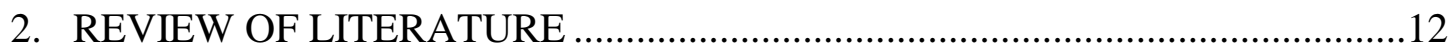

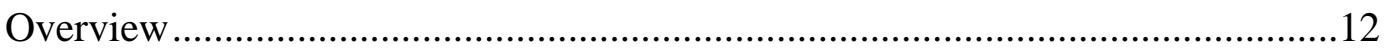

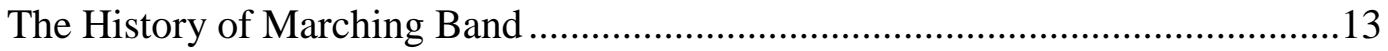

The History of Competition in Music ....................................................... 15

Research on Marching Band Competition ......................................................18

Directors' Attitudes Toward Marching Band Competition .................................19

Anxiety and Marching Band Competition .....................................................21

Marching Band Competition Findings From Individual States ...........................23 
Nation Wide Studies of Marching Band Competitions

Teacher Behavior Associated with Marching Band Competitions

Reliability of Marching Band Competitions ...................................................28

The Influence of Drum and Bugle Corps on Marching Band Competitions .........29

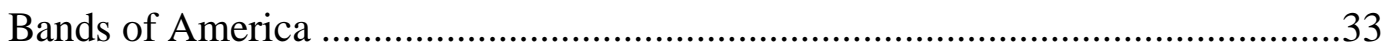

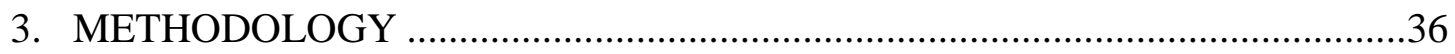

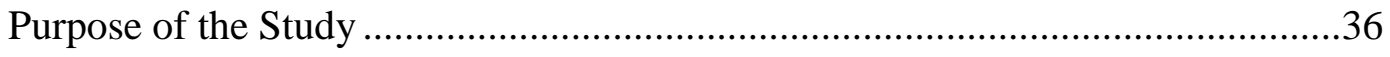

Main Research Questions ...............................................................................

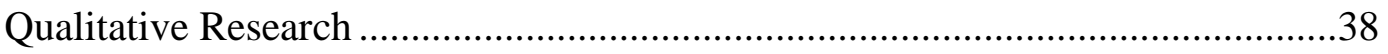

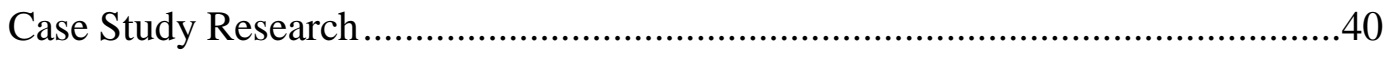

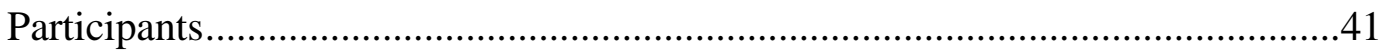

The Camdenton High School Pride of the Lake Marching Band. ..........................41

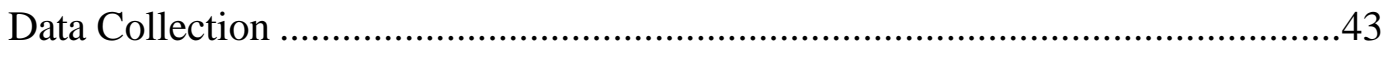

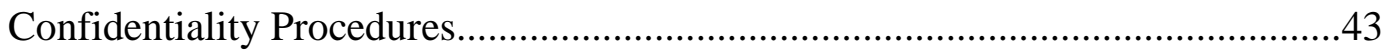

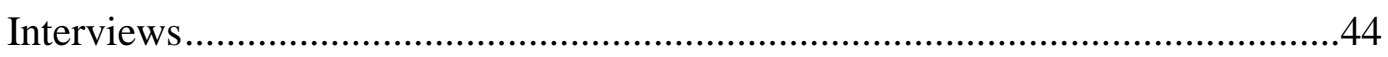

Field Notes, Observations, and Participant Journal ...........................................50

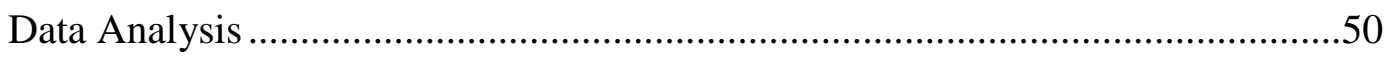

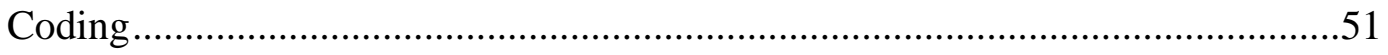

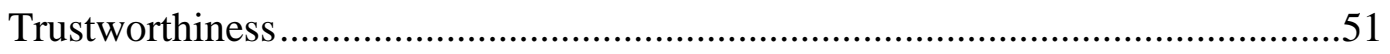

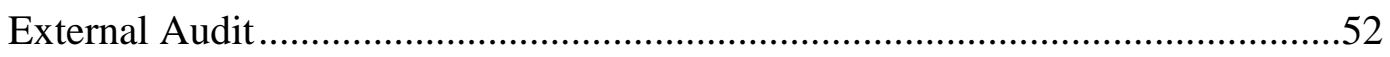

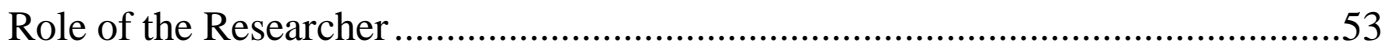

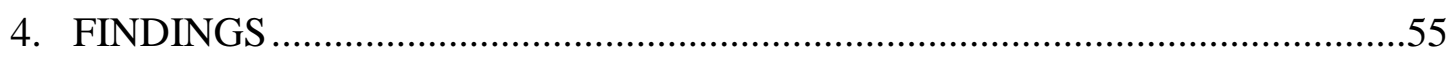

BOA as a Standard of Excellence .................................................................56 
Consistent and Rigorous Adjudication Criteria

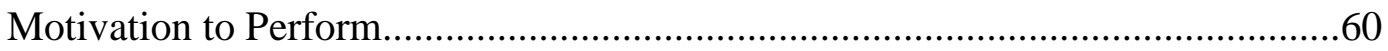

Effect on Marching Band Members' Attitudes ..............................................62

Changes to Band Practices .....................................................................66

Changes in the Band's Performance .........................................................67

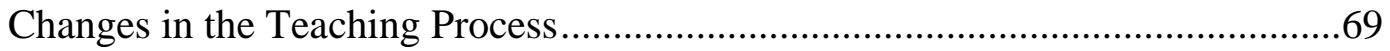

Changes in the Students' Participation in Band................................................. 72

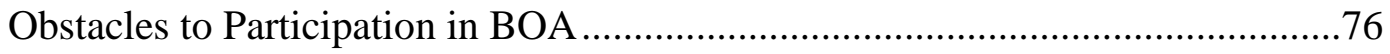

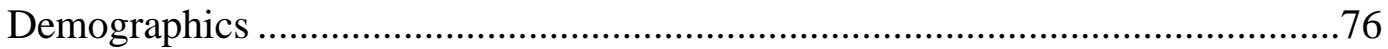

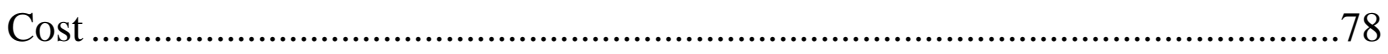

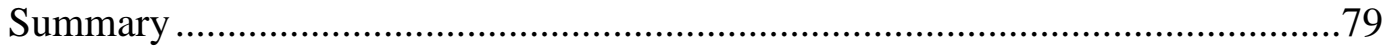

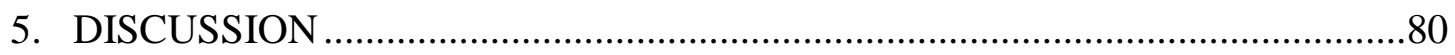

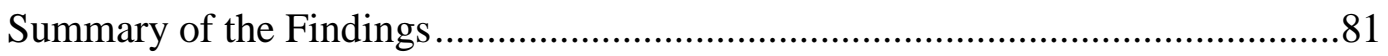

What are the key motivators for a high school marching band to participate in a

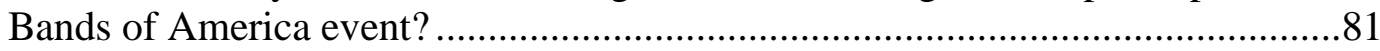

In what ways does participation in BOA influence the practices of a high school

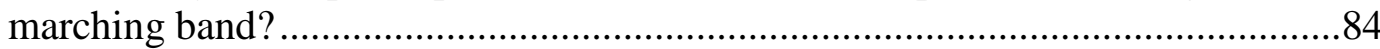

What obstacles, if any, does a rural high school marching band face while participating in Bands of America?

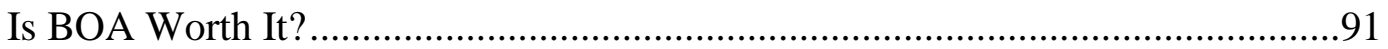

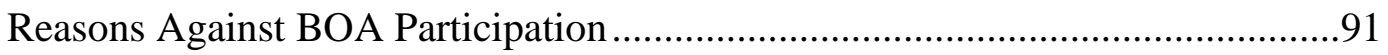

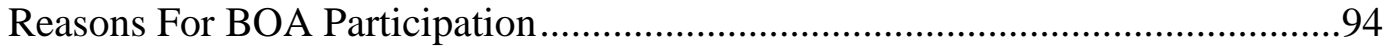

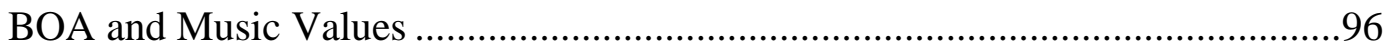

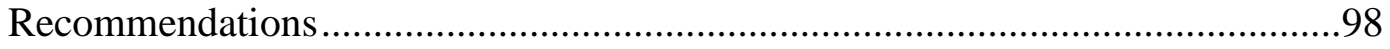

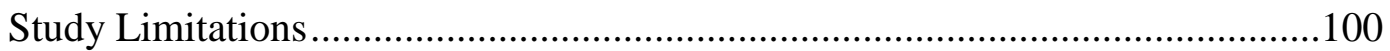




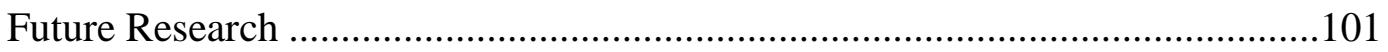

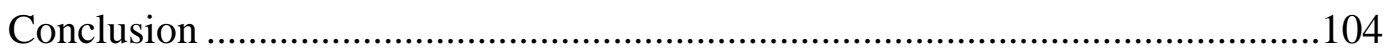

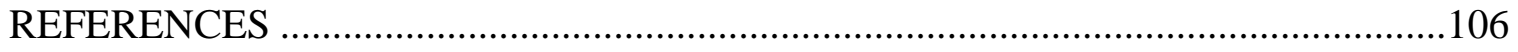

APPENDICIES

A. Campus Institutional Review Board Approval Letter .........................................116

B. Camdenton High School Principal Approval Letters ...........................................118

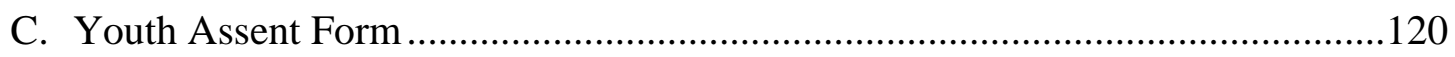

D. Parental Consent Form.....................................................................................

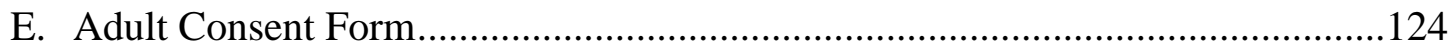

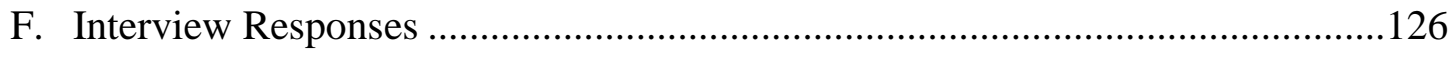

G. BOA Music Adjudication Sheets and Rubrics...................................................139

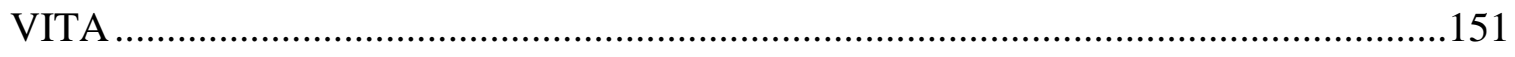




\section{LIST OF TABLES}

Table $\quad$ Page

1. Camdenton High School Marching Band St. Louis BOA Results ......................42

2. Method, Location, and Data Collection Sequence..........................................46

3. Camdenton High School Marching Band Staff ...............................................47

4. Camdenton High School Marching Band Student Interviewees .........................49 


\title{
THE INFLUENCE OF BANDS OF AMERICA ON ONE HIGH SCHOOL MARCHING BAND: A SINGLE CASE STUDY
}

\author{
Stephen C. Eubanks
}

Dr. Brian Silvey, Dissertation Supervisor

\begin{abstract}
The purpose of this research study was to examine the influence of participation in Bands of America competitions (hereafter referred to as BOA) on one central Missouri high school marching band program. I chose to study a Missouri high school marching band that had been involved with BOA for a minimum of five years. Participants in this study were marching band members plus staff of the Camdenton High School marching band

$(N=22)$.
\end{abstract}

My goal was to produce a study that was descriptive of the influence, if any, that participation in BOA had on the Camdenton High School marching band. I sought to discover this through observations of their rehearsals and performances at their marching band contests. I chose to conduct a qualitative, single case study. Data were collected through structured and open-ended interviews, observations, field notes, and my participant researcher journal.

To date, there has been limited research on BOA participation by high school marching bands. BOA claims to be the largest and most prestigious national marching competition available to high school marching bands in the United States. BOA has grown nationally from eight contests in 1985 to 20 contests in 2015 . When BOA expanded in 1997 to include the St. Louis, Missouri regional championship, only five 
Missouri bands participated in the event. The number had grown in 2015 to include 25 Missouri bands.

During my research, I assumed the role of an active participant and observed the band's music and marching drill preparation, and attended their competitions in order to observe their BOA performances. My research questions focused on the following areas: (a) the key motivators for a high school marching band to participate in BOA, (b) how BOA influences the practices of a high school marching band, and (c) what barriers a rural marching band faces in order to participate in BOA.

Through my investigation, I discovered that there were several motivators for the Camdenton High School marching band staff to elect to participate in BOA. The standard of excellence that exists at BOA marching contests is consistent from state to state, and provides the staff and students with an adjudication rubric that serves as a guide for them to rehearse and perform at a higher musical level. Participation in BOA has led the staff to change the design practices of their marching show design. In addition to the planning of the show, the staff has improved their teaching process. This, in turn, has affected the students' attitude and approach toward their rehearsals. They have an increased work ethic and feel responsible for each other. All of these factors exist despite certain obstacles the band faces, including limited resources and an increased cost factor.

Other high school band directors who are considering BOA participation might consider the Camdenton High School marching band program as a model. By looking into the reasons why Camdenton chose to participate in BOA and some of the resultant influences, directors might be able to apply them to their own school marching band programs. 


\section{CHAPTER ONE}

\section{Introduction}

The dark sky gently gave way to reds and blues as the sun boldly made its way over the horizon of the small Lake of the Ozark community of Camdenton. As I looked over the quiet setting, I observed the new high school with its artificial turf practice field. My attention was immediately drawn to the word "Lakers," which was formed of painted particleboard on the steep hillside and centered perfectly to the field. All was quiet, but the feeling of anticipation existed for what would soon take place as members of the Camdenton High School Pride of the Lake marching band began arriving. Band camp would soon begin on what will surely be one of many hot July days in preparation for the marching season that was ahead.

\section{The High School Marching Band Tradition}

Marching bands have long been a tradition of high schools across the United States. The marching band was an outgrowth of the military community and gradually became integrated within the public school system. Bands perform in community parades, high school football games, and marching competitions. These outdoor bands consist of woodwind, brass, and percussion instruments. They may also include a drum major who leads the band, as well as a color guard, consisting of flags, rifles, sabers, and/or twirlers (Binion, 1973).

For years, marching bands could be described as precision units - primarily due to their military influence. The bands would perform step-two drills and create block formations on the field (letters, or other objects) while playing military march music. 
Marching bands later evolved into show bands, performing a variety of formations on the field that resembled the content of their popular musical arrangements. With the increased popularity of the drum and bugle corps, marching bands began to take on a new look, exchanging military-style uniforms for a more contemporary style. Flags used in the color guard were artistically designed to portray the mood of the music (Spohn, 1969).

Many marching bands changed their marching style from the traditional military step to a glide step. This made it easier for high school musicians to perform music with more body stability. Other marching bands continued the traditional marching styles popular in their community. Marching band competition organizers eventually adapted procedures to match those used by Drum Corps International (Robinson \& Middleton, 1975).

Bands that chose to adopt this new style became known as corps style bands. These marching bands used adjusted step sizes to facilitate the execution of their continuously changing forms on the field. These forms might be linear, curvilinear, or scatter design. Music included a wide range of styles from symphonic music to jazz, pop, rock, or even film scores (Bailey, 2003). A wide variety of color guard equipment might be used along with costumes, props, or backdrops placed behind the band. The percussion section expanded to include two major elements, the battery and the front ensemble. The front ensemble might also include electronic instruments, such as keyboard and guitar (Holston, 2004). These changes helped make the marching band more popular, and resulted in a culture that increased students' motivation for participating in the marching band activity (Rickels, 2009; Vance, 2014). 


\section{The Value of the High School Marching Band}

The high school marching band has been viewed as one of the most popular secondary school performing organizations, oftentimes providing the only contact between the music program and school administrators (Garrison, 1986). The marching band also provides exposure for the high school to the community, connecting the public with the music department. Mayerhofer (cited in Mason et al, 1985) noted that this visibility has helped to build valuable community support not only for the band and the music department, but also for the entire school.

Marching band can also help students develop a sense of pride in their school, their band, and themselves. As band students work to learn their music and marching movements on the field, they begin to acquire an understanding of the artistic elements surrounding a marching band show and may begin to comprehend the overall effect of their show and their performance (Heselton, 2011). By focusing closer attention to the musical elements of intonation, tone quality, rhythms, balance, as well as the coordination of the visual elements of a marching band show, students experience a musical performance that is both intellectually and emotionally satisfying (Garrison, 1986).

Through marching band, students also learn a variety of skills that have the potential to make them function better as adults. Leadership opportunities associated with marching band may be developed through squad instruction, and may include teaching marching drill, assisting with musical rehearsals, and dealing with student complaints. Students also develop a sense of trust, acceptance, and self-confidence, all benefits that may serve to enrich the life of a young person as they move toward 
adulthood. This leadership helps to foster teamwork, allowing students to understand the importance of working together. The teamwork achieved through working together in music and drill preparation during rehearsals helps to shape a culture in which participants are motivated to perform at a high level of excellence (Allsup, 2012; Dagaz, 2012; Heselton, 2011).

\section{Competition and the High School Marching Band}

The goal of performing at a high level is most frequently associated with marching competitions. Rockefeller (1982) noted that marching band competitions had grown in popularity over the past several years, and may include local, state, regional, and even national contests. Payne (1997) underscored that the terms "contest" and "festival" were frequently used interchangeably in the profession, and may involve two scoring systems used to judge the performance level of the marching band. One scoring system consists of a ranking system where bands are given a numerical score for their performance and are placed sequentially from first to last, whereas the other consists of a rating system, where a band's performance is awarded a Division rating, such as Division I (excellent), Division II (superior), Division III (average), Division IV (weak), or Division $\mathrm{V}$ (poor). The ultimate goal for receiving rankings or ratings is for students to experience the feeling of accomplishment and to develop a sense of pride in a job well done in a competitive situation (Mason et al., 1985).

\section{Bands of America}

The adoption of corps style marching brought about a change in marching band competitions, resulting in the creation of Bands of America (BOA), a division of "Music for All." Originally called "Marching Bands of America," this organization began in the 
summer of 1976 at the University of Wisconsin - Whitewater as a single summer workshop for band teachers. A simultaneous marching band competition known as "Summer Nationals" occurred during the evening. In 1984, the contest was renamed Bands of America and moved to the Hoosier Dome in Indianapolis, Indiana. In 2006, Bands of America merged with the Music for All Foundation (www.musicforall.org/bandsofamerica, 2015).

BOA includes fall marching band Regional Championships and Super Regional Championships held across the country and the Grand National Championships held in Indianapolis, Indiana. The philosophy behind BOA centers around the idea that competition is part of the very fabric of what has made America a great nation and a world leader. The competitive arena of BOA has created a climate through which participants strive for achievement beyond their potential through excellence in performance (www.musicforall.org, 2015).

The Bands of America competition, now held in Lucas Oil Stadium in Indianapolis, Indiana, is perhaps the largest and most prestigious national marching competition available to high school marching bands in the United States (Markworth, 2008). BOA has grown nationally from 8 contests in 1985 to 20 contests in 2015 . The impact of this event has grown not only on the national level, but also in the state of Missouri. When BOA expanded in 1997 to include the St. Louis Regional Championship, only five Missouri marching bands participated in the event. The number increased in 2015 to include 25 Missouri marching bands (www.musicforall.org/bandsofamerica, 2015). 


\section{Need for the Study}

Given the rapid growth in BOA participation by Missouri marching bands as well as limited research in this area, I decided to investigate the influence of participation in BOA on one high school marching band program in Missouri. From personal discussion with many band directors from around the state, I know that many are contemplating whether or not to enter BOA contests. I hope that my study may provide information to assist them with their decision. Payne (1997) wrote, "there is a need for continued research related to competitive settings for school bands" (p. 14). As a high school band director with 30 years of experience in the state of Missouri, I have witnessed both the growth of participation in and the evolution of the marching band activity in our state as well as increased participation in BOA.

From late August, through the beginning of November, numerous marching band contests are held throughout Missouri. These contests range in design from festivals to placement contests. Many of these, although not official BOA events, have adopted the BOA judging format and scoring system. In recent years, there has been increased interest toward and participation in official BOA competitions. This event serves as a venue where bands may compete on a national level.

As bands have become more involved with BOA, I have witnessed the increased amount of time that teachers and students spend in preparation for and participation in this event. The number of parent volunteers required for BOA has also increased. Increased parental support is required for fundraising, student transportation, and equipment moves. Perhaps one of the major items affecting bands that participate in BOA is that of increased cost. 
During my last few years as a public school band director, an increasing number of my colleagues asked my opinion of BOA and sought my advice about whether they should involve their marching bands in Bands of America. For many band directors, consideration of BOA participation has become a divisive issue. Their inquiries, along with my own curiosity about the importance of BOA in shaping the direction of Missouri marching bands, provided the impetus for this study.

\section{Statement of Purpose}

The purpose of this study was to investigate the influence of Bands of America on one high school band program. Although I had participated in BOA contests on a limited basis during my teaching career, I decided to conduct a qualitative, single case study in order to investigate the topic in depth. I selected the Camdenton High School Marching Band located in Camdenton, Missouri. I was particularly interested in why the Camdenton band staff made the decision to participate in BOA, as well as the impact of participation in BOA upon student interest, motivation, and performance. My goal was to provide an investigation of the BOA experience through the lens of one high school band program in central Missouri.

\section{Camdenton High School Marching Band Show - 2015}

The title of Camdenton High Schools competitive marching band show was "Coronation," with the theme being a fairytale of a beautiful girl that is promised a falling star that lies on the other side of a supernatural parallel universe. A young lad, who is in love with her, must enter a mysterious kingdom in order to retrieve the star for his love. If he succeeds, he will also uncover the secret to his own identity. Music selections included a montage from Howard Hanson's "Merry Mount Suite" and Ilan Eshkeri's "Coronation" 
from the movie soundtrack "Stardust." Each movement had been sketched out and the musical arrangements timed to fit within the timeframe allowed at BOA contests. The color guard uniform was also designed to fit the show theme. All elements of the show design had been printed in a show design booklet designed by the marching band staff. 


\section{Definition of Terms}

6 to 5 or 8 to 5 - The number of steps a marcher uses between every five yards on a football field.

Adjudication - The act of judging or rating a musical ensemble's performance.

Adjudication may include both comments and the award of a rating or numerical score.

Bands of America - A division of Music For All that organizes marching band contests.

Battery Percussion - The section of a drum line consisting of snare drums, tenor drums, bass drums, and cymbals.

Caption - A specific category of adjudication (see General Effect, Musical Performance, and Visual Performance).

Color Guard - The flag, rifle, sabre, and/or dance line of a drum and bugle corps or a marching band.

Corps - Refers to a drum and bugle corps.

Corps Style Marching Band - A high school marching band that patterns its marching show after a drum and bugle corps.

Curvilinear Line - A curved line used in drill design.

DCI - An abbreviation for Drum Corps International, the member organization of drum and bugle corps.

Division I, II, III, IV, or V Rating - An adjudication system based on the criteria of superior, excellent, good, fair, or weak performance.

Drill - The movement of the students in the band on the field while playing music on their instruments or using color guard equipment. Drill consists of marching style, instrument and body carriage, and calls for a great deal of integration of the color guard, percussion placement, and wind instrument staging.

Drum and Bugle Corps - A musical organization consisting of brass bugles, percussion, and color guard members.

Drum line - The percussion unit of the marching band (see Battery Percussion, Front Ensemble/Pit).

Front Ensemble/Pit - The section of the drum line that is positioned on the front sideline of the football field. This section may consist of bells, xylophone, marimba, chimes, timpani, drum set, guitar, or other keyboard or electronic instruments. 
General Effect - Refers to the judging caption covering how well a marching band's music and drill design compliment each other, along with how well the marching band members perform both of these elements.

Glide Step - A smoother marching step used by corps style marching bands where the marcher rolls from toe through the heel with a more relaxed knee and leg.

Grand Nationals - The final marching band competition of Bands of America.

Horn line - The wind instrument players in a marching band.

Linear Line - A straight line used in drill design.

Marching Band - A group of individuals who collectively teach and/or perform instrumental music while in physical motion. This may be in a parade performance, football performance, or similar venues.

Marching Drill - The movements that performers in a marching band execute while performing to music. This can be on a football field, on a street, or similar venues.

Marching Season - The time of year when a marching band learns and performs their marching music and their marching drill. These performances may include parades, football games, marching competitions, or similar venues.

Military Step - A style of marching used by military bands where the marcher may either step with the toe striking the ground first or the heel, but with a straight knee and leg.

Musical Performance - Refers to the judging caption covering how well the music was performed by the marching band.

Precision Drill Marching Band - A marching band that performs shows using military style movements.

Regional Championships - A one-day BOA event consisting of an average of 30 marching bands that compete in a ranked preliminary competition. The top 10 scoring bands participate in the finals competition held later that evening.

Scatter Design - Moving in random order in drill design.

Show Band - A marching band whose show design consists primarily of the formation of letters, animals, people, or buildings, along with corresponding musical selections on a football field. 
Show Design - Show design refers to the coordination of the music and drill in a marching band show. Show design includes marching style, instrument and body carriage, and the staging of band members in the wind instrument section, the percussion section, and the color guard.

Step-Two - A marching band movement where individuals start their marching maneuvers two counts before or after the person to their left or right.

Super Regional Championships - A two-day BOA event consisting of an average of 60 marching bands that compete in a ranked preliminary competition. The top 14 scoring bands participate in the finals competition.

Visual Performance - Refers to the judging caption covering how well the marching band on the field executes formations. 


\section{CHAPTER TWO}

\section{Review of Literature}

\section{Overview}

The purpose of this research study was to examine the influence of participation in Bands of America (hereafter referred to as BOA) on one Missouri high school marching band program. An examination of extant literature regarding music education, concert bands, and their role in public schools yields many findings. Unfortunately, there are few investigations that focus specifically on marching band, especially those relating specifically to BOA.

This review of literature will examine the following topics (a) the history of marching band, (b) the history of competition in music, (c) research on marching band competition, (d) directors' attitudes toward marching band competition, (e) anxiety associated with marching band competition, (f) marching band competition findings from individual states, $(\mathrm{g})$ nationwide studies of marching band competitions, $(\mathrm{h})$ teacher behavior associated with marching band competition, (i) reliability of marching band competitions, (j) the influence of drum and bugle corps on marching band and competitions, and (k) Bands of America. These topics will help to establish how marching bands and marching band competitions have evolved over the years, and illustrate the types of attitudes and anxieties that are associated with the pursuit of success at marching band contests. Teacher behaviors associated with the preparation of marching bands for competitions, such as show design, drill, and music preparation, 
including the reliability of marching contests will also be examined. Finally, the influence of the drum and bugle corps on high school marching contests will be explored.

\section{The History of the Marching Band}

The presence of bands in the educational system of the United States dates from the mid-1800s. A mixed instrumental music program consisting of both wind bands and string orchestras was included in Boston in 1857 (Humphreys, 1989). After the Civil War, community bands grew in popularity throughout the United States. In 1884, one of the earliest school band programs was established in Tennessee (Keene, 1982). John Phillip Sousa (1854-1932) furthered the cause of school bands by encouraging the development of the American school band movement through the advancement of concert band literature. He also campaigned for the standardization of band instrumentation (Bierley, 1973; Hansen, 2005). This led to the addition of bands within the public school curriculum, many of which were modeled after John Philip Sousa's military ensembles (Mark \& Gary, 2007).

In the years that followed World War I and II, there were many instrumental music teachers, mostly former military personnel, employed in public schools (Mark \& Gary, 2007). Macleod (1993) wrote that bands during this era were designed to "appear masculine in order to recruit boys through their desire for uniforms and their inherent love for the military" (p. 301). Fisher (2013) noted that, "marching band as we know it today and its physical demands evolved directly from this apparent desire for uniforms and military-influenced performance" (p. 3).

This military influence was seen not only in the public schools, but also at the university level where bands were designed to boost morale in times of war (Fisher, 
2013; McCarrell, 1973). University bands were frequently affiliated with local ROTC programs and consisted of men dressed in military-type uniforms (Madsen, Plack, \& Dunnigan, 2007; Shellahamer, Swearingen, \& Woods, 1986). As the popularity of college football increased, university marching bands in the United States became more associated with entertainment such as sporting events and holiday parades, rather than with their military heritage (Mark \& Gary, 2007; Shellahamer, Swearingen, \& Woods, 1986).

One of the earliest university marching bands that greatly influenced public school band programs was found at the University of Illinois. This band, under the direction of Austin Harding was "particularly influential in the development of field marching shows" (Rickels, 2009, p. 6). Many high school bands copied their marching style and presented similar halftime shows at local football games (Mark \& Gary, 1999).

For years, marching bands could be described as precision units, primarily due to their military influence. Precision units were those in which members of the band executed line or block movements together at exact tempos. Clad in military uniforms, bands would perform step-two drills resulting in block and diamond formations on the field while playing a series of military marches. Marching bands later evolved into "show bands" in which more popular music was played while the band made formations on the field that reflected the music they were performing. For example, a band might form a horse on the field while performing a musical arrangement of "The Horse" (Binion, 1973). With the creation of Drum Corps International (DCI) during the 1970's, marching bands across the United States changed again. Military uniforms were traded for those with a more contemporary style and flags no longer represented the school's colors, but 
rather attempted to portray the mood of the music through their artistic design (Hopper, 1977; Spohn, 1969).

Marching style evolved from the traditional military step to a smoother glide step (Hopper, 1977). In an effort to further reflect the style of music being performed and the influence of the drum and bugle corps, marching band shows became more intricately designed. Whereas marching bands had been known for parade-style forms, through the formation of figures and the spelling of letters, marching band shows evolved into abstract depictions on the field (Hopper, 1977; Spohn, 1969; Vance, 2014). Many marching band competition organizers quickly began to pattern their judging format after the one used by Drum Corps International (Rogers, 1985). Rickels (2009) noted that although nationwide competitive events such as BOA standardized their adjudication training and practices, not all local and state competitions followed these guidelines.

\section{The History of Competition in Music}

Competition has long been a part of musical performances. Mark and Gary (1999) reported that contests for instrumental and vocal performers were present as early as 1737. Their findings indicated that musical competitions existed in a variety of formats during the eighteenth and nineteenth centuries, including contests involving violin and singing performances that were held as part of community holiday celebrations. This was followed by the introduction of the Welsh miner tradition of the eisteddfod. This event included solo and choral singing, as well as contests for poetry and harp playing. The first eisteddfod took place in the United States in 1850, and grew to influence other musical competitions in New England by encouraging the inclusion of public school students (Keene, 1982; Mark \& Gary, 1999). 
Keene (1982) noted that the first contest for public school music students was held in Boston in 1897. This event, sponsored by the New England Conference of Educational Workers, involved third-, fifth-, and seventh-grade students who competed for prizes in sight singing and song interpretation. There were also competitive singing events for high school students, including song interpretation and sight singing. Many contests featured memory events where students would identify musical selections by ear (Payne, 1997; Rickels, 2009). Hash (2016) noted that in 1897, music contests started in Kansas with the Musical Jubilee. At this event, high school choruses, grammar school choirs, and adult choirs competed in separate categories. Payne (1997) wrote that the motivation for these contests was a result of the influences of immigration and the accompanying population explosion in the United States.

As concert bands began their rise to prominence in America, so did band contests. Keene (1982) noted that Welsh immigrants, who came to the United States to work in the coal fields of Pennsylvania, started band contests because of their appeal to the energetic and competitive American population. He also wrote that bands competed at a convention in Portage, Wisconsin, on June 7 and 8, 1877, and later that year at the Grand Tournament and Musical Jubilee in Port Huron, Michigan, an event that featured both marching and concert bands. Hazen and Hazen (1987) add that military bands participated in a pass-in-review event at the 1904 St. Louis World's Fair. After military officers reviewed the marching bands, they were presented with citations and awards for outstanding performance.

The first national school band contest or "tournament" was held in 1923. This competitive event featured music students performing in a concert band venue. 
Sponsored by the music instrument manufacturing industry, this tournament was designed to promote increased popularity in bands and to expand the market for musical instruments (Holz, 1962; Moore, 1972; Payne, 1997; Silvey, 2009). A parade marching event was originally planned but was cancelled due to low turnout. Beginning in 1926, state contests were held regularly in 15 states for concert bands (Hash, 2016). Rickels (2009) reported that national contests continued to grow from 1926 through the 1930s, with yearly scoring modifications being made over that time. These modifications included separate scoring for marching execution and music playing in order to more accurately select the winner. In 1927, bands participating in these events were separated into classes based on school enrollment. In 1928, band size was also considered, with a 72-member requirement for national contests. After 1931, the contest award system was modified from a placement format to that of a "division" rating system based upon a band's performance, with a "I" rating standing for superior performance, a "II" for excellent performance, a "III" for good performance, a "IV" for below average performance, and a "V" for poor performance.

By 1940, district and state contests had become an important factor leading to the promotion and expansion of instrumental music instruction in the United States (Keene, 1982). Although the state contest movement slowed during World War II, states began to alter their own systems by organizing their district events with traveling judges, required graded music selection, and the incorporation of educational clinics. These events continue to be an important part of the music education curricula today (Rickels, 2009). 


\section{Research on Marching Band Competition}

Early marching band competitions were a direct result of bands' military tradition (Hazen \& Hazen, 1987) and were an outgrowth of military-style pass-in-review parade events involving drum and bugle corps, which were sponsored by groups such as the American Legion and Veterans of Foreign Wars. These events were originally organized for youth and non-school organizations, but later evolved into public schools events (Vickers, 2002). Street parade competitions were popular during the decades of the 1960s and 1970s, but were later replaced by competitions held on a football field (Rickels, 2009).

Marching competitions are now held in all fifty states (Rogers, 1985). These competitions provide a venue for marching bands to perform, be evaluated, and receive ratings and/or rankings. Judging formats of marching band competitions have evolved over the years, with many contest organizers using the same adjudication criteria that has been adopted by Drum Corps International (Laib, 1984). Although nationwide competitive events such as BOA have standardized their adjudication training and practices, not all local and state competitions have followed these guidelines (Rickels, 2009).

Standardized marching band adjudication systems have included the use of captions for scoring purposes, including musical, visual, and general effect categories (Vance, 2014). Music performance refers to the performance accuracy, tone quality, intonation, and the musical demand placed on the performers. Visual performance refers to both the individual performers' marching movement (drill) execution on the field, including the individual performers' problems in drill execution. General effect refers to 
the marching band members' ability to produce an emotional response from the audience. BOA had adopted these guidelines for their marching contests.

\section{Directors' Attitudes Toward Marching Band Competition}

Competitive marching bands typically begin their season with a summer band camp in late July or early August, followed by rehearsals several times a week during the marching season. Marching band competitions generally occur from September through November (Vance, 2014). During this time, many high school marching bands learn only one basic show to be performed at both local football games and contests. The emphasis on competition and learning only one show per year is a recent development and is largely due to the influence of drum and bugle corps on high school marching bands (Garrison, 1986; Rockefeller, 1982), which has shaped band directors' attitudes toward marching band competition.

Many high school directors who actively compete in several marching contests throughout the year feel that they have a balanced approach when it comes to the issue of marching band competition in context to the overall band program (Burnsed \& Sochinski, 1983). Directors based this feeling of balance on the fact that they could select the number of competitions in which their marching bands would perform. They also could compete in contests that resulted in ratings only, or those that provided rankings and trophies (Burnsed, Sochinski, \& Hinkle, 1983; Mason et al., 1985). Fleming (1976) investigated the participation of high school bands in marching competitions and the emphasis that directors placed on winning. He found differing opinions between high school and collegiate marching band directors regarding their motivations for attending marching competitions and the emphasis placed on competing. High school band 
directors felt that they demonstrated a balanced approach between competition in both the marching band and the concert band settings, whereas college band directors felt the opposite, expressing their opinion that high school band directors placed too much emphasis on winning marching competitions at the expense of the concert band. This emphasis on winning has influenced not only band directors, but also school administrators and parents.

High school students, directors, school administrators, and parents' attitudes toward marching band have also been investigated. Rogers (1985) surveyed both band directors and administrators from 421 high schools in all 50 U.S. states and found that $62 \%$ of the band directors responded that they participated in marching band competitions. Sixty percent of the directors surveyed expressed feelings of pressure from both school administrators and parents to compete. These directors felt that the benefits received from marching competitions included student discipline, responsibility, and selfesteem. Administrators expressed their opinion that one of the main values of marching band competition was in improving public relations for their respective schools.

In a survey involving high school and college students' attitudes about their competitive high school marching band experience, Burnsed, Sochinski, and Hinkle (1983) found that high school seniors and college freshmen reported positive attitudes about their high school competitive band experience. They found that college students indicated a neutral to slightly positive attitude toward their high school competitive marching band programs. These positive attitudes included feelings of pride, accomplishment, and respect associated with their performances, discipline, and teamwork. Their findings also indicated a positive correlation between the students' high 
school band size and the number of competitions entered, with larger marching bands entering more competitions. Marching band members who were a part of bands that entered a greater number of contests reported a more positive attitude toward marching band competition than those who did not report attending as many contests.

High school students were found to hold a more positive attitude toward marching band competitions than college students. Male marching band members held more positive attitudes toward competition than did the female members. High school upperclassmen indicated more positive attitudes toward marching competitions than did freshmen or sophomores. Findings also indicated that the number of competitions a high school band enters could have an impact on enrollment.

\section{Anxiety and Marching Band Competition}

The subject of competition and music has been an ongoing area of debate among educators. This concern has extended beyond competition to include the anxiety that members may feel while participating in marching band competitions. Miller (1994) wrote: "Music contests have been a part of secondary education almost from the beginning. They have been controversial for almost as long" (p. 30). Of concern to many educators is whether or not marching band competition is a positive experience for students. Much of this concern has surfaced as a result of the change to corps-style marching. The inclusion of concert band literature by corps-style marching bands has served to make it an extension of the concert band. The playing of quality band literature on the marching field has been supported with the inclusion of a smooth glide step, allowing for higher quality musical blend and balance by the performers (Mason et al., 1985). Burton (1985) agreed and stated that: "Consistently award-winning marching 
bands attain the same high quality of performance expected of concert bands in tone quality, intonation, technical precision, and balance” (p. 27). Marzulli (1985), however, made the claim that the one show concept, along with the hiring of noncertified instructors and attendance at numerous contests failed to serve what is best for the students. Moss (1985) commented on the performance of only one competition show in order to achieve success, adding that "A music program that has groups that win contests but whose members do not learn basic skills is exploitive" (p. 31).

Some educators believe that the competitive nature of marching band is a mere reflection of innate human behavior and that competition yields high achievement (Austin, 1990; Festinger, 1954; Kohn, 1986). Others such as Amabile (1982) believe that competition may distract from musical performance and result in increased anxiety. Robson (2004) conducted a review of literature in the area of sports psychology in order to form a basis for addressing the issues of competition as they relate to music psychology, including marching band. Her findings indicated that many people felt competition was important because the visibility of competing bands made the public more aware of music education. In addition, competition served as positive motivational force for students toward attaining higher goals and better musical performance.

Musical performance anxiety (MPA) has been found to exist in marching band students, particularly among those whose marching bands participate in high-level competition. Levy and Farley (2011) surveyed 780 high school marching band members, indoor percussion ensembles, indoor winter color guard units, and members of drum and bugle corps. Respondents were asked to indicate how often they experienced somatic symptoms (e.g., nervousness, sweaty palms, heart palpitations) and cognitive symptoms 
(e.g., critical, worry, apprehension about performances) of MPA. They found that cognitive symptoms were most frequent, with 57\% reporting the response of "I am overly critical of my performance." The two most common somatic symptoms reported were "I feel nervous" and "I have sweaty palms." MPA was found to be more prevalent among color guard performers than in any of the other activities studied. Although their findings indicated relatively low levels of musical performance anxiety, its existence was found to relate directly to the desire for success at marching band competitions.

\section{Marching Band Competition Findings From Individual States}

Saul (1977) examined results of Mississippi band festivals, including marching, concert, and sight-reading performances. Variables in this study included director education and experience, student demographics, and administrative support. Saul found that the most significant predictor for success at marching band contests was how the band program was organized and managed. Other determining factors included the number of students receiving lesson instruction, the amount of funding provided by the school's administration, the playing experience of the students, the extent of cooperation between the high school and feeder programs, and the number of extra rehearsals held during the marching season. These factors also overlapped in predicting the success of concert band and sight-reading performances, although administrative funding seemed to have no bearing on contest results.

Laib (1984) conducted survey research in Georgia to determine if there was a relationship between marching band competitions, show styles, and the number of shows performed by high school marching bands. His study was an outgrowth of the perception of the influence of drum and bugle corps on marching bands in his state. Information 
requested in the survey included the number of competitions that a band entered during the 1981-82 school year, the number of different shows a band performed during that time frame, and the style of the marching band (e.g., corps style, traditional style, or a combination of the two). Findings revealed that the mean number of competitions that bands participated in was 1.457 , the mean number of different shows a band performed per year was 2.83 , and that $72.7 \%$ of the bands were corps style marching bands. Furthermore, corps style marching bands competed more than traditional bands and adjudicators at these marching competitions tended to favor the corps style. Bands that adopted the corps style of marching also tended to adopt rehearsal techniques used by drum corps, requiring more rehearsal time per show. For this reason, the number of shows learned by corps style marching bands in a season declined.

Frenze (1988) examined the correlation between band size and success in marching band competitions. After analyzing marching band scores in the state of Ohio, he found that larger bands tended to receive higher general effect scores than smaller bands. Smaller bands also received lower marching scores than larger bands. His results also indicated that state scores were higher than national scores for the same bands.

In a separate study of Arizona high school bands, Sullivan (2003) discovered that smaller bands found it difficult to compete with larger bands due to the availability of resources and the inconsistencies in judging practices and classification systems. Band directors who were surveyed indicated that the positive elements of the Arizona competitive system included constructive feedback, motivation to practice, and exposure to other marching bands. Recommendations for further investigation into socioeconomic issues involving bands that participate in marching festivals were made. Sullivan reported 
that bands that demonstrated success at marching band competitions such as BOA had large memberships, numerous staff members, and large budgets.

In a replication of Saul's 1977 study, Washington (2007) examined results of Mississippi band festivals and included the same variables of director education and experience, student demographics, and administrative support. Consonant with Saul's findings, Washington found that the director's age, teaching experience, and tenure at the school were the most significant predictors of marching band success. Washington also confirmed Saul's assertion that the sizes of the marching band, as well as the number of assistant directors on staff were factors that led to the success of the marching band. Contrary to Saul's findings, Washington reported that the funding level provided by the school administration contributed to the achievement of the marching band.

Rickels (2008) examined the relationship between selected variables (e.g., marching band enrollment, assistant/non-certified marching band staff, and band budget) and the results of Arizona marching band contests. Band directors who participated in marching band festivals sanctioned or sponsored by the Arizona Band and Orchestra Director's Association (ABODA) during the 2004 marching band season were asked to provide their highest marching competition score. The directors were also asked to include information regarding variables such as band director experience, the number of marching band staff, band enrollment, the number of rehearsal hours per week, the band budget, and the total number of marching contests attended. Rickels found that the experience of the band director or the number of rehearsal hours per week had no significant impact on the marching band's success. The number of non-certified staff, budget size, and number of marching contests attended had a slightly positive correlation 
to the band's success. Results also indicated that larger schools with bigger marching band enrollments received higher scores.

\section{Nation Wide Studies of Marching Band Competitions}

Oakley (1972) examined adjudicators' scores at marching band competitions in 37 states in the United States as well as in Canada. He found that music performance accounted for as little as $30 \%$ to as much as $60 \%$ of a band's total score, whereas marching scores accounted for between $30 \%$ to $50 \%$, and scores for general effect contributed from as little as $10 \%$ to as much as $40 \%$. Although this is older data, it demonstrated the impact of adjudication upon a marching band's success. Competing marching bands whose shows emphasized the music and visual captions were assigned higher scores in the musical performance and visual categories.

Rickels (2009) investigated the relationship between nonperformance variables and competition scores in a marching band setting. An online questionnaire was administered to 418 band directors from six geographical areas of the United States. Nonperformance variables of director age and experience, director level of education, number of band staff members, number of hours spent in marching band rehearsal, marching band size, and school budget were considered. Rickels found similar results to his previous study, namely that a director's age, experience, and level of education, as well as the number of hours spent in marching band rehearsal, were not significantly correlated with the success of the marching band. The degree of funding for the marching band, both from the school's budget, fundraising activities, and the assessment of fees was an area of concern, with differences in funding levels perhaps carrying over into 
competitive outcomes. The size of the marching band was a better predictor of success than school size alone.

Marching bands that have participated in events such as BOA demonstrated highlevels of music execution through their music arrangements as well as their intricate show designs. In a study of 439 high school marching band directors from 10 states, Hewitt (2006) examined marching band contest scores and discovered that they were higher when custom music arrangements (i.e., music arranged specifically for a particular marching band) were used for both the wind and percussion sections. He also found that the visual scores for marching bands were lower if the director had personally designed the marching drill. He concluded that score variability might be due to "the size of the band, its staff, budget, the abilities and experience of the band and its director, teaching/rehearsing methodology, and the amount of time spent in rehearsal” (p. 29).

\section{Teacher Behavior Associated with Marching Band Competitions}

Many directors demonstrate a consistent degree of success throughout their careers as a result of their teaching/rehearsing methods and pedagogical content knowledge. In many instances, these directors may teach at a number of different schools of varying sizes during their career with the same degree of success. Davis (2000) surveyed Georgia high school band directors and examined rehearsal procedures, director characteristics, and marching band characteristics. Although his investigation did not reveal any direct relationship between contest ratings and rehearsal procedures, he did find positive correlations between scores and certain characteristics of band directors such as teaching experience, advanced education, and tenure at their current school.

Marching band is an activity that requires motivational and leadership skills from 
both the band director and the students. Smith (1999) investigated four marching band directors and their teaching rehearsal methods and discovered that higher marching band performance scores were a result of specific behavior observations. Smith reported high rates of teacher verbalizations regarding specific musical aspects, including (a) expression, or instructions relating to ensemble balance, balance of parts, blend, or interpretation; (b) general, or instructions regarding part assignments, repeats, codas, or endings; (c) notation, or comments regarding key signature, key changes, or accidentals; (d) pedagogical, or instructions relating to note names, note fingerings, or trill fingerings; (e) rhythm, or instructions regarding reading rhythms or counting; and (f) style, or comments regarding dynamics, accents, articulations, tempo, or tempo changes. Other instructional behaviors or comments that Smith noted included specific musical feedback to students, teacher modeling of marching and music style, and pacing of the rehearsal through the use of short, precise comments.

Davison (2007) investigated the impact of motivational and leadership skills demonstrated by directors and students in both marching band and concert band. $\mathrm{He}$ found that a positive relationship existed between the levels of director and student leadership skills. Strong leadership skills did not necessarily result in higher marching band scores, but did result in higher concert contest scores when students and directors worked together.

\section{Reliability of Marching Band Competitions}

Adjudicator reliability and consistency has been an area of continued examination and controversy (Payne, 1997). Guegold (1990) examined the five-rating plan that the Ohio Music Educators Association (OMEA) used to qualify marching bands for their 
statewide final competition. The five-rating plan resulted from concerns that marching band contests were becoming too closely associated with sporting events, and that band directors were being hired or fired based upon their marching band's placement or ranking. Ratings were based on a I to V system, with I meaning superior, II meaning excellent, III meaning good, IV meaning fair, and V meaning poor. In this study, Guegold focused specifically on caption scores, such as visual performance or musical performance. He found that a positive correlation existed between caption scores and the judges' collective ratings. Judges were generally able to score bands consistently, with no single caption dominating the band's overall score.

Dawes (1989) investigated the relationship between the reliability and consistency of both marching band and concert band contest scores. He investigated the correlation between the number of marching competitions a band attended and their concert band contest ratings. Dawes also compared the educational level of Alabama band directors with the number of marching competitions attended. He found that those directors with higher education degrees and more years of experience attended fewer marching contests than did younger directors. In addition, Dawes discovered that younger directors received fewer division I ratings (the highest awarded rating) than directors with higher degrees and more experience. He concluded that the number of marching competitions a school attended was not affected by school size, nor was it a factor in concert band ratings.

\section{The Influence of Drum and Bugle Corps on Marching Band and Competitions}

Research into the reliability and consistency of marching contests has emphasized the value many band directors place in attending marching band competitions. The impact of the drum and bugle corps on high school marching bands has influenced the 
goals and direction of marching contests (Rockefeller, 1982). In addition, the style, direction, instrumentation, and quality of high school marching bands has evolved as band directors have attempted to embrace the drum and bugle corps (Garrison, 1986; Vance, 2014).

The drum and bugle corps movement began following World War II with the return of thousands of service-trained buglers and drummers from active military service. Through the efforts of the Veterans of Foreign War (VFW), the American Legion, and American Veteran (AmVet) posts in the late 1940s and early 1950s, national drum and bugle corps competitions began. Opening with a fanfare, the drum and bugle corps would perform a variety of parade formations while playing patriotic music (Hopper, 1977). Beginning in the 1960s, drum and bugle corps abandoned the concept of marching strictly parade formations and began maneuvering on the football field. The formations used included straight lines, horizontal, vertical, diagonal, and combinations of these elements. Because drum and bugle corps only prepared one competitive show, the performance level was very high. Bugles were improved with better valves for playing and slides for intonation, percussion sections were expanded, and the color guard began to incorporate choreography in routines. With the creation of Drum Corps International (DCI) in 1973, contests, tours, and championships began to be governed by a complete set of rules (Cahill, 1982).

As the drum and bugle corps activity grew and expanded, its influence upon the high school marching band became more noticeable:

An increasing number of competitive marching bands are turning to corps style instrumentation, show design, and uniforms. The role of the color guard is expanding, both on the football field and as a separate unit competing in winter color guard activity. More drum corps arrangers are also producing corps 
style band arrangements sold by major publishers; and corps personnel are instructing bands or presenting clinics during the marching band season (Hilton \& Vickers, 1983, p. 17).

Throughout the years, high school marching bands have used a variety of marching and performance styles. During the 1950s and early 1960s, marching band style was centered on the concept of pageantry. This term refers to bands whose shows consist primarily of themes that included creating field design formations such as pictures of vehicles, buildings, animals, or the making of letters or words on the field. In the late 1960s and 1970s, marching band show design shifted from pageantry to precision drills (Wells, 1976). Precision drill refers to step-two drill movements, diamond formations, and the use of 22.5 inch or 30 inch marching steps (Binion, 1973). Beginning in the late 1970s, many high school marching bands adopted the marching style used by drum and bugle corps (Hopper, 1977; Vance, 2014). This evolution in marching band design followed a similar pattern to that of the historical development of the drum and bugle corps.

The movement to corps style has been one of the most significant events in the development of the high school marching band. With the one-show concept per marching season, the adoption of corps style has shaped the direction of high school marching bands toward the goal of perfecting both music and drill (Garrison, 1986; Rockefeller, 1982). Rockefeller (1982) noted that through the adoption of this style, the use of flags, rifles, bell-front brass instruments, and large percussion units led to interesting and complex show designs that included challenging musical arrangements, exciting visual pageantry, and audience appeal through intricate color guard movements. Holston (2004) wrote that the sophistication of the color guard has been the result of the addition of a 
wide variety of color guard equipment, and corps-style shows also included costumes, props, or backdrops. The percussion line expanded to include two major elements: the "battery" (snare drum, tenor drum, bass drum, cymbals) and the "front ensemble" (timpani, drum set, xylophone, marimba, chimes). The front ensemble also included electronic instruments, such as a bass guitar or electronic keyboard.

The influence of the drum and bugle corps on the high school marching band has further resulted in an increased emphasis on the aesthetic potential of the marching band. Directors who have adopted the corps style approach to their marching band believe that the music and drill must match in order to generate an emotional response from the audience (Garrison, 1986). The modern marching band produces not only a sense of excitement and energy, but also tends to be aesthetically pleasing to the audience (Heselton, 2011). This has been accomplished through the incorporation of such concepts as line and shape, rhythm and movement, musical and visual texture and contrast, and color.

A result of these influences on high school marching bands has been that competitive shows have taken on the excitement and variety of the drum and bugle corps. Vance (2014) noted that this has led band directors to "recreate drum corps shows with their high school marching bands" (p. 31). Furthermore, high school marching band contests have been patterned after drum and bugle corps competitions (Rogers, 1985). This influence has further led to the creation of competitive marching band circuits, such as BOA, that are similar in nature and adjudicated by drum corps instructors and affiliates (Vance, 2014). 


\section{Bands of America}

Bands of America is a division of "Music for All, Inc." BOA was formed in 1976 under the name of "Marching Bands of America." Originally, Marching Bands of America was a single summer workshop for band directors held on the campus of the University of Wisconsin - Whitewater. The workshop included drill design and adjudication sessions for high school band directors along with student sessions in drum line and color guard. A marching band competition known as the "Summer Nationals" was held simultaneously that included bands from across the United States. The purpose of the competition was to provide a national competitive event for marching bands. It also served as a venue for band directors and students to observe how the curriculum covered in the workshop sessions could be directly applied to a marching band (www.musicforall.org, 2015).

Marching Bands of America was renamed Bands of America in 1984 and merged with the Music for All Foundation in 2006. The Music for All Foundation expanded its operations to include national events for concert band as well as marching band. BOA Regional and Super Regional Championships continue to be held across the United States with the Grand National Championships being held in Indianapolis, Indiana (www.musicforall.org, 2015). Music for All is one of the largest and most influential national music education organizations in the country. Bands of America regards their contest as the largest and most prestigious national marching competition available to high school marching bands in the United States (Markworth, 2008). By 2015, BOA had expanded its fall regional championships to 20 locations across the United States, making Bands of America accessible to (within a six hour bus ride) 79\% of the nation (Martin, 
2015).

According to Doster (2015), the mission of Bands of America is "to create, provide, and expand positively life-changing experiences through music for all” (p. 2). Regarding competition, the Bands of America Official Procedures and Adjudication Handbook (2015) states:

Bands of America and Music for All believe that competing is a great motivator and provides amazing opportunities for learning life-lessons. The essence of competition is in the striving for performance excellence and being held accountable for learning.

The competitive arena provides a very precious opportunity to practice quality sportsmanship and sincere appreciation for the hard work of others. It also is the place where the very best models in our activity can be displayed and celebrated. All performers need models to demonstrate possibility at the highest levels of performance and artistry.

First place is fleeting, but the learning associated with the striving for excellence, the cooperative work ethic, and the appreciation of others is everlasting. Bands of America encourages participants, parents, and friends to celebrate the high value of the competitive environment for its lessons and to become immersed in "positively life-changing experiences" (Retrieved from http://musicforall.org/bandsofamerica, p. 1).

This review of literature examined the history of marching band, along with how competition has developed for music in general and marching band specifically. Marching band contests have been studied on both statewide and national scales. Researchers have investigated directors' behaviors and attitudes toward marching contests. Both the anxiety that accompanies marching band competitions and the reliability of those events has also been studied. The history and influence of the drum and bugle corps on marching bands has also been investigated. BOA has been one product of this movement, but little research has been conducted on how BOA participation may influence a band program. The purpose of this research study was to 
examine the influence of participation in Bands of America (BOA) on one high school marching band program. 


\section{CHAPTER THREE}

\section{Methodology}

\section{Purpose of the Study}

The purpose of this research study was to examine the influence of participation in Bands of America on one Missouri high school marching band program. I sought to examine how participation in this highly competitive environment of BOA influenced the culture of one mid-Missouri high school marching band program. My goal was to investigate what motivated the Camdenton High School band staff to become involved in BOA contests. I was also curious about the ways in which participation in BOA might influence the practices of a high school marching band. I further sought to explore what obstacles, if any, a rural high school marching band such as Camdenton might face while participating in BOA.

I chose a qualitative, single case study. A researcher may elect to use a qualitative approach in order to investigate why certain decision were made as well as to gain an indepth understanding of human behaviors (Creswell, 2013). The researcher may select a single organization as the case. Regarding the use of a case study methodology, Schramm (1971) wrote:

The essence of a case study, the central tendency among all types of case study, is that it tries to illuminate a decision or set of decisions: why they were taken, how they were implemented, and with what result (p. 15).

My single case study was the Camdenton High School marching band, and took place during one marching season. 


\section{Main Research Questions}

According to Stake (1995), "Research questions should be carefully developed in advance and a system set up to keep things on track" (p. 68). In order to investigate why the Camdenton marching band staff made the decision to begin attending BOA and the subsequent impact of that decision, I formulated the following research questions:

- What are the key motivators for a high school marching band to participate in a Bands of America event?

- In what ways does participation in BOA influence the practices of a high school marching band?

- What barriers, if any, does a rural high school marching band face while participating in Bands of America?

I asked the following questions to the student leadership of the Camdenton marching band to help discover their perceptions of BOA participation:

- What do you feel is the main influence of BOA on: (a) you, (b) your band?

- How does BOA effect or influence the way you approach: (a) band practice, (b) learning your drill, and (c) learning your music?

- How does BOA effect or influence the band's approach to: (a) band practice, (b) learning drill, and (c) learning music?

- Do you feel that BOA challenges/motivates you more than a Missouri contest would? If so, how? 
- Do you feel that BOA challenges/motivates the band more than a Missouri contest would?

- Do you like the fact that your band participates in BOA? Why or why not?

- Would you rather just go to a Missouri marching contest and compete with other Missouri schools?

- Do you feel that BOA makes Camdenton a better marching band? If so, how?

- How do you feel that other Missouri bands view the Camdenton marching band?

- How do you feel about BOA?

- What has been BOA's impact upon the culture of your marching band?

\section{Qualitative Research}

Given the nature of my research questions, I chose a qualitative research study paradigm. The observer's main objectives in qualitative research is to discover what life is like for the participant, how they construct their worlds, how people interpret their experiences, what meanings they ascribe to their life experiences, and to formulate an analysis of collected data that offers a depth of understanding (Creswell, 2013). This methodology places the researcher in a natural setting in order to learn about a particular phenomenon and to achieve an understanding of how people make sense out of this phenomenon in their lives. Merriam (2009) states that the goal of any form of qualitative research is to focus on "discovery, insight, and understanding from the perspective of those being studied" (p. 1). Patton (1985) wrote:

Qualitative research is an effort to understand situations in their uniqueness as part of a particular context and the interactions there. This understanding is an end in itself, so that it is not attempting to predict what may happen in the future necessarily, but to understand the nature of the setting - what it means for participants to be in that setting, what their lives are like, what's going on for 
them, what their meanings are, what the world looks like in that particular setting - and in the analysis to be able to communicate that faithfully to others who are interested in that setting. The analysis strives for depth of understanding (p. 1).

In a qualitative study, the researcher is the primary instrument for data collection and analysis is conducted through interviews and observations (Creswell, 2013; Merriam, 2009). The focus is on finding meaning and requires data collection that is sensitive to finding the underlying meaning of the gathered data. Qualitative researchers build their theory from the ground up based upon observations and intuitive understandings gathered from being in the field. As the researcher enters the field and begins the collection of data, the goal is to engage in the best practices that provide the most variety of perspectives on a topic. Bits and pieces of information are extracted from interviews, observations, or documents and are organized into units of information, then coded into themes. This coding process enables the researcher to move from general to specific themes (Creswell, 2013; Merriam, 2009; Patton, 1985; Stake, 1995).

Researchers must position themselves in a qualitative study (e.g., their background, experiences, and history) in order to provide reflexivity for the study. The end product of any qualitative study should be richly descriptive, with words and pictures used rather than numbers to convey what the researcher has learned about the phenomenon (Creswell, 2013).

My focus was to gain an understanding of how the staff and student membership of the Camdenton marching band viewed their experience with BOA. As an active participant, my research allowed me to observe the entirety of the Camdenton marching band's competition season, beginning with their first day of band camp and concluding with their last BOA competition. Through observations of their rehearsals and 
performances at their marching contests, along with collecting data from interviews, my goal was to produce a study that was descriptive of the influence, if any, that participation in BOA had on the Camdenton High School marching band.

\section{Case Study Research}

A case study is selected due to the researcher's desire to gain insight into a particular phenomenon through discovery and interpretation, rather than hypothesis testing. Regarding case study research, Creswell (2013) wrote that it "involves the study of an issue explained through one or more cases within a real-life, contemporary setting. Cases study research is a qualitative approach in which the investigator explores a reallife, contemporary, bounded system" (p. 97). The bounded system may be a single entity or a unit with boundaries, allowing the researcher to focus on what is to be studied, whether a program, school, or other institution. Adelman, Jenkins, and Kemmis (1983) wrote, "The most straightforward examples of 'bounded systems' are those in which the boundaries have a common sense obviousness, e.g., an individual teacher, a single school, or perhaps an innovatory programme" (p. 3).

Creswell (2013) writes that case study research begins with the identification of a specific case, often an individual, a small group, or an organization:

Case study research is a qualitative approach in which the investigator explores a bounded system (a case) or multiple bounded systems (cases) over time, through detailed in-depth data collection involving multiple sources of information (e.g., observations, interviews, audiovisual material, and documents and reports), and reports a case description and case-based themes (p. 73).

Through a case study, the researcher aims to uncover the interaction of the significant factors that are characteristic of the topic of investigation (Merriam, 2009). Yin (2014) describes case study research as follows: "A case study is an empirical inquiry that 
investigates a contemporary phenomenon within its real-life context, especially when the boundaries between phenomenon and context are not clearly defined" (p. 16).

Case study research is highly personal and requires a great deal of time on the part of the researcher. In a case study, the researcher gathers the data through observations, interviews, and the review of documents, and then organizes the material. According to Bromley (1986), case study researchers "get as close to the subject of interest as they possibly can, partly by means of direct observation in natural settings, and partly by their access to subjective factors (thoughts, feelings, and desires)" (p. 23). The researcher must define the case, and then decide upon the purpose of the study, the general questions, the methods of inquiry and analysis, and then "take a particular case and come to know it well" (Stake, 1995, p. 8). The end result of the case study should be a rich description of the phenomenon under study (Creswell, 2013; Merriam, 2009; Stake, 1995; Yin, 2014).

\section{Participants}

Participants in this study were marching band members plus staff of the Camdenton High School marching band $(N=22)$. Following Institutional Review Board approval, I distributed student assent and parental consent forms to all marching band members. As part of my instructions, I informed the students that participation in this study was voluntary. If students elected to participate in this study, they were told that they might be selected for student interviews. Participants were further instructed that if they chose to participate, they could withdraw at any time from the study without penalty.

\section{The Camdenton High School Pride of the Lake Marching Band}

I chose to study a high school marching band that had been involved with Bands of America for a minimum of five years in order to study the prolonged influence of 
BOA on their program. I selected the Camdenton High School marching band as my single case study because they met these criteria. In the last five years of their participation in the St. Louis BOA Super Regional, their competition scores have improved, with only one exception (see Table 1). Camdenton High School has a student population of 1,307, with 184 students participating in the Camdenton High School marching band, reflecting a school participation rate of $14 \%$. Another factor in my selection of the Camdenton High School marching band as my single case study was the convenience of their location. The close proximity of their school to my home in Jefferson City, Missouri (57 miles away) allowed me to travel frequently to Camdenton, conduct interviews, and observe rehearsals (Merriam, 2009).

Table 1

Camdenton High School Marching Band St. Louis BOA Results

\begin{tabular}{ccc}
\hline Year & Score & Class Placement \\
\hline 2015 & 79.40 & 2 \\
2014 & 68.75 & 9 \\
2013 & 75.30 & 9 \\
2012 & 74.10 & 6 \\
2011 & 70.05 & 9 \\
\hline
\end{tabular}




\section{Data Collection}

Data collection took place over a four-month period from July through October 2015 during Camdenton High School's marching band season. I made three separate visits to the Camdenton High School band booster organization for the purpose of introducing myself, to explain my research study, and to distribute assent/consent forms to the parents of the band members.

I began data collection by attending the summer marching band camp as an active participant observer (Stake, 1995). During this time, I participated in the teaching of marching fundamentals, marching drill, and music. This role allowed me to observe their rehearsal techniques from a unique perspective. Creswell (2013) writes, "The procedures of qualitative research, or its methodology, are characterized as inductive, emerging, and shaped by the researcher's expertise in collecting and analyzing the data" (p. 22). My data collection continued from July through the third week of October, following the band's last competitive performance of the marching band season.

Data were collected through structured and open-ended interviews, observations, field notes, and my participant researcher journal. Stake (1995) explained that in case study research, the researcher selects a particular case and comes to "know it well" (p. 8). I used these data collection approaches in order to discover the way that the marching band members and staff viewed, understood, and perceived the influence of BOA on their marching band.

\section{Confidentiality Procedures}

The evaluation forms used in this study were stored securely and kept confidential. Authorized persons from the University of Missouri, members of the 
Institutional Review Board, and (study sponsors, if any) have the legal right to review the research records and the confidentiality of those records is protected to the extent permitted by law. I received permission to use Camdenton High School's name from school principal, Dr. Brett Thompson. Although I used Camdenton's name in this study, I provided confidentiality to each participant by using pseudonyms throughout this document.

\section{Interviews}

Throughout the fall marching band season, I attended five evening rehearsals lasting 4 hours each (20 total hours). I also traveled with the band to four marching band competitions, including Clarksville, Tennessee, Ozark, Missouri, Broken Arrow, Oklahoma, and the St. Louis, Missouri BOA Super Regional, for a total of 136 hours. Merriam (2009) wrote that the qualitative researcher should spend a substantial amount of time in the natural setting conducting research. Throughout band camp, band rehearsals and competitions (see Table 2), I interviewed the six band staff members (see Table 3) as well as 16 student members (see Table 4) from each section of the marching band (woodwinds, brass, percussion, color guard, and drum major). Each high school grade level was represented which allowed me to obtain a balanced sample (Creswell, 2013).

The purpose of a case study is to obtain the descriptions and interpretations from others relating to their experiences (Stake, 1995). Data for a qualitative case study, according to Merriam (2009) consists of "direct quotations from people about their experiences, opinions, feelings, and knowledge” (p. 85). Charmaz (2014) wrote "Interviews are the most common form of data collection in qualitative research, 
including grounded theory studies. Moreover, interviews are the most effective way of obtaining data for certain research questions" (p. 79). These detailed personal accounts of lived experiences directly relate to the research topic (Wertz et al., 2011). Researchers can ask questions of individuals in a variety of forms, including structured and unstructured interviews that reflect their observations and experiences. Interviews serve to identify existing phenomena that might not be directly observed (Fischer, 2013; Patton, 2002; Schwandt, 2007). 
Table 2

Method, Location, and Data Collection Sequence

\begin{tabular}{|c|c|c|}
\hline Method & Location & Date \\
\hline $\begin{array}{l}\text { Observation/ } \\
\text { Field Notes }\end{array}$ & Camdenton High School & July 27 -August 7, 2015 \\
\hline Staff Interviews & Camdenton High School & August 7, 2015 \\
\hline $\begin{array}{l}\text { Staff/ } \\
\text { Student Interviews }\end{array}$ & Camdenton High School & September 3, 2015 \\
\hline $\begin{array}{l}\text { Staff/ } \\
\text { Student Interviews }\end{array}$ & Camdenton High School & September 10, 2015 \\
\hline $\begin{array}{l}\text { Staff/ } \\
\text { Student Interviews }\end{array}$ & Camdenton High School & September 17, 2015 \\
\hline $\begin{array}{l}\text { Observations/ } \\
\text { Interviews }\end{array}$ & $\begin{array}{l}\text { BOA Regional } \\
\text { Clarksville, TN }\end{array}$ & September 18-19, 2015 \\
\hline $\begin{array}{l}\text { Observations/ } \\
\text { Interviews }\end{array}$ & $\begin{array}{l}\text { "Pride of the Ozarks } \\
\text { Invitational," Ozark, } \mathrm{MO}^{1}\end{array}$ & September 26, 2015 \\
\hline $\begin{array}{l}\text { Staff/ } \\
\text { Student Interviews }\end{array}$ & Camdenton High School & October 1,2015 \\
\hline $\begin{array}{l}\text { Observations/ } \\
\text { Interviews }\end{array}$ & $\begin{array}{l}\text { Broken Arrow Invitational } \\
\text { Broken Arrow, } \mathrm{OK}^{1}\end{array}$ & October 3,2015 \\
\hline $\begin{array}{l}\text { Observations/ } \\
\text { Interview }\end{array}$ & $\begin{array}{l}\text { BOA Super Regional } \\
\text { St. Louis, MO }\end{array}$ & October 17,2015 \\
\hline
\end{tabular}

I chose to structure my interviews using an informal conversational format in order to establish rapport with each interview participant. Turner (2010) wrote that in this type of interview the researcher "relies on the interaction with the participants to guide 
the interview process" (p. 755). The initial interview questions centered on aspects of the marching season and were based upon my personal experience as a high school band director and my knowledge of BOA.

Table 3

Camdenton High School Marching Band Staff

_ Name $^{1}$ Position $\quad$ Years in School District

Eric Benson

Assistant Director of Bands

17

Skylar Christiansen

Assistant Color Guard Director

5

Merlin Oaks

Color Guard Director

18

Karissa Snow

Assistant Director of Bands

8

Flora Taylor

Director of Percussion

20

Jaren Taylor

Director of Bands

20

${ }^{1}$ All band staff names are pseudonyms.

During the student and staff interviews, I began with the same question: "How would you describe the influence of your band's participation in Bands of America on your marching band?" I used open-ended questions to follow-up on participants' initial responses so they could describe any additional details and/or feelings they had.

According to Stake (1995), "each interviewee is expected to have had unique experiences, special stories to tell” (p. 65). The follow-up questions were not necessarily the same, or asked in a similar order with each interviewee. Rather, these questions were 
based on responses that came up as a result of the initial interview question and the natural flow of the conversation. According to Creswell (2013), this type of questioning allows the researcher the ability to gather "additional information from individuals different from those people initially interviewed to determine if the theory holds true for those additional participants" (p. 90). By following this protocol, I could more deeply examine certain subject areas that might surface during the interview (Glesne, 2011; Patton, 2002). 
Table 4

Camdenton High School Marching Band Students Interviewees

\begin{tabular}{|c|c|c|}
\hline Name $^{1}$ & Grade & Band Section \\
\hline Anita & 11 & Flute \\
\hline Antoine & 11 & Mellophone \\
\hline Carl & 12 & Drum Major \\
\hline Claudia & 10 & Saxophone \\
\hline Fletcher & 9 & Saxophone \\
\hline Fred & 11 & Mellophone \\
\hline Jake & 9 & Trumpet \\
\hline Julie & 10 & Clarinet \\
\hline Kim & 9 & Color Guard \\
\hline Mark & 12 & Sousaphone \\
\hline Mike & 12 & Drum line \\
\hline Sherry & 12 & Color Guard \\
\hline Stewart & 11 & Drum line \\
\hline Sally & 10 & Flute \\
\hline Trevor & 10 & Baritone \\
\hline Ted & 9 & Trumpet \\
\hline
\end{tabular}

${ }^{1}$ All student names are pseudonyms. 


\section{Field Notes, Observations, and Participant Journal}

Throughout my data collection, I kept an active participant journal in which I recorded my daily field notes, along with my personal thoughts. Concerning the role of an active participant, Charmaz (2014) wrote that this approach provides "the ability to perceive reality from the viewpoint of someone 'inside' the case rather than external to it. Many have argued that such a perspective is invaluable in producing an accurate portrayal of a case study phenomenon" (p. 117). My observations included all aspects of the band's rehearsals, starting with the manner in which band members prepared physically through stretches, to practice their marching fundamentals (e.g., step-offs, halts, and other marching maneuvers used within the show), as well as the way the wind players warmed-up musically through the use of long tones and scales. I recorded how marching band members rehearsed sections of their marching drill, how they made corrections, and how the band members responded to both positive and negative feedback from the band staff.

\section{Data Analysis}

All data recorded from interviews were placed in a file on a Macbook Pro computer for subsequent analysis. Anfara, Brown, and Mangione (2002) reminded us "the purpose of analysis is to bring meaning, structure, and order to data" (p. 31). All data were analyzed between July and November 2015. Each interview was recorded and transcribed using the Dictation and Speech software on a Macbook Pro. One week after each interview, participants were provided with a transcript of their responses, allowing them to check for accuracy and to ascertain the trustworthiness of my interpretations. According to Lincoln and Guba (1985), member checking is "the most crucial technique 
for establishing credibility" (p. 314). All participants responded that the transcripts provided to them accurately reflected their feelings regarding the questions they were asked. A few respondents offered grammatical corrections, but no content revisions. Once the transcripts were considered accurate, I began the coding process.

\section{Coding}

Early in data collection, qualitative researchers begin the process of sorting and synthesizing all data through the process of coding. Merriam (2009) noted "this process of making notations next to bits of data that strike you as potentially relevant for answering your research questions is called coding” (p. 178). Regarding coding, Charmaz (2014) wrote:

Coding means that we attach labels to segments of data that depict what each segment is about. Through coding, we raise analytic questions about our data from the very beginning of data collection. Coding distills data, sorts them, and gives us an analytic handle for making comparisons with other segments of data (p. 4).

Kvale (2007) remarked that by following this procedure we are "highlighting specific aspects of the phenomenon being investigated and bringing new dimensions forward, contributing to a multi-perspectival construction of knowledge" (p. 86). Creswell (2013) stated, "forming codes or categories represents the heart of qualitative data analysis" (p. 184). The search for meaning begins with a search for patterns (Stake, 1995). Through the process of coding, certain words, patterns and ways of thinking began to emerge (Bogdan \& Liklin, 1982; Charmaz, 2014; Glasne, 2011; Yin, 2009).

\section{Trustworthiness}

Because qualitative research is subjective, the qualitative researcher has an obligation to demonstrate trustworthiness for all observations (Glasne, 2011; Lather, 
1986; Stake, 1995; Yin, 2009). The process of establishing trustworthiness begins by reviewing interview transcripts, field notes, observations, and journal entries, and jotting down notes in the margins of these documents (Creswell, 2013; Wetz et al., 2011). The best-known protocol used to provide this validation is known as triangulation (Merriam, 2009). Triangulation has been defined as a "method of cross-checking data from multiple sources to search for regularities in the research data" (O’Donoghue \& Punch, 2003, p. 78) and "a validity procedure where researchers search for convergence among multiple and different sources of information to form themes or categories in a study" (Creswell \& Miller, 2000, p. 126). Creswell (2013) added that "in triangulation, researchers make use of multiple and different sources, methods, investigators, and theories to provide corroborating evidence" (p. 251). Triangulation was achieved by cross-referencing interview transcripts with participant observations, field notes, and journal entries.

\section{External Audit}

As a final step in establishing trustworthiness, I conducted an external, expert audit (Glasne, 2011; Schwandt, 2007). I requested the assistance of a music education doctoral student who had six years of public school teaching experience, which included six years as a high school marching band director. All interviewees were given pseudonyms to ensure anonymity. This person checked all cross-references between interview transcripts, participant observations, field notes, and journal entries.

This auditing process, according to Miles and Huberman (1994) provides "a good reliability check" (p. 64). Following our audit, 87\% agreement was found. This number was determined by dividing the number of coding agreements by the total number of agreements plus disagreements. Because Miles and Huberman (1994) suggest that an 
agreement of $70 \%$ is considered high, I deemed that our coding reliability was acceptable.

\section{Role of the Researcher}

Although I have been officially retired from public school music teaching since 2009, I have remained active as a marching band clinician and adjudicator in the state of Missouri. During my doctoral studies, I have maintained professional relationships with band directors throughout the state whom I regard as both colleagues and friends, including many in the Central Missouri District of the Missouri Music Educators Association in which Camdenton High School is located. As the immediate past director of the Missouri Lions All-State Marching Band, I have also remained in contact with the directors in this district for the purposes of membership recruitment for this organization. I feel that it is important for readers to understand that I am passionate about high school marching band. However, I also want readers to know that I had no preconceived ideas regarding BOA participation in the findings of my research.

In light of my own attitude toward the marching band activity, I attempted to limit my biases. Merriam (2009) has reminded us that qualitative researchers are most interested in exploring how people interpret their life experiences and what meaning they attribute to their experiences. The researcher, therefore, becomes the primary instrument for data collection and analysis. Lincoln and Guba (2000) state that the researcher's position is critical to the integrity of the study because the researcher's position is "the process of reflecting critically on the self as researcher, the "human as instrument"' ( $p$. 183). The researcher's role provides clarification for biases and assumptions gleaned from the study (Merriam, 2009). 
Stake (1995) explained that the case study researcher might play different roles, including that of "teacher, participant observer, interviewer, reader, storyteller, advocate, artist, counselor, evaluator, consultant, and others" (p. 91). He further noted that observations may be interpreted by the experience or intention of the researcher.

Because of my teaching experience as director of bands at Jefferson City High

School in Jefferson City, Missouri, I feel that I was allowed access to information, including students and travel privileges, which I might not have otherwise been allowed. I interviewed students and staff with whom I was not familiar. During the course of my data collection, I kept a personal journal in which I noted feelings and observations, thus allowing me to maintain a self-reflexive critique of my research. 


\section{CHAPTER FOUR}

\section{Findings}

The purpose of this research study was to examine the influence of participation in Bands of America (BOA) on one central Missouri high school marching band program. I conducted a qualitative, single case study, collecting data through interviews and observations (Creswell, 2013; Merriam, 2009; Patton, 1985; Stake, 1995; Yin, 2014). I interviewed staff $(N=6)$ and students $(N=16)$ throughout their marching season, including band camp, evening rehearsals, and at marching competitions.

BOA is a marching band competition that includes contests in various locations across the United States. This event includes Regional Championships, Super-Regional Championships, and the Grand Nationals. The philosophy behind BOA centers on the idea that competition is part of the very fabric that has made America great. BOA's mission is "to create, provide, and expand positively life-changing experiences through music for all” (Doster, 2015, p. 2).

In order to investigate why the Camdenton Missouri High School marching band chose to participate in BOA and the subsequent influence of that decision, I formulated the following research questions:

- What are the key motivators for a high school marching band to participate in a Bands of America event?

- In what ways does participation in BOA influence the practices of a high school marching band? 
- What obstacles, if any, does a rural high school marching band face while participating in Bands of America?

Across all of the data sources, I identified three larger themes: (1) BOA as a standard of excellence, (2) changes in band practices, and (3) barriers to participating in BOA. These themes as a whole suggest BOA has had a positive impact on the Camdenton High School marching band.

\section{BOA as a Standard of Excellence}

Both staff and students viewed BOA as a contest that provided a standard from which to evaluate their skills. They felt that this standard was a result of the level of excellence accompanied with each BOA event. As a result of my interviews with the Camdenton High School marching band staff and band members, these sub-themes emerged: (a) consistent and rigorous adjudication criteria, (b) motivation to perform, and (c) affect on students' attitudes.

\section{Consistent and Rigorous Adjudication Criteria}

The consistent and rigorous adjudication criteria that is applied at BOA competitions was a positive factor emphasized by the band staff. The same adjudication rubrics are used at each BOA contest (see Appendix G), and all BOA adjudicators are trained how to use these rubrics. This allows for consistency in judging at all BOA events, regardless of the state in which the competition may occur.

Assistant director of bands, Karissa Snow, noted the frustration experienced at marching band contests prior to making the decision to attend BOA events: "It was difficult going from week to week with one judge saying 'you are too loud' and then

another week saying, 'you are too soft."' Assistant director of bands, Eric Benson agreed: 
The advantage of participating in BOA or BOA-style events is that we know exactly what to expect from our adjudication. Plus, BOA judges are trained in such a way that scoring is as close to uniform across the country as one can expect.

Camdenton marching band staff members commented on the consistency of scoring at BOA contests. They liked that the same standard of judging is used along with identical scoring rubrics, regardless of where the BOA contest takes place. Percussion instructor Flora Trevor commented: "Bands of America has an established rubric for scoring on all levels of marching band. Whereas the 'traditional' marching festivals would have different scoring sheets and different expectations from festival to festival.” Mr. Benson added, "It is very useful to know that everywhere we go, we are adjudicated with the same judging sheets by judges who have been similarly trained."

Through the BOA judging system, the staff collectively observed that there is a consistency of adjudication criteria. This has led them to create a good balance between the visual and the musical aspects of their marching band show. The rigorous criteria of BOA have fostered a degree of precision and excellence that has translated into all of their rehearsals.

The students of the Camdenton marching band also noted that the consistent and rigorous adjudication criteria of BOA participation have provided them with the impetus to practice with purpose and efficiency. Following one day of marching band camp, I made the following journal entry:

I have observed that this band thinks on a bigger scale - in other words, they don't think of themselves in comparison to most high school bands in Missouri, but rather in terms of those bands they compete with at BOA from other states. Everything they do in rehearsal is done with that focus and goal in mind. This includes their music and their marching/drill preparation. 
In order to compete successfully at BOA, they believe that they must master the performance of both their marching music and drill. The students I interviewed shared their beliefs that $\mathrm{BOA}$ is more competitive than those competitions held within the state of Missouri.

Students expressed their feeling that because BOA is a national organization, the adjudication at $\mathrm{BOA}$ events is consistent from contest to contest, rather than each contest having its own set of adjudication standards. Stewart remarked, "It (BOA) is more organized. Missouri contests are not regulated by any national system.” Students said that the reason they felt motivated to learn their music with greater efficiency is due to their belief that music performance was more important at BOA events. As Anita said, "Music and musicality aren't as important at other contests."

Because every BOA contest has the same judging standard, the students feel that they will be treated fairly, a belief shared by Antoine: "With BOA, I trust that my efforts will be rewarded." This feeling was echoed by Sally, "It's the level of strictness they have with their judging and the caliber of bands we compete against." Competing on a national level, the desire to rehearse with purpose and efficiency, and the consistency of BOA contests over Missouri marching competitions provides strong motivation for the Camdenton marching band students to strive for excellence.

In addition to these factors, students further discussed that the quality of bands that participate in BOA events exceeds what they might encounter at local or state marching contests. BOA contests frequently include bands that are consistent finalists at BOA Regionals and Super Regionals. Fred stated that, "I am competing with bands that 
are on the national level and that have actually won Grand Nationals. It is making me try harder." Stewart agreed:

BOA puts us into competition with bands that we wouldn't normally be in contact with in the state. Some Missouri bands that we might otherwise compete against don't go to BOA. Part of it is an inspiration-we see a band that has won Grand Nationals so we think that we should do that. We get a level of success that we haven't attained yet. We see how other bands do what they do and how we can get better.

Sally commented, “...it's the level of strictness they have with their judging and the caliber of bands we compete against." Jake added:

I definitely feel that when there are 60 bands in the competition and 12 or 15 are in the finals, you want to make it in to the top 12 or 15. In all these other competitions, we are always up there in the top. But when it comes to BOA, we all really have to work and do our best if we are going to make finals.

Students consistently felt that the bands with whom they compete at BOA motivate them to try harder, do better, and to see how much they can increase their work ethic.

When the marching band students were asked if they wouldn't be just as happy to attend regular Missouri marching competitions over BOA competitions, all interviewees commented that they felt they wouldn't be as motivated to work as hard and might not have the necessary focus during rehearsals. Jake commented, "If we were to just go to some of these little competitions, we might be a little more loose." The option of attending Missouri contests versus the work ethic that accompanies BOA competitions was further commented upon by Stewart:

No. I think if we did that we would lose the work ethic-we have been pushed by going to BOA competitions. And it would turn the marching band program into a joke. We would just expect to go in and beat them we would not expect a challenge. It wouldn't be like we go into this to learn the music-it would become just like a sport. 
Students felt that their motivation extended beyond rehearsals into performance, as Anita remarked:

No-definitely not. They don't push you when you know that you are going to be at the top, and so you don't try as hard. If we went into a competition where we knew we would do well, we would only halfway play the show and not concentrate. The musicality that comes from BOA pushes us.

For the members of the Camdenton High School marching band, competing at BOA affords them a national perspective on competitions they feel could not be acquired if they only participated in Missouri contests.

The effect of being challenged at BOA events as opposed to merely attending local and state contests with the possibility of winning lots of awards and trophies was not important to the students that I interviewed. As Trevor mentioned: "No-trophies aren't important to me. Working harder and being more challenged are more valuable rather than going to random festivals that we could easily win." When asked if winning was important, the Camdenton band members feel that the quality of their performance is more important than winning. As Ted said, “The reward of being a BOA band is just getting to perform and doing what you do your best; to go out on the field and show people what you have spent hours trying to perfect."

\section{Motivation to Perform}

The consistent and rigorous adjudication criteria of BOA has given the Camdenton marching band members a strong motivation to perform at a level to meet the expectations of the BOA adjudicators. This performance motivation extends to all sections of the band: wind players, percussion players, and color guard members. The motivation is increased as they face bands from across the United States and affects their musical and marching performance. 
The decision to compete at BOA has motivated the staff and students to push themselves toward a new and higher level of musical achievement and performance. Criss (2011) wrote that, "The ability to create motivation within students is one of the most important and challenging responsibilities of any teacher" (p. 61). Legette (1998) commented, "Music educators have long been concerned with motivating students toward greater musical achievement" (p. 102). The motivation to perform at a higher level of excellence extends to every member of the horn line, the drum line, and the color guard. And as color guard director Merlin Oaks noted, it is that next level of performance and achievement that is the challenge:

In order for us to get to the next level, our kids need to understand what it feels like to be at that next level. We don't know what it feels like-what it means to be a consistent BOA finalist band. It's the commitment to work toward excellence that gets you to the next level.

Assistant color guard director Skyler Christiansen added, "I feel the biggest challenge was the transition to the theatrical types of shows and getting the rest of the staff, student participants, and community to buy into the 'next level' of competition for us."

When asked if the students felt that BOA made Camdenton a better marching band, students responded positively. Students appreciated that participation in BOA motivates them to constantly strive for improvement in their music and marching performance. As Julie stated, "Yes-BOA pushes us to be better players and marchers, and to just improve as a band." The students agreed that by attending BOA events, they are motivated to push themselves toward a higher standard. Jake mentioned, "Yes-it gives us a higher standard that we have to push ourselves to. We have to work harder and push ourselves harder and stronger-it motivates us more." Part of this higher standard is 
realized through observing other competing bands' performances. Mr. Oaks made this observation:

Because we are a rural school, participating in BOA has broadened the horizons of our students. They are not just seeing what happens in Central Missouri, but they are seeing what is happening in Minnesota, Colorado, Ohio, or other parts of the country. They are being exposed to a broader range of marching band concepts. They get to meet kids from all over the US. Some of them have made friends and contact each other periodically. They compare notes. They become this larger group of common people who share common elements through marching band.

Sally added, "We compete against bands that are high caliber and it pushes us to be better." Sherry continued, "Yes, it makes us better. We compare ourselves to better bands and we see what other bands do and if we need to improve."

Student respondents frequently commented that competing on a national level was the main influence of BOA. Kim said, "It (BOA) affects everything-how we shape our show-the standard for which we strive-we strive for a national standard." Ted added, "BOA just makes us a better product in general. Everything about our performancevisual or musical—is just at a better level by attending BOA." Students said that by attending BOA events, they were competing at a higher level than they would if they only went to Missouri contests. Getting to see and compete with bands on the national level makes the Camdenton band members want to perform and achieve at a higher level. And Trevor shared, "Everyone is motivated to push further and do better. BOA pushes us more than any other contest. It gives us a sense of achievement when we push further."

\section{Effect on Marching Band Members' Attitudes}

The consistent and rigorous adjudication criteria of BOA events coupled with the motivation to reach a higher level of performance have affected the attitudes of the marching band members. The staff feels that they have a better attitude toward the 
manner in which they teach the marching band students. They have seen a better attitude from the students toward their individual and collective musicianship. Both students and staff have witnessed a more positive attitude toward competition.

The staff is convinced that they have developed into better teachers as a result of BOA. This has evolved from the belief that they do a better job of paying attention to every musical detail involved with the marching band, and that their students are becoming more aware of the importance of their individual musicianship. Mr. Christiansen said, "Our kids are much more rounded individuals as far as musicianship, literature, and performance quality than in the past." The move to BOA has impacted every part of the Camdenton band program. In the words of Director of Bands Jaren Trevor, "BOA has made my concert band better, my jazz band better, my pep band better, my middle school bands better."

The Camdenton band staff believes that their students have begun performing with more musicality. They feel their students have developed a greater appreciation for the importance of their individual musicianship and its effect upon the entire ensemble as well as the audience. Mr. Trevor summarized this belief:

BOA has become a huge driving force in our band program. Years ago, our goals were to win. That's all, just to win. But how did we make that happen? Well first we picked local festivals where the " higher, faster, louder" approach seemed to work. Really, we didn't concern ourselves with musicianship. We didn't ask about musical lines. We were not concerned about making better musicians. We were only set on blowing loud. We chose contests in smaller venues, against local bands and usually came out near the top...so, BOA has made my entire program better, and we no longer have an outdoor sound and an indoor sound. We only work for a great sound, regardless of where we are playing.

Students feel a greater sense of responsibility to themselves and each other to learn and perform their music to the best of their ability. Anita said, "(BOA) makes you 
want to perform the music with musicality." Marching band members expressed their belief that competing at BOA caused them to constantly strive for improvement in their individual musical performance, as Julie commented "It (BOA) makes me practice more and makes me push myself to be a better marcher and player and to show improvement at each contest." This, in turn, has contributed to their improvement as a band. BOA gives them a higher standard to which they must strive.

One reason for this higher standard comes from competing with other bands that regularly compete on the national level and have won the Grand National Championship. Seeing these bands serves as inspiration for them and pushes them to try harder, to be better, and to see how far they can push themselves. As Carl said, "I am competing with bands that are on the national level and that have actually won grand nationals. It is making me try harder." Mr. Christiansen summarized the improved student musicianship through BOA participation this way: "I feel that participation in BOA has improved our program. We may not finish with a win at any BOA contest, but our kids are much more rounded individuals as far as musicianship, literature, and performance quality than in the past."

This improvement in student musicianship has also contributed to a more positive competitive attitude among the band students. Regarding BOA contests, Mrs. Trevor commented, "Every time we go to a BOA event, the air of positiveness is overwhelming. Everyone claps for everyone else. The feeling at BOA is a more 'all in this together' feeling, rather than "every man for himself."' The students have a very positive attitude about and enjoy the competitiveness of marching band as they observe other groups and how they perform. This positive attitude has broadened the perspective of their students 
beyond central Missouri. Mr. Benson reflected, "Our students enjoy seeing other groups and what they can do. While it is not always pleasant, holding ourselves to the highest standards we know is just sound educational policy."

Both staff and students enjoy the competitiveness of BOA, but at the same time wish other band members success as they cheer on their competitors' performances. At the conclusion of BOA events, time is allotted for bands to "disband" and get to know each other as fellow musicians and human beings. Sherry described her feelings this way, "I love BOA—seeing other bands and meeting new people. Antoine described the experience: "Once the contest is over-you understand you are all there for the same reason-pushing yourself and communicating emotion." The competition field becomes a sea of color as the band members move about. There is a distinctive aura of camaraderie among the band members who compete in BOA.

BOA's influence on Camdenton's band rehearsals can be seen in the attitude of the marching band members and their motivation to achieve during their practices and performances. The goal orientation associated with BOA participation is reflected in statements like those of Mark who commented, "For me-when it comes down to practice, it comes down to what you want from yourself-for you to see how far you can push yourself." Trevor said, "I try to work and do everything with greater efficiency." Carl added, "It makes me want to be better." Ted continued:

I like the BOA aspect of Camdenton's rehearsals quite a bit. I think the directors push us quite a bit harder. They require more of the students because we need to be on a different level. Rehearsals become quite rigorous. 
The band members feel that BOA has influenced them to have a more aggressive attitude toward their marching band by pushing themselves, working harder, striving to become better, and to rehearse with purpose.

In summary, BOA as a standard of excellence was the principal motivator for making the decision to compete at BOA events. The consistent and rigorous adjudication criteria of BOA provided a benchmark from which they could be evaluated as they reach for a higher standard of excellence. This has translated into a stronger motivation for the band members to achieve mastery of both their music and drill performance. Finally, this standard of excellence has affected the attitudes of the students in the Camdenton High School marching band. They display a better attitude toward their individual and collective musicianship, as well as during their competition performances.

\section{Changes to Band Practices}

Staff and students commented that since they began participating in BOA contests, they had observed changes to their band practices. The staff noted that they had changed the manner in which they design their marching band shows. Through BOA participation, the staff believes they have become better teachers through an improved teaching process. Students believe they work harder in order to be successful and to support their fellow band members whom they regard as family. During my research on the changes in band practices, I discovered these sub-themes: (a) changes in the band's performance, (b) changes in the teaching process, and (c) changes in the students' participation in band. 


\section{Changes in the Band's Performance}

Changes in the band's performance as a result of BOA participation has been reflected in how the staff designs their competition shows. This change has been influenced as a result of competing on a national level at BOA events as well as the recent influence of drum and bugle corps on high school marching bands. The Camdenton marching band staff now designs their shows to meet the expectations of adjudicators as outlined in the BOA handbook.

Staff members discussed how attending BOA had transformed their approach to show design. Mrs. Trevor said, "BOA has influenced the Camdenton Band in a number of ways. First and foremost, it has transformed how the directors and staff approach the design of the show. It (BOA) has also changed our design direction to a more cohesive theme with elements precisely directed to the overall theme of the entire show." Because participation in BOA takes the Camdenton marching band beyond Missouri's borders, they compete with all sizes and types of bands, providing motivation for them to establish the expectation of a higher level of achievement. The goal was to make all of the show components work together to produce a show theme, as Mrs. Trevor said:

What I have realized from the years that we have been in the BOA circuit is that the components that make up the show have become more cohesive. The performers are also much more aware of how their role influences the show theme as well as each other's performance. Finally, just being a part of the BOA circuit has made each staff member and student performer aware of the national level of excellence.

Show design, therefore, becomes critical to meeting their objective.

In addition to the school's band staff, several consultants outside of the school district were involved in the design of the show. Mr. Oaks remarked, "We have a show/concept designer and a separate flag/book writer.” Mr. Christiansen commented: 
BOA has pushed the Camdenton band to strive to produce more theatrical productions that need to be achieved at a higher level of performance quality. It is no longer about "rah rah," get the crowd excited about the music, but the telling of a story where everyone is not only a musician, but an actor.

The show design for marching bands that participate in BOA must consist of a cohesive structure. This includes staff collaboration about every aspect of the show, including musical, visual, and general effect.

The BOA influence on show design extends beyond the visual element to that of musical development. Mr. Trevor stated: "BOA has become a huge driving force in our band program. Years ago, our goals were to win. That's all, just to win.” He also mentioned that the band attended contests where everything was simply "higher, faster, and louder." The move to BOA resulted in an increased emphasis on the difficulty of the music played as well as the performance quality of the marching band's sound. He continued, "We no longer have an outdoor sound and an indoor sound. We only work for a great sound, regardless of where we are playing."

The Camdenton band directors believe that competing with and comparing themselves to nationally recognized marching bands is one of the results of marching band contests emulating the influence of drum and bugle corps contests. Rockefeller (1982) mentioned the impact and influence of drum and bugle corps on high school marching bands and band competitions such as BOA. In addition, Garrison (1986) and Vance (2014) noted the influence of drum and bugle corps on the style and direction of high school marching bands. Mr. Oaks made this observation:

Overall, I think our kids before BOA only compared themselves to a lot of Missouri schools and now their perspective is one of a Midwest or national basis and how those programs are doing what they are doing. The kids are more aware of the influence of drum corps and its influence on band. Now we use drum corps as a comparison to what we are trying to achieve. 
As part of their rehearsals, the Camdenton marching band frequently reviews current videos of drum and bugle corps shows. This allows the students the opportunity to view the musical, marching, and visual techniques of the drum and bugle corps and discover how they could incorporate those techniques into their own marching band.

\section{Changes in the Teaching Process}

All Camdenton band staff members feel that they are better teachers as a result of deciding to participate at BOA contests. The staff commented that they communicated with each other much more since competing in BOA. They felt that frequent collaboration was a must in order to have productive rehearsals and successful performances. Mr. Oaks described their teaching effectiveness this way:

The staff communicates a lot more now-we have more collaboration. Its about drill sets - how can we fix drill problems, etc. We used to try and put the show on the field first and then go back and clean drill. Now, we try and clean up things as we go. Now, staff members will jump outside their own particular caption in order to address other issues that haven't been brought up in a meeting. It is a little more cross caption teaching. No one is afraid to step out of his or her caption and help another caption.

Staff members who specialize in woodwind instruments feel free to discuss musical issues with the brass players. The percussion instructor might address balance issues between the wind players and the percussion section. All staff members might address students who are not marching correctly. Mr. Trevor commented, "We have become better teachers because of Bands of America." Furthermore, Mrs. Trevor also stated: "For my participation in the Camdenton band program and our participation in the BOA circuit, it has made me a better director for our students."

The band directors believed that the consistency in BOA adjudication has also assisted in the educational process of teaching the students. They believed that being 
judged on the same level at all BOA events helps the students to understand what is expected of them by both the staff and their fellow marching band members. Mrs. Snow noted, "It has created a common language that we can use and both the staff and the kids can understand. For example, 'today we want to strive to achieve performance in Box 5." Mr. Benson added, "The BOA judging sheets have given us a high standard to which we can aspire."

Mrs. Trevor commented on the BOA handbook, the BOA judging sheets, and its influence on the Camdenton marching band staff's teaching process:

When we first entered the BOA circuit, the rules and regulations put forward in the BOA handbook were quite intimidating. But as the years go by, you, as a director, realize the rules and regulations are not put in place for intimidation or rigidity, but for overall fairness from ensemble to ensemble, competition locations to competition locations.

The official Bands of America Official Procedures and Adjudication Handbook covers all performance procedures and adjudication criteria. Procedures include music copyright compliance requirements, school eligibility, performance procedures, competition format, and rules for Regional, Super-Regional, and Grand National Championship events. The adjudication handbook includes an explanation of the Criteria Reference System used in the rating and scoring of bands, as well as explanations of the score sheets used to evaluate music performance, visual performance, and general effect. Through the BOA judging system, the staff collectively observed that there is a good balance between the visual and the musical aspects of a marching band show.

This awareness of expectations leads the students to continually push themselves and to gauge their improvement as the marching season progresses. Mr. Christiansen commented: 
I feel that we started going to BOA contests to continue to push ourselves as musicians and performers. So to continue to grow and improve, this competitive venue (BOA) was the next step. Also seeing the types of musicians and performers BOA groups were producing motivated us to follow suit.

As a result of making the decision to attend BOA contests, the directors feel that the students are more motivated to improve. The consistency of adjudication helps them strive to be better musicians and gives them a true sense of excellence. Mr. Trevor discussed this feeling:

We went on a three or four year run when we won everywhere. We padded the trophy case. It was cool and we ran with it. Then we would go to a BOA show and get killed. The kids began to see through our trophies to realize that we as a staff were giving them a false sense of success. Kids are smart. They can see the difference in winning a local festival but losing in the overall band world. They knew that they were not performing at the same level of your average BOA-type band.

As I participated in Camdenton's band camp, I commented in my journal on the teaching style of the Director of Bands. I wrote, "Mr. Trevor was very animated and the students seem to be very excited to get started learning drill. They seem to have a positive attitude and a common understanding of what they want to accomplish this year." As I continued to participate in their band rehearsals, I observed the clarity of instruction and attention to detail demonstrated by every staff member. In my journal, I noted:

For the past 2 days, I have observed the great attention to detail by both the band staff and band members. It is obvious to me that these students take a lot of pride in their band. They know what needs to be accomplished in order to achieve excellence and are willing to do it from the beginning of their season.

The band staff has established precise and focused rehearsal procedures that seemed to be very effective, thus meeting their high school's stated mission “Every Student Learning Every Day" (Camdenton High School, 2015). 
Through the decision to participate in BOA, the staff feels that their band students understand the challenge of competing on a national level. They believe that observing and competing with the top bands in the nation makes them work harder and more efficiently, and also brings a greater understanding of a standard of excellence to their program, which gives them a truer sense of success.

\section{Changes in the Students' Participation in Band}

The changes in the band's performance and the staff's teaching process have been accompanied by changes in the students' participation in band. Through BOA participation, students feel they have a stronger work ethic. This work ethic has resulted in band members working together to achieve their goals. Through this process, the band members feel a strong sense of family and belonging.

Students feel that BOA participation motivates them to put forward their best effort into learning their drill more efficiently and effectively. This was evidenced by the strong work ethic that I observed during the Camdenton marching band rehearsals, in which students practiced with focus and intensity. Trevor shared, "I think BOA is what has increased the work ethic and the motivation to work harder. The work ethic with everyone is a lot better." Carl pointed out "BOA is harder and it is a more difficult thing to accomplish-so it makes you go the extra mile."

This stronger work ethic can be seen in the way band members learn the specifics of their individual marching band drill. Jake said, "When it comes to drill, it (BOA) makes me want to strive and find the best way to make it to my spot." Students shared that because of BOA, they approach each rehearsal with a sense of purpose rather than simply going through the motions of "another rehearsal." Ted said, "I think the BOA 
aspect affects Camdenton's rehearsals quite a bit. I think the director pushes us a bit harder. We require more of the students because they need to be on a different level. Rehearsals become quite rigorous." Jake agreed, "Yes—BOA gives us a higher standard that we have to push ourselves to. We have to work harder and push ourselves harder and stronger-it motivates us more.” The sense of purpose translated into rehearsals with greater efficiency and rigor.

Students in the Camdenton band also feel that they concentrate more on the musical aspect of their marching band show. Anita said that in their rehearsals and performances you want to "perform the music with musicality." Antoine agreed, adding that the influence of BOA "makes me focus on how the music moves me. $\mathrm{BOA}$ is the most competitive competition and it really pushes you to feel the music - music should have feeling." Regarding the learning of his music, Jake added, "When it comes to my music, I want to sound great for these competitions-it just makes me want to strive to do my best."

The stronger work ethic the students feel applies to both the drill and the music.

As Julie shared, "It makes me practice more and makes me push myself to be a better marcher and player and to show improvement at each contest." Ted offered that this work ethic goes beyond marching band:

Students can get quite a few things as a result of the band's participation in BOA. There is a greater degree of work ethic by being involved in this group and I think that helps in more than just the band aspect of your lifea work ethic is good for life-college. There is also a greater sense of family and camaraderie and I don't know if that would be the same if they weren't pushed as hard. 
Ted's comment summarized the feeling of many band members, "BOA just makes us a better product in general. Everything about our performance-visual or musical-just at a better level by attending BOA."

This desire to become a better band has also influenced the culture of the Camdenton marching band positively. This can be illustrated from a journal entry I made following one day of marching band camp:

The issue of talking came up on the field today, and it was interesting to observe how the students took charge of this and corrected the situation. Self-discipline seems to be an important part of their established culture.

The students at Camdenton frequently referred to the closeness of their band culture. As Ted commented, "There is a greater sense of family and camaraderie, and I don't know if that would be the same if we weren't pushed as hard." Kim, a member of the color guard, expressed similar feelings as they related not only to the members of the guard, but to the band staff as well:

We are a family - you are closer to the people in your section. It is like having a ton of little sisters. If they need help, you are going to be there for them and we are always going to be together. With the instructors, you know that they are going to be there. The staff makes this what it is. They may push us, but they know us as people and they know what we need. They are extra parents-they know how far we can be pushed to be great.

Students remarked that the band is a foundation for the building of relationships, as Fred stated: "I think we get along. We have our bumps and struggles like every family, but we all work together for the bigger picture. We make new relationships. We help new people out." Concerning the feelings of camaraderie and building relationships, Stewart commented, "It (BOA) focuses on unity within the whole program. We are all here to help one another." 
Students feel a responsibility to everyone, and that includes helping one another during rehearsals. Band members feel they should not only strive to be their personal best, but to help others strive for the same. As Jake expressed: "There are two types of practices. There is the kind that you do for yourself and the kind that you do for your band." He continued:

We see our marching band as a team sport-for what it is. BOA means that EVERYONE must be performing to his or her utmost potential. We see that every mistake we make affects all 179 other members. We also see the emotional effect of the music. BOA makes you remember-makes you think about every mistake you make and you remember that there are 179 other people who are working for your score as you are working for their score. It is selfish not to perform at your highest level.

The students interviewed all expressed the desire to work hard and push themselves, while encouraging their fellow colleagues to do the same. Jake summarized this feeling: "It really makes me want to do my best and to step up to the plate and help others so that they can do their best, so that we can compete well in these competitions."

The Camdenton band has experienced changes in their band practices as a result of the influence of BOA participation. Changes in the band performance can be seen as a result of the staff's approach to show design. There is a more cohesive approach to the establishment of a show them the unification of all elements of the marching band (wind instruments, percussion instruments, and color guard)—partially as a result of the impact of the drum and bugle corps on high school marching bands. This approach to show design has led the staff to improve their teaching process through better collaboration with each other and improved communication with the students. Finally, the students have changed their participation in band through a more focused and intense work ethic. 
This stronger work ethic has also influenced the culture of the marching band, creating a sense of family and belonging.

\section{Obstacles to Participation in BOA}

The Camdenton High School marching band has experienced several positive influences as a result of their participation in BOA. There have also been obstacles associated with BOA. During my investigation, I found two sub-themes that emerged as barriers: (a) demographics, and (b) cost.

\section{Demographics}

The obstacle of demographics was a potential major barrier in Camdenton High School's participation in BOA. Because of their location and their socio-economic population, Camdenton did not seem to be an ideal candidate for BOA participation. Compared to most of the schools with which they compete at BOA events, they did not seem to be well suited for BOA participation.

Camdenton is a small rural community in central Missouri. From its original 73 founders in 1931 (Burke, 1981), this community has grown to its current population (2015) of just under 3800 citizens. Camdenton High School, with a current student population (2015) of 1307, was opened in 2007. At the time of this study, the student population was $92.8 \%$ White, $1.8 \%$ Hispanic, $1.3 \%$ Asian, 1.1\% African American, and $.5 \%$ Native American Indian. $51 \%$ of the student body qualified for the free or reduced lunch program (www.camdentonschools.org, 2015).

The closest metropolitan area to Camdenton is two hours away. Private lesson teachers, music arrangers, drill writers, and other consultants are not readily accessible. Camdenton does not have much industry; therefore, there are few places from which to 
receive community funding. Thus, the directors depend heavily on the efforts of their band parents, which despite being a rural community, affords the band a degree of affluence untypical of a community this size. The Camdenton band staff has established professional relationships with colleagues whose bands successfully compete in BOA. Through these relationships, they have been able to secure music arrangers and drill writers. Students have to compensate for the lack of private music instruction by practicing their instruments regularly. They also have developed an intense work ethic to make up for the lack of access to additional marching band consultants.

When Mrs. Snow was asked about the major challenge facing the Camdenton marching band as it competes with other bands on the national level, she stated:

Our demographic-we don't have access to get kids private lessons. We just have to do our best-no one will come here because we are so far away. This is the lake area-the middle class is so small here. We have a lot of seasonal employees here.

Mr. Benson agreed and added, "The major challenge we face participating in the BOA circuit is that we must accept the fact that we are a small fish in a big pond."

Despite the fact that Camdenton is a small, rural high school in a rural community, that the Camdenton High School marching band competes at BOA brings a feeling of pride and confidence to the band members. Stewart pointed out: "After this year, we have made a name for ourselves. We are in the same league as some of the highest level bands in the state." Band members expressed their opinions that other bands, particularly in the state of Missouri view the Camdenton marching band in a positive light as a result of attending BOA contests. Carl expressed, "I feel they see Camdenton stepping up and going the extra mile and taking the initiative." Anita added, "It definitely makes them look at us higher. We have competed against bands from all 
over and we are comparable to them. If the tiny town of Camdenton can do it, some of them can too." In summary, the Camdenton band staff and students do not allow their demographics (size, location, and economy) to keep them from participating in BOA.

\section{$\underline{\text { Cost }}$}

A second obstacle to BOA participation for the Camdenton High School marching band was that of cost. Because of the high standard of excellence at BOA events, marching bands that choose to participate in BOA must spend a lot of money on show design, custom music arrangements, improved instruments, and uniforms. In addition, because BOA events are located throughout the United States, food, transportation, and lodging expenses must be anticipated.

The challenge for the directors of the Camdenton marching band program to adopt the rules and regulations of BOA meant a change in show design and an increase in expenses for the marching band program. Mr. Trevor discussed these issues at length:

Gone are the days of playing stock charts-this will not get it done. You have to have your music arranged for your band. Top arrangers are expensive$\$ 8,000$ is not out of the question, and that is just for the wind book. You have to pay to have your drum book written and a different person for your front ensemble book. Then, you have drill writers and guard writers and band body movement specialists. $\$ 35,000$ just for basically the textual component. But there is more, too. We stopped marching trombones, so we had to buy 20 marching baritones at $\$ 1500$ a pop. Then, your sound system had better be 'top of the line' with a guy running it that understands gate and wattage and gain and timbre and reverb, etc. Guard members are so important, you need a minimum of 30 kids in guard-that's 30 new guard uniforms every year. Don't forget about the staff-you need color guard specialists, low brass techs, pit people, and snare techs, and it goes on and on. When I started teaching, it was me. I was the music writer and the drill writer and color guard guy, etc. Those days are over.

These expenses reflect the change in show design over the years to include a more cohesive theme, with all elements of the show (music, drill, colors) bringing vibrancy to 
the selected show theme. The goal is to make all of these show components work together to enable the show theme and, in the words of Mrs. Trevor, to "speak to the audience." The expenses involved in the development of a show theme and the design of a successful marching band show produced words of caution from Mr. Benson:

The single drawback I would highlight would be that each year, bands are constantly trying to "out-do" themselves and each other. I think that some day this may make the proper execution of a marching program in the BOA-style cost and time prohibitive for many groups.

\section{Summary}

In summary, the influences of BOA participation on the Camdenton High School marching band have been positive. As a result of the BOA standard of excellence, the band has worked to reach a new level of excellence because of BOA's consistent and rigorous criteria. The students have been motivated to perform to a higher standard and display a more positive attitude toward their musical excellence. BOA participation has resulted in changes to the band's practices. The staff has changed their approach to show design in order to comply with BOA expectations and compete more successfully. The staff now collaborates more and has established a more effective teaching process. The students have also developed a stronger work ethic, both towards their own performance and that of their fellow band members. Despite the potential obstacles of demographics (such as size, location, or economy) or the cost, the Camdenton High School marching band has accepted these as challenges and not allowed them to negatively influence their participation in BOA. 


\section{CHAPTER FIVE}

\section{Discussion}

In this research study, I set out to answer the following research questions:

- What are the key motivators for a high school marching band to participate in a Bands of America (BOA) event?

- In what ways does participation in BOA influence the practices of a high school marching band?

- What obstacles, if any, does a rural high school marching band face while participating in Bands of America?

Through my investigation and answering of these questions, I discovered that there were several motivators for the Camdenton High School marching band staff to elect to participate in BOA. The standard of excellence that exists at BOA marching contests is consistent from state to state, and provides the staff and students with an adjudication rubric that serves as a guide for them to rehearse and perform at a higher musical level. Participation in BOA has led the staff to change the design practices of their marching show design. In addition to the planning of the show, the staff has improved their teaching process. This, in turn, has affected the students' attitude and approach toward their rehearsals. They have an increased work ethic and feel responsible for each other. All of these factors exist despite certain obstacles the band faces, including limited resources and an increased cost factor.

Other high school band directors who are considering BOA participation might consider the Camdenton High School marching band program as a model. By looking 
into the reasons why Camdenton chose to participate in BOA and some of the resultant influences, they might be able to apply them to their own school marching band programs.

\section{Summary of the Findings}

What are the key motivators for a high school marching band to participate

\section{in a Bands of America event?}

One of the key motivators of the Camdenton marching band staff's decision to participate in BOA events was BOA's standard of excellence. This standard is achieved through the application of consistent and rigorous adjudication criteria at all BOA contests. The staff noted that the adjudication criteria are uniform at every BOA event because the rubric remains constant and BOA judges are all trained to use the same rubrics, resulting in greater consistency. BOA uses a Criteria Reference System that is designed to provide a consistent adjudication standard from which bands are evaluated. These rubrics are included in the Bands of America Official Procedures and Adjudication Handbook received by every competing band (see Appendix G). The staff felt confident that by attending BOA events, they would be judged uniformly, regardless of which state the contest was located. Students agreed with the marching band staff that BOA contests are more competitive and rigorous events than those held within the state of Missouri.

The Camdenton band staff commented that during the years they competed solely in Missouri marching band contests, there was a lack of uniformity in performance expectations that may have resulted from judging inconsistency. For example, a successful performance at one contest did not necessarily translate into equal or greater success the following week, even if musical and marching improvements were made in 
the marching show. This finding was similar with other researchers who also found that consistency at marching band festivals was an area of concern (Austin, 1988; Jarrell, 1971; Rockefeller, 1982; Rohrer, 2002). Payne (1997) reported that, although competitions have been regarded as sources of motivation for band students, scoring consistency at festivals has been problematic for many high school marching band directors. The staff felt that this was due to the use of different judging sheets at each Missouri event, no uniform adjudicator training, and a lack of consistent and rigorous adjudication criteria.

The consistency of adjudication at BOA contests was one reason that Camdenton students felt motivated to perform at a higher level of excellence. This was directly reflected in their participation during band camp as they attempted to more accurately learn their band music and their marching drill. As the Camdenton marching band progressed through their marching season, I observed that the staff and students seemed to have a common motivation for improvement. In my journal on the evening before the Broken Arrow, Oklahoma competition, I wrote:

Following a week of hard work and much cleaning of drill, tonight had to count. All students were very quiet and had great concentration. Time in class today had been spent watching the BOA Grand National Championships from the previous year. The band members' goal was to make their performance at Broken Arrow on the same level.

Buyer (2009) discussed how hard work and competition can bring students together:

Life skills, such as hard work, preparation, confidence, commitment, consistency, attitude, leadership, teamwork and focus can be developed by participating in competitions. Although band members can learn these skills without competing, their value is reinforced when a group receives rankings, ratings, and scores. Students become better people (p. 30). 
At BOA events, the marching band students felt that their efforts would be rewarded because every band is adjudicated similarly. It was obvious in my investigation that this commitment to improvement was grounded in the belief that they could improve each week and would be judged by a consistent standard. This belief that they could improve and reach the consistent and rigorous adjudication criteria of BOA resulted in an increased desire to perform at a higher level of excellence.

In addition to the improvement of student musicianship, the staff noted that the students' attitudes toward each other (and those band members with whom they compete) had become more positive. Before going to BOA events, the staff mentioned that contests were viewed as "every man for himself" with the main objective being to see who they could beat and how many trophies they could bring home. This finding is consistent with those of Austin (1990), who discussed competition and some of these pitfalls that highly competitive music programs may face. He wrote that although band directors and students viewed competition as an important part of a music program, the desire to be "number one and win at all cost" (p. 22) was often used as a yardstick of success. He went on to contrast goal structures in highly competitive programs: "In competitive goal structures, students work against each other toward some goal or reward. In cooperative goal structures, students work with each other toward a common goal" (p. 23).

As the Camdenton band staff has participated in BOA over the past five years, they have worked to incorporate these cooperative goal structures within the ranks of their band members. As a result of the emphasis on performance rather than winning, the staff and students demonstrated a much more positive and friendlier attitude toward their fellow competitors. The emphasis is no longer on winning or on how many trophies the 
marching band members can acquire, but rather on performing their best. Through the implementation of these cooperative goal structures, students place a greater emphasis on the activity itself, such as the performance of a marching band show, rather than focusing on winning a contest.

\section{In what ways does participation in BOA influence the practices of a high}

\section{school marching band?}

The marching band staff at Camdenton high school reported that one of the initial changes in their band practices as a result of participating in BOA competitions was their approach to show design. This is congruent with previous findings on the importance of show design, a process that begins with establishing a theme, followed by the selection of music (Garrison, 1986; Rockefeller, 1982). In a survey of high school band directors across 10 states, Hewitt (2006) found that the important components of show design included music selection and drill design, and that these were essential for superior marching band performances. Laib (1984) indicated the importance for marching band directors to be involved in all aspects of show design in order to capitalize on both the musical and visual strengths of their ensemble.

Because bands that participate in BOA are judged with a rubric that all bands across the nation use, the Camdenton band staff has changed their show design to include a more cohesive theme, with all elements of the show (music, drill, uniform colors) deliberately planned to accentuate the selected show theme. All elements of the show, including choice of music, design of the marching drill, and color schemata, were designed by the Camdenton band staff to create a cohesive theme. This finding is consistent with current studies involving marching band show design that indicate the 
movements in the marching drill as well as color selection should visually reflect the music (Haselton, 2011; Hosler, 1996).

The Camdenton marching band staff worked closely with music consultants outside of the school district in order to develop high quality musical arrangements for all instrumentalists. Other consultants were involved in the development of the marching drill, percussion techniques, and choreography for the color guard. An appropriate color scheme for the flag design as well as other pieces of equipment to be used in the visual program such as sabers and air blades were also selected. Because BOA participation meant that the band would compete nationally, all elements of the show were carefully designed to present a complete production on the marching field and to demonstrate a high level of achievement.

The Camdenton band staff also expressed their feeling that another observable outcome from their participation in BOA was an improvement in their teaching process. They feel that this has resulted in the achievement of a higher level of musical and marching excellence. Because BOA has explicit adjudication language outlined in their handbook, the marching band staff is able to use a common language when instructing their students. The staff engaged in more collaboration when planning by establishing their collective goals for the band, which resulted in greater clarity of instruction during rehearsals. It is no surprise that this instructional clarity has allowed students to push themselves further in both rehearsals and performances and to gauge their achievement more accurately throughout the marching season.

This staff's perceived improvement in their own pedagogical techniques is not unprecedented. Researchers have investigated the correlation between competition and 
quality teaching. Hash (2016) investigated the National School Orchestra Contest between 1929-1937 and discovered that teachers who participated in the event raised the musical standards of their performing ensembles. Rohrer (2002) found evidence that music competitions (a) raised the standard of literature performed, (b) improved the level of performance, and (c) increased students' work ethic.

The Camdenton marching band staff's improvement in their teaching process is similar to what investigators have written as it relates to music teachers in general, and band directors specifically. Hosler (1996) wrote that marching band directors should explore a variety of means to develop the musical skills of their students during marching band season. The band staff and student members hope to become a consistent finalist at BOA contests. The goal for the students involved in the marching band activity should be to look and sound great. The staff believes that this goal can be realized as a result of their improved teaching process.

Students commented that competing at a national level shapes not only the instruction they received from their staff, but also the standard for which they strive. This finding is consistent with Angeline (2014) who discussed that music teachers must consistently strive to find new and interesting ways of stimulating both themselves and their students. Schmidt (2005) examined participants' academic motivation within the context of instrumental music and concluded that motivation was a crucial element in music education and that there was a definitive link between student motivations, performance, and the teaching processes demonstrated by the music teacher. All of this comes from the challenge and motivation of BOA participation, pushing them to work hard, and to rehearse their marching drill and their music in a more efficient manner. 
Because music performance receives so much emphasis from the judges at BOA events, marching band students feel the responsibility to learn their music so well that they are able to perform it accurately and expressively. Students feel that they must "go the extra mile" in rehearsals and performances due to BOA being a higher-level series of contests. They believe that a strong work ethic is vital in making their performance—both visually and musically — congruent with BOA standards. Previous research findings have indicated that improvement in student musicianship can be witnessed through marching band participation (Hosler, 1996; Rockefeller, 1982). This is one of the positive aspects of marching band as written by Mason et al. (1985):

Consistently award-winning marching bands attain the same high quality of performance expected of concert bands in tone quality, intonation, technical precision, and balance. Outstanding groups do not merely imitate the sound of the drum corps (p. 27).

This stronger work ethic has not only led to the improvement of the Camdenton band students' musicianship, but also to a change in the practices of how students relate to and treat each other.

A strong feeling of camaraderie has developed with the members of the Camdenton marching band. Since competing at BOA, the band members note that there is a greater sense of family, a foundation for making friends and building relationships, and a means of feeling "a part of something" (Adderly, Kennedy, \& Berz, 2003, p. 195). School music ensembles such as marching bands have been recognized as musical cultures. Morrison (2001) wrote that music ensemble culture is often overlooked in secondary schools. He writes, "any group of people sustained by a common interest or a set of shared values will develop customs, conventions, and conversational manners of a more or less specialized kind, creating a sub-culture. Students take ownership of the 
ensemble experience in a unique and personal way" (p. 25). Students in the Camdenton marching band feel a sense of responsibility to learn their music and marching drill and to perform well. The culture that develops within these groups results from regular and extensive interactions, such as those from concerts, football games, and marching band competitions. Schouten et al. (1983) wrote, "The team effort necessary to be successful at contests also helps build spirit de corps and a feeling of family" (p. 29). These interactions helped to create a feeling of responsibility among the members of the Camdenton marching band to learn their music and marching drill, as well as to perform admirably.

As I spent time with the students in the Camdenton marching band, I observed a demonstration of responsibility toward each other. Students helped each other learn their drill and music, and offered words of encouragement when their peers became discouraged. This feeling of responsibility has caused the development and sense of a connection within their band community, along with an acceptance of each individual's contribution to the success of the marching band. The students feel that they are here to help one another strive to be their personal best.

During my participation in the Camdenton band's rehearsals and attendance at their contests, I observed that all members of the marching band are considered equally important. There are no "bench warmers" - everyone is a "starter." Everyone is an active participant in their rehearsals and performances, and individuals are regarded as vital to the success of the marching band. Students feel accepted because of their strong sense of responsibility toward one another. 


\section{What obstacles, if any, does a rural high school marching band face while}

\section{participating in Bands of America?}

The Camdenton band staff commented that demographic factors are one of the major obstacles they have had to overcome. Camdenton is a small, rural community in central Missouri located near the Lake of the Ozarks. Students at Camdenton High School do not have direct access to private music teachers. Music consultants such as music arrangers and drill writers are not readily accessible. Their school has a relatively small student population (approximately 1,307), meaning that at BOA events they compete with schools sometimes twice their size.

Smaller bands that compete against bands from larger schools and communities have been the focus of previous research studies (Rickels, 2008; Saul, 1977; Washington, 2007). Burnstead and Sochinski (1983) explored the attitudes of students, parents, administrators, and band directors toward marching band competitions, including a discussion of the relationship between the number of competitions a band chooses to enter and the size of the band. Because larger bands tend to enter more competitions, smaller bands face continued challenges when attempting to succeed. Rickels (2008) found that Arizona marching band contests favored larger bands and that larger competitive marching bands were generally more successful than smaller bands (2009).

The obstacle of funding for the Camdenton band is amplified by the increased expense the band incurs by competing in BOA events. Marching bands that choose to participate in high-level competitions such as BOA are faced with the reality that competitive marching band is a "big business" (Rockefeller, 1982, p. 31), with a wide range of expenses such as custom music arrangements and show designs, color guard 
choreography, expanded percussion equipment for both the battery and the front line, special uniforms for both the wind/percussion players and/or color guard members. Additional expenses encumbered for marching band includes instruments and marching consultants.

Despite being a rural community, Camdenton High School does enjoy a degree of affluence, although the marching band staff expressed concern over many of the expenses they incurred by participation in BOA. When it comes to acquiring the necessary funds required due to the costs associated with BOA participation, the small size of the community and the large percentage of the population who are seasonal employees present fundraising challenges. Some of these costs include the need for a quality music arranger (wind and percussion parts), a drill writer, a sound equipment consultant, and visual equipment expenses, such as color schemes for flags. Additional funds are necessary for instruments including marching trombones, marching baritones, sousaphones, and battery percussion instruments (e.g. five tonal bass drums, tenor drums, miscellaneous keyboard instruments). Other considerations include expenses for traveling, lodging, and food. BOA participation is an expensive endeavor for any marching band, but those incurred expenses by a marching band from a school and community the size of Camdenton are considered a greater challenge.

The Camdenton band staff acknowledged their feeling that the size of their school put them at a considerable disadvantage when they decided to participate in BOA. However, they felt a sense of accomplishment as their marching season progressed. As I traveled with the Camdenton band this fall, I witnessed the band's excitement as they won their division at competitions in Clarksville, Tennessee, Ozark, Missouri, and 
Broken Arrow, Oklahoma. The Camdenton marching band overcame the obstacles of demographics and cost, and was able to compete successfully.

\section{Is BOA Worth It?}

There has been a limited amount of research on BOA, particularly as it relates to the influence that the decision to participate in BOA events has on marching band programs. Due to the increased interest in BOA in Missouri, I hoped that this research study might provide information to assist band directors who are considering participating in BOA marching band competitions. With that in mind, I would like to address the question "Is BOA Worth It?"

\section{$\underline{\text { Reasons Against BOA Participation }}$}

Although BOA's popularity continues to rise, as evidenced by increased marching band participation, there are those who oppose the activity. The main reasons that I have discovered for band directors' opposition to BOA participation center around three main areas: (a) one show learned per season, (b) time commitment, and (c) cost.

Bands that participate in BOA contests traditionally learn only one main show during a competitive marching band season. Although these shows may be "tweaked" throughout the season, the main portion of the show generally remains intact. Band directors who oppose the one-show concept feel that this limits students' exposure to a wide variety of music. With the emphasis of learning one set of music over a period of several months, which generally includes only three or four musical selections, opponents of BOA feel that students are denied the opportunity to work on and improve the music fundamentals and techniques of musicianship specific to their individual instruments. 
Along with the concern over the development of students' individual musicianship, a second concern results from the time commitment necessary for BOA participation. Bands that compete at BOA contests spend a great deal of time in rehearsal over several months in the pursuit of music and marching perfection. Band camps frequently begin as early as mid-July, with large amounts of time spent in learning marching fundamentals, marching movements, and the incorporation of the marching music into the show. Percussion and color guard sections generally spend more hours rehearsing by themselves (in addition to those hour spent with the entire marching band as a whole). This time commitment expands to one or two evening rehearsals once the school year has begun. Because BOA events are located in a variety of states, increased travel time is required for band staff and students.

Opponents to BOA point out that this excessive amount of rehearsal time takes away from both staff and students' other academic endeavors. Staff members have less time to prepare for the other classes they teach, and students have less time for homework. Furthermore, with the concentration of rehearsals, students are often limited in their participation in other school related activities. This may limit schools from producing "well-rounded" students.

The third major reason for opposition to BOA participation given by band directors is that of cost. Simply put, BOA is expensive. In order to compete successfully, shows must be designed by professionals. Music must be arranged to fit the marching drill. Music arrangers generally charge marching bands for music at a certain rate per minute of the marching band show. In addition, fees must usually be paid to publishers to acquire copyrights or pay for permission to perform a certain musical selection. These 
arrangements are usually only produced for the wind instrument players. Arrangers frequently rely on percussion specialists to write the percussion parts for the battery and the front ensemble, which is an additional cost.

Once the marching band show and music have been put together, the color guard uniforms must be designed, followed by the creation of corresponding designs for the flag (or flags) to be used in the show. This cost includes the selection of fabrics, color schemes, and manufacturing costs. Included in the color guard section is what props (e.g. flags, sabers, or rifles) will be used to visually enhance the music. Many bands choose to purchase specifically-designed marching band instruments, such as marching baritones and sousaphones. In addition to color guard equipment and marching band instruments, a large amount of sound equipment is generally used to support soloists on the front sideline, or to amplify the sound of the front ensemble, or even the entire marching band. Many bands that compete in BOA hire consultants during the marching season. These are specialists in specific areas, such as woodwinds, brass, percussion, or color guard. Consultants may be hired to come to one or more band rehearsals and share their expertise with their respective sections. These individuals generally charge a specific fee, and expect lodging and meals to be provided for their services.

In addition to the time it takes travelling to BOA contests, the expense associated with that travel is great. Bands that participate in BOA frequently use charter busses rather than traditional school busses for ease of travel. When attending BOA contests, bands often have to pay for one or two nights lodging. Added to this is the expense incurred with meals for students. It is becoming more and more common for band parent organizations to travel with and to feed their students. 


\section{$\underline{\text { Reasons For BOA Participation }}$}

Although band directors opposed to BOA present several arguments in support of their position, directors who are currently participating in BOA contests (or are considering participating) cite three positive factors: (a) the standard of excellence, (b) performance opportunities, and (c) positive public relations.

Band directors who favor BOA feel that the standard of excellence associated with BOA events is a positive reason for participating in these contests. They mention that BOA contests use the same Criteria Reference System of adjudication, with all BOA judges being trained to use this system. The result of this adjudication training means that every band is judged by the same standard at each BOA contest. All bands are expected to achieve at certain levels of proficiency (as indicated by the rubric) in order to attain a certain score. BOA contests are judged by the same standard of excellence, regardless of location.

This standard of excellence can be achieved because of the concentration of participating marching bands on one show during the competitive season. Directors who favor BOA believe that it is more important to learn one show and to learn it well rather than to learn several different shows at varying degrees of proficiency. This line of thinking also applies to the performance of the marching band music. Band directors who compete at BOA stress the importance of striving for musical excellence, rather than just spending a lesser amount of time on a larger repertoire of musical arrangements. These directors feel that BOA participation allows them to teach the music fundamental of their students' respective instruments in greater detail in order to achieve excellence in their musical performance. 
Band directors like the idea of having other consultants work with their marching band students. They believe that this provides students with a greater amount of supplementary instruction from experts that they wouldn't get if their bands did not participate in BOA. Through this approach, they feel that the other ensembles in their band program (e.g. concert band, pep band, jazz band) are also improved.

Participation in BOA contests provides marching band students with a venue for performance that they would not necessarily receive at non-BOA competitions. Not only do they receive consistent adjudication, but they also compete with bands from across the United States. This exposes them to a greater variety of musical approaches to marching band, as well as a diverse population of participants that they would likely not encounter at local contests. Students are able to make associations with students from several states, many of which may last a lifetime.

BOA contests are designed to provide a positive atmosphere and to promote a healthy approach toward competition. Marching band participants that compete at BOA learn to appreciate the efforts of their fellow competitors and to treat each other with respect. At the conclusion of all BOA contests, all marching band students disband on the field in order to meet and congratulate each other for their efforts. Band directors appreciate this positive approach to BOA events.

Band directors believe that the BOA standard of excellence, in concert with the approach to competition, provides a positive public relations image for their respective high schools. Many bands that participate in BOA events are also known for their strength in other academic and school-related areas, such as athletics. Band directors, administrators, and parents who believe in BOA share their belief that their marching 
band's participation in BOA competition provides a positive image of their band program, their school, and their community.

\section{BOA and Music Values}

Of important consideration for this discussion is BOA's educational value to high school marching band programs. The reasons found in the preceding section are both valid arguments regarding BOA, depending on the context and values of music education for the rural school. One way for directors to help make the determination whether or not BOA is worth it is to assess these arguments in light of the goals and values of American music education. The National Association for Music Education (hereafter referred to as NAfME) is the largest organization of American music educators (NAfME, 2016). The purpose of this organization is to promote the advancement and preservation of music education as a part of the core curriculum of schools in the United States. The mission of NAfME is "to advance music education by promoting the understanding and making of music by all" (NAfME, 2016). The stated values of NAfME (www.nafme.org/strategicplan revised 2016) are:

Community: Collaborating with our family of associations, members, and partners to carry out our mission.

Stewardship: Empowering volunteerism and strategically developing leadership, fostering a spirit of accountability and a culture of giving of our time, talents, and resources.

Comprehensiveness: Uplifting the human spirit and providing opportunities for all students to create, perform, respond, and connect to all styles of music. Inclusion and Equity: Building strength and promoting diversity in a profession representing the wide spectrum of people and cultures, abilities, economic backgrounds, and gender identities.

Innovation: Enhancing music teaching and association program management through combining effective and dynamic new practices with proven strategies in the context of our changing global community.

BOA also publishes their values, which in many cases align or overlap with those 
of NAfME. The stated mission of Bands of America (and Music for All, Inc.) is "to create, provide, and expand positively life-changing experiences through music for all" (Bands of America Official Procedures and Adjudication Handbook, 2015, p. 1).

Included in the beliefs and values of BOA are the following:

"Bands of America and Music for All believe that the essence of competition is in the striving for performance excellence and being held accountable for learning. By choosing to participate in competition, individuals and groups have already "won" simply by being highly motivated.

The competitive arena provides a very precious opportunity to practice quality sportsmanship and sincere appreciation for the hard work of others. It also is the place where the very best models in our activity can be displayed and celebrated. First place is fleeting, but the learning associated with the striving for excellence, the cooperative work ethic, and the appreciation of others is everlasting" (Bands of America Official Procedures and Adjudication Handbook, 2015, p. 1).

These are the values of music education as expressed by both NAfME and BOA.

I will now examine these values as they relate to BOA participation in order to assess if BOA might be of value to a high school band director.

Both NAfME and BOA believe in the spirit of accountability. They value consistent and rigorous criteria for competition. Through the use of the Criteria Reference System, all bands are held to the same standard of excellence, regardless of school or band size. The essence of competition is affording all marching bands the opportunity to reach for and achieve this standard of excellence.

BOA participation provides students with the opportunity to perform, a value held by both NAfME and BOA. Students are given the opportunity to participate in a highly competitive arena that includes some of the best marching bands in the United States. This opportunity allows students to perform, respond, and connect to a large variety of musical styles as demonstrate by marching bands from across the nation.

BOA promotes the value of strength through diversity by attracting marching 
bands from all regions of the United States. Through the promotion of quality sportsmanship and the appreciation of others' hard work, BOA encourages a positive competitive atmosphere. This is in line with NAfME's value of strength through diversity. Students are placed in a competitive marching band event in which the talents and efforts of others are celebrated, without reference to people's abilities, cultures, economic background, or gender identity.

Finally, BOA participation may have a positive impact on the teaching process. Band directors of participating BOA bands must become good teachers in order to compete effectively. This supports the value of the enhancement of music teaching as put forth by NAfME and learning associated with striving for excellence as suggested by BOA. Band directors who participate in BOA stress the musicianship of their individual students as well as that of the marching band as an ensemble. Music instruction is very detailed. Therefore, including music fundamentals for each respective instrument and fostering the development of student musicians as performers first and marchers second should be an important goal.

\section{Recommendations}

The findings of this study suggest that bands might benefit from participation in BOA. The decision to participate in BOA must be approached with much thought and caution. Based upon this study, I will now briefly discuss some items that I feel band directors should take into consideration as they contemplate whether or not to participate in BOA.

Band directors should look at their respective schools and communities in order to assess what resources they have available to them. Directors of rural schools that are 
located a considerable distance from marching band consultants need to examine how they might possibly meet this need. Is it possible to establish relationships with some of these consultants in order to bring them to the marching band's rehearsals? If not, does the band parent organization or community have the resources to acquire their services? Band directors should look closely at bands that currently participate in BOA and examine how they meet the financial commitment associated with BOA participation. This should be followed by an examination of the economic makeup of their school and community in order to assess if they can fully support a BOA program.

Band directors should also study currently active marching band programs in BOA that most closely reflect their community and school. They should find out how these marching bands have approached BOA, what challenges they have faced, and how they have approached them. These challenges might extend beyond the financial considerations to include band enrollment, school class schedule, academic requirements, time schedule requirements, and travel considerations.

Band directors must become familiar with the standards of excellence expected of marching bands that participate in BOA. They should also study the adjudication rubric as well as the rules and regulations in order to know how to properly prepare for and perform at BOA contests. All marching band staff members should be included in this study, and if possible should attend training sessions provided by Bands of America or Music for All, Inc.

Before beginning BOA participation, it would be advisable for the marching band staff to discuss this fully with the school's administration as well as their parent organization. It would also be recommended that the marching band staff and/or the 
entire marching band, along with administrators and parents, attend a BOA contest. This would allow all parties associated with the marching band to observe what they are getting into before they commit to this endeavor.

The marching band staff should approach BOA participation with a positive attitude. Clear, educational goals should be submitted by the staff to the students and discussed before beginning to prepare for a BOA event. Bands that elect to participate in BOA should not anticipate winning Grand Nationals in their first year of participation. Approaching BOA from a musical frame of reference, with the goal of improving individual and group student musicianship, would be most beneficial.

\section{Study Limitations}

There are several limitations about this study that should be noted. My research was conducted with only one small, rural high school band in central Missouri that had participated in BOA events for five years. Another limitation of this study was the use of a marching band with little demographic variety (e.g., mostly white students). Future researchers could examine the impact of Bands of America on a broader range of schools of varying sizes in additional settings (e.g., suburban, rural) as well as those with a student population of more diverse socio-economic backgrounds. This might provide additional evidence in determining if the influences of Bands of America are consistent in a variety of marching band programs across the United States.

This study was conducted over a single marching band season. Investigators could examine marching band programs that have participated in BOA contests over a period of several years in order to assess if the influences of BOA participation are consistent. This study was also limited to a band that continues to participate in BOA. 
Future investigators might also examine bands that have decided not to continue with their BOA participation, focusing on the reasons for their withdrawal. In addition, further research might be conducted with band programs that do not participate in BOA. This might be helpful in determining if similar influences to those of BOA bands are experienced in their programs.

\section{Future Research}

The focus of this study was the Camdenton High School Pride of the Lake marching band. My goal was to examine the influence of participation in Bands of America (BOA) on their band program. Through interviews and observations, I found a number of positive influences on the band program, as well obstacles faced by the band staff and students.

One aim of my research was to discover some of the motivations for the band staff to choose to participate in BOA. From the results of my study, I found that the first theme that emerged was BOA as a standard of excellence. Within this theme were several sub-themes, including consistent, rigorous adjudication criteria associated with BOA. This was based on the band staff and students' belief that there was a consistency in the judging practices of BOA marching contests, as opposed to those in the state of Missouri. For greater understanding, future researchers might conduct studies to examine if there is a lack of consistency in marching band adjudication in the state of Missouri. Investigators might also survey Missouri high school marching band directors to see if there have been efforts to establish unified marching band adjudication standards, procedures, and training. They might want to expand their research beyond the state of Missouri and examine other states' marching band contest adjudication procedures as well. 
A motivation to perform and an effect on students' attitudes were additional subthemes that I discovered. As a result of BOA participation, the Camdenton band staff observed that their students have a greater motivation to perform along with a more positive attitude. Questions for future researchers to consider might be: (a) Does a positive attitude exist in every band that participates in BOA? and (b) What about the attitudes of members of marching bands that do not compete in BOA? Comparative research could show if these attitudes are present and to what extent these attitudes may be found in a variety of marching bands.

A second theme that emerged dealt with changes in band practices, with the subthemes of the band's performance, teaching processes, and student participation. Changes in the band's performance included detailed emphasis upon show design. In order to meet BOA's established adjudication criteria, competition shows were designed, utilizing consultants for both marching drill and music arrangements. Researchers might want to investigate whether or not participation in BOA demands that bands consult with outside experts in order to compete successfully. They might interview band directors in order to investigate the role of consultants in show design and musical arrangements for bands that choose to participate in BOA. This information might be helpful for band directors who are contemplating participation in BOA.

Changes in the teaching process and students' participation in marching band at Camdenton High School were also discovered. The band staff felt that since participating in BOA contests, they had significantly improved their teaching process. In order to study the influence of BOA participation on other marching bands, future researchers might consider exploring if BOA participation affects the teaching process and the work ethic 
of other marching bands. Investigators could study high school instrumental music programs that are consistent finalist bands in BOA each year to learn if there are reasons why they experience success on a regular basis. Observational studies involving high school marching band directors (or other band staff members') teaching strategies would be helpful in identifying characteristics that are important for student success.

At the same time, the students felt that they had a greater work ethic as a result of motivation to rehearse and perform with a greater degree of excellence at BOA events. Future researchers might attempt to find if there are other ways of instilling an increased work ethic in band students besides competing at BOA. They could explore the various motivational techniques used in marching bands in order to learn which of those are most effective with high school students.

In addition to a greater work ethic, the students that I interviewed felt that the culture of the Camdenton marching band had evolved from BOA participation into a strong sense of family. Students felt a responsibility to work hard for each other, as well as for themselves. The extent to which involvement in BOA can be credited with the establishment of such a sense of family might be a further topic for future researchers. It would be interesting to explore if bands that do not participate in BOA develop the same feeling of family. Investigators might explore the cultures that develop within marching bands to determine if this is a result of the band's competitive focus or is it established by some other means.

Obstacles that I discovered related to Camdenton's participation in BOA centered on those of demographics and cost, and comprised the third major theme of my study. In the future, each of these elements might be studied individually. It might be useful to 
conduct a qualitative study where a greater racial and ethnic diversity exists among student participants in marching band. A study of this nature might provide additional insight on the extent of BOA's influence on a school with students from a more diverse socio-economic background.

An analysis of the cost factor associated with BOA participation might also be of interest to those band directors who are considering whether or not to begin attending BOA contests. Investigators could survey schools that compete in BOA to discover if this increased expense is prevalent among all competing bands or associated with only those that are more successful. If so, do the observable outcomes from BOA participation justify the increased expense? Researchers might also explore alternative approaches used by band directors to address the increased cost of BOA participation.

\section{Conclusion}

Bands of America has become a strong influence on marching band programs across the nation. Each year, participation increases at BOA, both in Missouri and across the United States. In this study, I looked at one of those high school bands, the Camdenton High School marching band, and found a number of influences through competing at BOA, including: better show design, an improved teaching process, increased level of student musicianship, a greater sense of family, and a stronger work ethic. At the same time, this marching band faced a variety of challenges that included demographics and cost.

The stated mission of Bands of America and Music for All is "to create, provide and expand positively life-changing experiences through music for all" (Bands of America Official Procedures and Adjudication Handbook, 2015, p. 1). Through this 
study, I witnessed the realization of this mission statement in one high school band in central Missouri, the Camdenton High School "Pride of the Lake" Marching Band. 


\section{References}

Adderly, C., Kennedy, M., \& Berz, W. (2003). A home away from home: The world of the high school music classroom. Journal of Research in Music Education, 51(3), 190-205.

Alderman, A.K. \& Salem, B. (2010. Survey Research. Plastic and Reconstrutive Surgery 126(4) p. 1381-1389.

Allsup, R. E. (2012). The moral ends of band. Theory Into Practice, 51(3), 179-187.

Allsup, R.E. \& Benedict, C. (2008). The problems of band: An inquiry into the future of instrumental music education. Philosophy of Music Education Review, 16(2), $156-173$.

Amabile, T.M. (1982). Children's artistic creativity: Detrimental effects of competition in a field setting. Personality and Social Psychology Bulletin, 8(3), 573-578.

Anfara, V. A., Brown, K. M., \& Mangione, T. L. (2002). Qualitative analysis on stage: Making the research process more public. Educational researcher, 31(7), 28-38.

Angeline, V. R. (2014). Motivation, professional development, and the experienced music teacher. Music Educators Journal, 101(1), 50-55.

Austin, J.R. (1988). The effect of music contest format on self-concept, motivation, achievement, and attitude of elementary band students. Journal of Research in Music Education, 36(2), 95-107.

Austin, J.R. (1990). Competition: Is music education the loser? Music Educators Journal, 76(6), 95-107. 
Bailey, W. (2003). The Complete Marching Band Manual: Techniques and Materials for Teaching Drill Design, and Music Arranging. Philadelphia: University of Pennsylvania Press.

Bands of America Official Procedures and Adjudication Handbook (2015). Retrieved from http://www.musicforall.org/bandsofamerica.

Bassi, M., Steca, P., Monzani, D., Greco, A., \& Delle Fave, A. (2014). Personality and optimal experience in adolescence: Implications for well-being and development. Journal of Happiness Studies, 15(4), 829-843.

Bierley, P.E. (1973). John Philip Sousa: American Phenomenon. Westerville: Integrity Press, Inc.

Bierley, P.E. (1984). The Works of John Philip Sousa. Westerville: Integrity Press, Inc. Binion, W.T. (1973). The High School Marching Band. New York: Parker Publishing Co., Inc.

Burnsed, V., \& Schinski, J. (1983). Research on competitions: Surveys reveal how students, parents, directors, and administrators feel about competitions. Music Educators Journal, 70(2), 25-27.

Burnsed, V., Sochinski, J., \& Hinkle, D. (1983). The attitude of college band students toward high school marching band competition. Journal of Band Research, 19(1), 11.

Buyer, P. (2009). Marching Bands and Drumlines. Galesville: Meredith Music Publications.

Braun, V. \& Clarke, V. (2006). Using thematic analysis in psychology. Qualitative research in psychology, 3(2), 77-101. 
Cahill, M.J. (1982). A capsule history of the drum and bugle corps. The Instrumentalist 36(11), 6-9.

Charmaz, K. (2014). Constructing Grounded Theory. Thousand Oaks: Sage Publishing, Inc.

Chen, H., Wigand, R. T., \& Nilan, M. S. (1999). Optimal experience of web activities. Computers in human behavior, 15(5), 585-608.

Creswell, J.W. (2013). Qualitative Inquiry \& Research Design: Choosing Among Five Approaches. Thousand Oaks: Sage Publishing, Inc.

Criss, E. (2011). Dance all night: Motivation in education. Music Educators Journal, 97(3), 61-66.

Crotty, M. (1998). The Foundations of Social Research. Thousand Oaks: Sage Publishing, Inc.

Custodero, L. A. (2002). Seeking challenge, finding skill: Flow experience and music education. Arts Education Policy Review, 103(3), 3-9.

Davis, R. B. (2000). A study of the relationship between rehearsal procedures and contest ratings for high school marching band (Doctoral dissertation, Auburn University).

Delle Fave, A. (2009). Optimal experience and meaning: Which relationship? Psychological Topics, 18(2), 285-302.

Doster, G. W. (2015). Greetings. Impact, 2.

Festinger, L. (1954). A theory of social comparison processes. Human Relations. 7(117). Fisher, S.H. (2013). Career Intentions and Experiences of Pre- and In-Service Female Band Teachers (Doctoral dissertation, The Ohio State University). 
Foster, R.E. (1978). Multiple-Option Marching Band Techniques. Los Angeles: Alfred Publishing Co., Inc.

Frenz, Terren L. A comparison of the factors influencing marching band competitions. Diss. Ashland University, 1988.

Garrison, P.K. (1986). The value of marching band. Music Educators Journal, 72(5), 48-52.

Gillett, M. (1966). A History of Education: Thought and Practice. Toronto: McGraw Hill, Inc.

Glesne, C. (2011). Becoming Qualitative Researchers. Boston, MA: Pearson Publications.

Hallam, S. (2002). Musical motivation: Towards a model synthesizing the research. Music Education Research, 4(2), 225-244.

Haselton, C.R. (2011). Artistic elements of a marching band. Music Educators Journal, 97(3), 24.

Hansen, R.K. (2005). American Wind Band: A Cultural History. Chicago: GIA Publications, Inc.

Hash, P.M. (2016). The national school orchestra contests: 1929-1937. Journal of Research in Music Education, 63(4), 397-420.

Hash, P. M. (2012). An analysis of the ratings and interrater reliability of high school band contests. Journal of Research in Music Education, 60(1), 81-100. Hendricks,

K. S., Smith, T. D., \& Stanuch, J. (2014). Creating safe spaces for music learning. Music Educators Journal, 101(1), 35-40.

Hjelmervik, K., Berg, R.C. (1953). Marching Bands: How to Organize and Develop 
Them. New York: A.S. Barnes and Co.

Hosler, M. (1996). Adding variety to halftime shows. The Instrumentalist, 51(1), 34-42.

Holston, K.R. (2004). The Marching Band Handbook. Jefferson: McFarland and Company, Inc.

Hopper, D. (1977). Corps Style Marching. Oskaloosa: Barnhouse.

Jarrell, J. A. (1971). An analysis of achievement, procedures, and activities of selected high school band programs in Oklahoma (Doctoral dissertation). Retrieved from http://google.scholar.com

Judge, T.A., Bono, J.E., Ilies, R., \& Gerhardt, M.W. (2002). Personality and leadership: A qualitative and quantitative review. Journal of Applied Psychology, 87(4), 765780.

Kassner, K. (2009). Reflections on career development and eclecticism in music education. Music Educators Journal, 62-66.

Keene, J.A. (1982). A History of Music Education in the United States. Centennial: Glenbridge Publishing, Ltd.

Kravig, D. (2014). What it takes. The Instrumentalist 69(2), 47-48.

Laib, J. R. (1984). The relationship between competition, show style, and number of shows performed by North Georgia high school marching bands. Journal of Band Research, 19(2), 51.

Kohn, A. (1986). No Contest: The Case Against Competition. Boston: Houghton Mifflin.

Lather, P. (1986). Issues of validity in openly ideological research: Between a rock and a soft place. Interchange, 17(4), $63-84$.

Legette, R. M. (1998). Causal beliefs of public school students about success and failure 
in music. Journal of Research in Music Education, 46(1), 102-111.

Levy, J. J., Castille, C.M., \& Farley, J. A. (2011). An Investigation of Musical Performance Anxiety in the Marching Arts. Medical problems of performing artists, $26(1), 30$.

Lincoln, Y., \& Guba, E. (1985). Naturalistic Inquiry. Beverly Hills, CA: Sage.

MacLeod, B. (1993). “Whence comes the lady tympanist?” Gender and instrumental musicians in America, 1853 - 1990. Journal of Social History, 27(2), 291308.

Mark, M.L. (1996). Contemporary Music Education. Belmont: Wadsworth/Thomson Learning.

Mark, M.L. \& Gary, C.L. (1992). A History of American Music Education. New York: Schirmer Books.

Markworth, W. (2008). The Dynamic Marching Band. Three Rivers: Isaac Publishing, Inc.

Martin, E.L. (2015). Greetings! Impact, 3.

Mason, T. L., Moulton, R., Burton, B., Johnson, D., Rogers, G. L., Goodstein, R. E., Berry, L. Jr., Marzulli, J., Wilke, L.H., Moss, M., Adams, G.W., Haies, D., Notari, R.J. \& Mayerhofer, F. (1985). Point of view: Is marching band in step with music education? Music Educators Journal, 71(9), 27-32.

McPherson, G. E., \& McCormick, J. (2000). The contribution of motivational factors to instrumental performance in a music examination. Research Studies in Music Education, 15(1), 31-39.

Merriam, S. B. (2009). Qualitative Research: A Guide to Design and 
Implementation. San Francisco, CA: Jossey-Bass.

Minichiello, V, Aroni, R., Timewell, E., Alexander, L. (1995). In-Depth Interviewing: Principles, Techniques, Analysis. Sydney: Addison Wesley Longman.

Morrison, S.J. (2001). The school ensemble: A culture of our own. Music Educators Journal, 88(2), 24-28.

O'Donoghue, T. O., \& Punch, K. (2003). Qualitative Educational Research in Action: Doing and Reflecting. London, UK: Routledge Falmer.

Okshevsky, W. (2008). The consequences of competition: An exploration of competitiveness within music education (Master's Thesis). Memorial University of Newfoundland: St. John's, Newfoundland.

Orford, E. H. (2007). A place for music: The importance of music education in the public school system. Canadian Music Educator, (48) 1, pp. 38-41.

Pace, S. (2004). A grounded theory of the flow experiences of Web users. International journal of human-computer studies, 60(3), 327-363.

Parncutt, R. \& McPherson, G.E. (2002). The Science and Psychology of Music Performance. New York: Oxford University Press, Inc.

Payne, B. (1997). A review of research on band competition. Journal of Band Research, 33(1), 1-18.

Pilafian, S. \& Sheridan, P. (2008). The Breathing Gym. Mesa: Focus On Music. Privette, G. (1983). Peak experience, peak performance, and flow: A comparative analysis of positive human experiences. Journal of personality and social psychology, 45(6), 1361-1368. 
Rainbow, B. (1989). Music in Educational Thought and Practice: A Survey from 800 BC. Boethius: Aberystwyth, Wales.

Reissman, C.K. (1993). Narrative Analysis: Qualitative Research Methods Series 30. Boston University: Sage Publications.

Rickels, D. A. (2008). A comparison of variables in Arizona marching band festival results. Journal of Band Research, 44(1), 25-39.

Rickels, D. A. (2009). A multivariate analysis of nonperformance variables as predictors of marching band contest results. (Doctoral dissertation: Arizona State University).

Robinson, W. C. \& Middleton, J. A. (1975). The Complete School Band Program. West Nyack, New York: Parker Publishing Company, Inc.

Robson, B. E. (2004). Competition in sport, music, and dance. Medical Problems of Performing Artists, 19(4), 160-166.

Rockefeller, D. (1982). Rifles, pom-poms, flags, and music? Music Educators Journal 69(4), 31-32.

Rogers, G.L. (1985). Attitudes of high school band directors and principals toward marching band contests. Journal of Research in Music Education, 33(2), 259267.

Rohrer, T. P. (2002). The debate on competition in music in the twentieth century. Update: Applications of Research in Music Education, 21(1), 38-47.

Schatt, M. D. (2011). High school instrumental music students' attitudes and beliefs regarding practice: An application of attribution theory. Update: Applications of Research in Music Education, 29(2), 29-40. 
Schmidt, C.P. (2005). Relations among motivation, performance, achievement, and music experience variables in secondary instrumental music students. Journal of Research in Music Education, 53(2), 134-147.

Schouten, F., Bauer, W.L., Sticks, L., Gifford, R.M., Griffith, O., Caldwell, B., Melillo, S., Gomes, M., Bendell, C.J., Moore, Jr., W.A., Hutchingson, J.L., Gobeen, S., \& Goolsby, T. (1983). Winners and losers: Point of view on competitions. Music Educators Journal, 70(2), 28-33.

Schwandt, C. (2007). The Sage Dictionary of Qualitative Inquiry. Thousand Oaks, CA: Sage Publishing, Inc.

Shepherd, J. (1991). Music and the last intellectuals. Journal of Aesthetic Education, (25) 3, pp. 95 - 114.

Silvey, B. A. (2009). The 1923 schools band contest of America. Journal of Band Research, 45(1), 56.

Spohn, C.L. \& Heine, C.L. (1969). The Marching Band: Comparative Techniques in Movement and Music. Columbus: Allyn \& Bacon Publishers.

Stake, R. E. (1995). The Art of Case Study Research. Thousand Oaks: Sage Publishing, Inc.

Strauss, A. \& Corban, J (1998). Basics of Qualitative Research: Techniques and Procedures for Developing Grounded Theory (2nd ed.). Thousand Oaks: Sage Publishing, Inc.

Sullivan, T. M. (2003). Factors influencing participation of Arizona high school marching bands in regional and state festivals. (Doctoral dissertation, Northern Arizona University). 
Turner, D.W. (2010). Qualitative interview design: A practical guide for novice investigators. The Qualitative Report, (15) 3, pp. 754-760.

Vallerand, R.J., Gauvin, L.I., \& Halliwell, W.R. (2001). Effects of zero-sum competition on children's intrinsic motivation and perceived competence. The Journal of Social Psychology, 126(4), 465-472.

Well, J.R. (1976). The Marching Band in Contemporary Music Education. New York: Interland Publishing, Inc.

Wertz, F.J, Charmaz, K, McMullen, L.M., Josselson, R., Anderson, R., \& McSpadden, E. (2011). Five Ways of Doing Qualitative Analysis. New York: The Guilford Press.

Vance, J.L. (2014). Findings from the field: A pedagogical and cultural study of the north American drum and bugle corps experience, (Doctoral Dissertation, Columbia University).

Vickers, S. (1982). The drum corps world in 1982. The Instrumentalist 36(11), 11.

Wells, J.R. (1976. The Marching Band In Contemporary Music Education. New York: Interland Pub., Inc.

Yin, R. K. (2014). Case Study Research: Design and Methods. Los Angeles: Sage, Inc. 


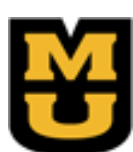

\section{Institutional Review Board University of Missouri- Columbia}

May 15, 2015

Principal Investigator: Stephen Craig Eubanks Department: School of Music 190 Galena Hall; Dc074.00 Columbia, MO 65212

Your IRB Application to project entitled the influence of bands of america on one high school band: a single-case study was reviewed and approved by the MU Institutional Review Board according to the terms and conditions described below:

IRB Project Number IRB Review Number Initial Application Approval Date IRB Expiration Date Level of Review Project Status

Expedited Categories

Risk Level Child Category

Type of Consent

External Funding

2002376

204162

May 15, 2015

May 15, 2016

Expedited

Active - Open to Enrollment

45 CFR 46.110.a(f)(7) 45 CFR 46.110.a(f)(6)

Minimal Risk 46.404

Written Consent Child Assent Parental Consent (One Parent) 
In-kind (donation of equipment or services)

The principal investigator (PI) is responsible for all aspects and conduct of this study. The PI must comply with the following conditions of the approval:

1. No subjects may be involved in any study procedure prior to the IRB approval date or after the expiration date.

2. All unanticipated problems, adverse events, and deviations must be reported to the IRB within 5 days.

3. All changes must be IRB approved prior to implementation unless they are intended to reduce immediate risk.

4. All recruitment materials and methods must be approved by the IRB prior to being used.

5. The Continuing Review Report (CRR) must be submitted to the IRB for review and approval at least 30 days prior to the project expiration date. If the study is complete, the Completion/Withdrawal Form may be submitted in lieu of the CRR.

6. Maintain all research records for a period of seven years from the project completion date.

7. Utilize the IRB stamped consent documents and other approved research documents located within the document storage section of eCompliance. These documents are highlighted green.

If you have any questions, please contact the IRB

Thank you, MU Institutional Review Board 


\section{APPENDIX B}

Subject: Research Study

Date: $3-27-2015$

From: Brett Thompson - Principal, Camdenton High School

To: Stephen C. Eubanks, University of Missouri $<$ scemrb@mail.missouri.edu $>$

CC: Dr. Brian Silvey <silveyba@missouri.edu $>$

I give Stephen C. Eubanks permission to conduct research with the Camdenton High School Marching Band, and to conduct interviews with students for his dissertation:

"The Influence of Bands of America Upon One High School Band: A Single-Case Study"

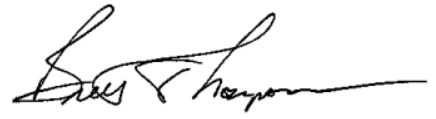

Brett Thompson

Principal

Camdenton High School

Camdenton, MO 65020 


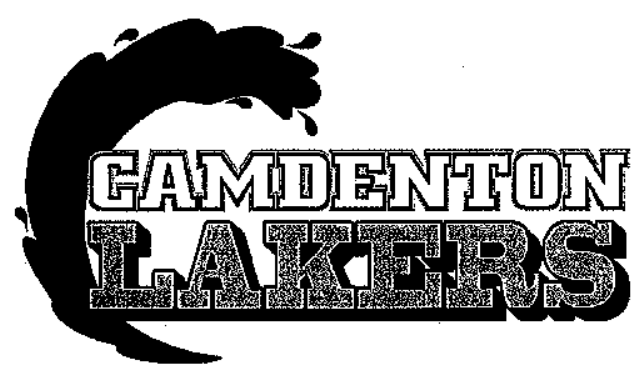

Mr. Brett Thompson - Principal Mr. J.D. Hunter - Assistant Principal Mr. Larry Lewis - Assistant Principal Ms. Anne Wall - Assistant Principal Director of Horizons

Mr. Jeff Whitney - Assistant Principal Activities Director

PO Box 1409, Camdenton, MO $\mathbf{6 5 0 2 0}$

\section{Camdenton High School}

April 19, 2016

To Whom It May Concern:

I give permission to Stephen C. Eubanks to use 'Camdenton High School' in his dissertation 'The Influence of Bands of America on One High School Marching Band: A Single Case Study. If you have further questions, please feel free to contact me.

Sincerely,

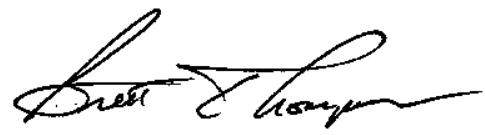

Brett Thompson

Principal 


\section{APPENDIX C}

\section{Assent Form to Participate in a Research Study}

INVESTIGATOR'S NAME: $\quad$ STEPHEN C. EUBANKS

Advison's NAmE: $\quad$ Dr. Brian A. Silvey, University of Missouri

\section{STUdY Title: "The Influence OF BANDS OF AMERICA UPON ONE High SCHOOL BAND Program: A Single CASE STUdY"}

The purpose of this study is to explore the impact of participation in the Bands of America marching band activity and the influence it has had upon the organization's students, staff, administration, and parents. This study will involve research.

You are invited to participate because you are a high school band student.

If you agree to participate in this study, I may ask you to do the following things:

- Participate in 4, 10-minute interview sessions throughout the marching season. Interviews will be audio-recorded.

- Evaluate through 4, 15-minute written pen and paper surveys of your marching band experience.

- Data collected through observations (direct and participant) during marching band rehearsals and marching competition performances.

Total estimated time to participate in the study is 1 hour, 40 minutes.

Risks and Benefits: The risk associated with this study is no greater than everyday life. Possible benefits of this study might include more intense and thorough preparation and performance of marching drill and music.

Compensation: You will not be compensated for your participation in this study.

Confidentiality: All research data collected will be stored securely in a locked office on campus that only my advisor and myself have access to. All publications will exclude any information that will make it possible to identify you as a subject. Names will be changed in the event that your quotes are used in the manuscript. 
Throughout the study, the researchers will notify you of new information that may become available and that might affect your decision to remain in the study. If the child decides to withdraw from the study, any data collected and audio-tapes will be destroyed.

Contacts and Questions: If you have any questions about the study, please ask now. If you have questions later, want additional information, or wish to withdraw your participation, call the researcher conducting the study. His name, phone number, and e-mail address are at the top of this page.

You may contact the Campus Institutional Review Board if you have questions about your rights, concerns, complaints or comments as a research participant. You can contact the Campus Institutional Review Board directly by telephone or email to voice or solicit any concerns, questions, input or complaints about the research study.

Do you want to be in the study?

$\square$ YES $\square$ NO

Date

\section{Signature of Student}

Campus IRB

483 McReynolds Hall

Columbia, MO 65211 


\title{
APPENDIX D
}

\section{CONSENT FORM}

\section{"The Influence of Bands of America Upon One High School Band Program: A Single Case Study"}

\author{
Conducted by: Stephen C. Eubanks \\ School of Music, The University of Missouri
}

Your student is being asked to participate in a research study. This form provides you with information about the study. The person in charge of this research will also describe this study to you and answer all of your questions. Please read the information below and ask questions about anything you do not understand before deciding whether or not to allow your student to take part. Your student's participation is entirely voluntary and your student can refuse to participate without penalty or loss of benefits to which your student might be entitled. You or your student can stop participation at any time and your refusal will not impact current or future relationships with MU or participating sites. To do so simply tell the researcher you wish to stop participation.

The purpose of this study is to explore the impact of participation in the Bands of America marching band activity and the influence it has had upon the organization's students, staff, administration, and parents.

If you agree to participate in this study, I will ask you to do one of the following things:

- If selected, participate in 4, 10-minute interview sessions throughout the marching season.

- If selected, evaluate through written surveys an assessment of the marching band experience through participation in Bands of America.

Total estimated time to participate in the study is 1 hour, 40 minutes.

Risks and Benefits: The risk associated with this study is no greater than everyday life. Possible benefits of this study might include more intense and thorough preparation and performance of marching drill and music on the part of the students and staff, along with greater support from administrators and parents.

Compensation: You will not be compensated for your participation in this study.

\section{Confidentiality:}


The evaluation forms used in this study will be stored securely and kept confidential. Authorized persons from The University of Missouri, members of the Institutional Review Board, and (study sponsors, if any) have the legal right to review your research records and will protect the confidentiality of those records to the extent permitted by law. All publications will exclude any information that will make it possible to identify you as a subject. Names will be changed in the event that your quotes are used in the manuscript. Throughout the study, the researchers will notify you of new information that may become available and that might affect your decision to remain in the study.

\section{Contacts and Questions:}

If you have any questions about the study, please ask now. If you have questions later, want additional information, or wish to withdraw your participation call the researcher conducting the study. His name, phone number, and e-mail address are at the top of this page.

You may contact the Campus Institutional Review Board if you have questions about your rights, concerns, complaints or comments as a research participant. You can contact the Campus Institutional Review Board directly by telephone or email to voice or solicit any concerns, questions, input or complaints about the research study.

483 McReynolds Hall

Columbia, MO 65211

\section{Statement of Consent:}

I have read the above information and have sufficient information to make a decision about my students' participation in this study. I consent to participate in the study.

Signature:

Date: 


\title{
APPENDIX E
}

\section{ADULT CONSENT FORM}

\section{"The Influence of Bands of America Upon One High School Band Program: A Single Case Study"}

\author{
Conducted by: Stephen C. Eubanks \\ School of Music, The University of Missouri
}

You are being asked to participate in a research study. This form provides you with information about the study. The person in charge of this research will also describe this study to you and answer all of your questions. Please read the information below and ask questions about anything you do not understand before deciding whether or not to take part. Your participation is entirely voluntary and you can refuse to participate without penalty or loss of benefits to which you are otherwise entitled. You can stop your participation at any time and your refusal will not impact current or future relationships with MU or participating sites. To do so simply tell the researcher you wish to stop participation.

The purpose of this study is to explore the impact of participation in the Bands of America marching band activity and the influence it has had upon the organization's students, staff, administration, and parents.

\section{If you agree to participate in this study, I will ask you to do the following things:}

- If selected, participate in 4, 10-minute interview sessions throughout the marching season.

- If selected, evaluate through written surveys an assessment of the marching band experience through participation in Bands of America.

Total estimated time to participate in the study is 1 hour, 40 minutes.

Risks and Benefits: The risk associated with this study is no greater than everyday life. Possible benefits of this study might include more intense and thorough preparation and performance of marching drill and music on the part of the students and staff, along with greater support from administrators and parents.

Compensation: You will not be compensated for your participation in this study.

\section{Confidentiality:}


The evaluation forms used in this study will be stored securely and kept confidential. Authorized persons from The University of Missouri, members of the Institutional Review Board, and (study sponsors, if any) have the legal right to review your research records and will protect the confidentiality of those records to the extent permitted by law. All publications will exclude any information that will make it possible to identify you as a subject. Throughout the study, the researchers will notify you of new information that may become available and that might affect your decision to remain in the study.

\section{Contacts and Questions:}

If you have any questions about the study, please ask now. If you have questions later, want additional information, or wish to withdraw your participation call the researcher conducting the study. Their names, phone numbers, and e-mail addresses are at the top of this page.

The Campus Institutional Review Board approved this research study. You may contact the Campus Institutional Review Board if you have questions about your rights, concerns, complaints or comments as a research participant. You can contact the Campus Institutional Review Board directly by telephone or email to voice or solicit any concerns, questions, input or complaints about the research study.

483 McReynolds Hall

Columbia, MO 65211

\section{Statement of Consent:}

I have read the above information and have sufficient information to make a decision about my students' participation in this study. I consent to allow my son or daughter to participate in the study.

Signature: Date: 


\section{APPENDIX F}

\section{Camdenton High School Staff/Student Interviews}

\section{Staff \\ How do you feel that BOA has influenced the Camdenton Band?}

Flora Taylor: BOA has influenced the Camdenton Band in a number of ways. First and foremost, it has transformed how the directors and staff approach the design of the show. From the selection of a theme, to music selections, colors, uniforms. What I have realized for the years that we have been in the BOA circuit, the components that make up the show have become more cohesive. Second, the performers are also much more aware of how their role influences the show theme as well as each other's performance. Finally, just being a part of the BOA circuit has made each staff member and student performer aware of the national level of excellence. Beyond our state's borders, the national level encompasses all types of band and school sizes and helps us establish a higher level of achievement we were not aware of by staying within our own state's levels. Having said that, I am not saying Missouri's level of marching band achievement is lower than the national level. The BOA level has skyrocketed our student's awareness of the nations' best bands.

Karissa Snow: The main thing that BOA has done for the Camdenton band is that it has given us a consistent goal of working toward boxes 4 and /5 and the language we use with our students. Box 4/and 5 are included on the BOA scoring sheets. It has created a common language that we can use and both the staff and the kids understand can understand. It is all the same. It has created the common goal: "lets perform to Box 5" and everyone gets it and understands it. I think the biggest thing that was difficult about attending non-BOA shows was the inconsistency with how you were going to be judged. It was difficult going from week to week with one judge saying you are too loud and then another week them saying you are too soft.

Skylar Christiansen: I feel that BOA has pushed the Camdenton Band to strive to produce more theatrical productions that need to be achieved at a higher level of performance quality. It is no longer about "Rah Rah" get the crowd excited music, but telling a story (like a theater production) where everyone is not only a musician, but an actor that needs to be able to move and dance like professionally trained dancers.

Eric Benson: "More than anything, the BOA judging sheets have given us a high standard to which we can aspire. The advantage of participating in BOA or BOA-style events is that we know exactly what to expect from our adjudication. Plus, BOA judges are trained in such a way that scoring is as close to uniform across the country as one can expect. It happens to be an adjudication system that I, and the rest of the staff, strongly agree with. The judging system demands a good balance between the visual and the musical aspects of a marching show, which to me is educationally sound. It also 
emphasizes a degree of precision and excellence that translates well into all of our preparation-not just marching band."

Jaren Taylor: BOA has become a huge driving force in our band program. Years ago, our goals were to win. That's all, just to win. But how did we make that happen? Well first we picked local festival where the " higher, faster, louder" approach seemed to work. Really, we didn't concern ourselves with musicianship. We didn't ask about musical lines. We were not concerned about making better musicians. We were only set on blowing loud. We chose contests in smaller venues, against local bands and usually came out near the top. BUT..... when we would go to a BOA event, we found ourselves near the bottom. Oh how we would moan and curse. How could we beat Lindbergh or Kickapoo at Valhalla and then lose to them by 8 points the next week at BOA St.Louis? I was asked several years ago by a prospective assistant director candidate "do you take your concert band outside or do you bring your marching band inside?" What??!??!? Uh...well...uh, we play really loud outside and then we spend 2 months getting the marching band out of their inside sound. Damn-I am a marching band guy, not a band director. So, BOA has made my entire program better, and we no longer have an outdoor sound and an indoor sound. We only work for a great sound, regardless of where we are playing. We refuse to go to events where the judges are not educated in a valued rubric. Too often, smaller local festivals do not judge by caption. They give a wide spectrum of judging which will not allow give the director a specific area for improvement. (Wow I'm rambling) BOA has made us dissect each area of the program to find ways to improve.

Merlin Oaks: From a guard perspective, we have pushed thresholds against people we compete against. I always tried to be a little bit different and creative rather than 'old school.' There used to be a discrepancy against how the guard performed and how the band performed. It took a while to get both the guard and the band on the same page. From a guard perspective, we haven't seen that much difference, only that the guard work we do is easier, not just cleaner. We have a show/concept designer and a separate flagbook writer. The guard work is more musical.

Overall, BOA has changed the way we think about the band - it is no longer a guard and a band, but a single element - its all one score. There is no separate guard score. Its not horns verses guard, it is everyone working together contributing to the visual score.

Band's bodywork is an evolution that has occurred with the wind players. Now they just expect it. We never did a lot of stretching before; now we do dance-based muscle stretching exercises during warm up instead of the old school, traditional type of body stretch. The band feels better in their bodies when they stretch.

\section{What have been the key motivators for your high school marching band to participate in the Bands of America event as opposed to more traditional marching festivals?}

Flora Taylor: Bands of America has an established rubric for scoring on all levels of marching band. It has single handedly explained the expectations of the art 
form. Whereas, the "traditional" marching festivals would have different scoring sheets, different expectations ranging from festival to festival. Going to BOA festivals, a marching band can be more aware of improvement throughout the season because the scoring will demonstrate that advancement through the scoring rubric. This simple cohesive scoring system has helped our students understand their expectation and improvement throughout the season. It also helps the students and staff to continue those expectations for areas to improve from season to season.

Karissa Snow: See answer above.

Skylar Christiansen: I feel that we started going to BOA contests to continue to push ourselves as musicians and performers. We were placing at, or near the top, of every traditional contest we entered. So to continue to grow and improve this competitive venue was the next step. Also seeing the types of musicians and performers BOA groups were producing motivated us to follow suit.

Eric Benson: "The key motivations for us to participate in BOA-style events are some of what I mentioned above. It is very useful to know that everywhere we go, we are adjudicated with the same judging sheets by judges who have been similarly trained. It makes it much easier to gauge our progress from one contest to another."

Jaren Taylor: There are a couple key motivators .

A. The kids. We went on a 3 or 4 year run when we won everywhere. We padded the trophy case. It was cool and we ran with it. But as I said before, we would go to a BOA show and get killed. The kids began to see through our trophies to realize that we as a staff were giving them a false sense of success. Kids are smart. They can see the difference in winning a local festival but losing in the overall band world. They knew they were not performing at the same level of your average BOA type band. We talked about it....A LOT. Kids understood the challenge and were comfortable finishing $25^{\text {th }}$ at a contest but having the knowledge that were improving. This was probably more difficult for me than for the kids. In 2013, we won two local festivals, but the trophies that the seniors chose to take their pictures with, were the $2^{\text {nd }}$ place class $2 \mathrm{~A}$ and the $8^{\text {th }}$ place over all from our $1^{\text {st }} \mathrm{BOA}$ regional. See, they know that a huge trophy from the local show did not compare with the success at the national level. In 2015, kids have written that they would rather compete and maybe not make finals at BOA show, then win every caption at a local festival. They want judges to help make them better. They want to BE excellent rather than have a false sense of excellence.

B. The top directors in the country. Yes - THE top people in the country want to see Camdenton be excellent. I have been fortunate to meet many of the "big boy/girls" in our activity and ALL of them that I have worked around have pushed me to push our group to the next level. We take our $8^{\text {th }}$ grade band outside to march a parade every year and I will tell you.....they look awful. BUT.... as soon as we have them march with the HS band, they look 
amazing. That is the way it is with BOA. We surround ourselves with the top bands in the nation and just seeing them, being around them, makes us work harder, makes us better and brings us an understanding of excellence.

Merlin Oaks: Overall I think our kids before BOA only compared themselves to a lot of Missouri schools and now their perspective is one of a Midwest or national basis and how those programs are doing what they are doing. The kids are more aware of the influence of drum corps and its influence on band. Now we use drum corps as a comparison to what we are trying to achieve.

\section{What are the major challenges you face by participation in Bands of America?}

Flora Taylor: When we first entered the BOA circuit, the rules and regulations put forward in the BOA Handbook were quite intimidating. I, as a staff member, had to be more precise with warm-up regimen, equipment usage and placement, all the way down to parent help. The first few years, "the get your feet wet" years, were a bit more stressful. But as the years go by, you, as a director, realize the rules and regulations are not put in place for intimidation of rigidity, but for overall fairness from ensemble to ensemble, competition location to competition location. It is now more relaxed at a BOA function rather than the traditional "Old School" festivals.

Karissa Snow: Our demographic — we don't have access to get kids private lessons-we just - no one will come here because we are so far away. The lake area - the middle class is so small here. We have a lot of seasonal employees here. There are the people who own the resorts and there are the people who work at the resorts. So I would say the area we are in-the demographics.

Skylar Christiansen: I feel the biggest challenge was the transition to the theatrical types of shows and getting the rest of the staff, student participants, and community to buy into the "Next Level" of competition for us.

Eric Benson: "The major challenge we face participating in the BOA circuit is that we must prepare to accept the fact that we are small fish in a big pond. We are a strong program with a dynamic and exciting marching show every year. It is possible for us to select contests at which we are pretty sure we can either win or finish very high. We must set aside our egos for the education of the students and ourselves."

Jaren Taylor: MONEY. Oh my, is it ever expensive. Gone are days of playing Arrangers Publishing. Stock charts will not get it done. You have to have your music specially arranged for your band. Top arrangers are crazy expensive. $\$ 8,000$ is not out of the question AND that is just for the wind book. You have to pay to have you drum book written and a difference person for your front ensemble book. THEN, you have drill writers and guard writers and band body movement specialists. $\$ 35,000$ just for basically the textually component. Seriously!?!?! Oh and don't forget the Copy Rights too. We got off cheap at $\$ 900$ to allow for someone to charge us $\$ 8000$ to arrange the 
music. It is really out of control. I think that this is what keeps people away from BOA more than anything. Money! But there is more too. We stopped marching Trombones, so had to buy 20 marching baritones at 1500 a pop. Hey and don't forget that your sound system better be top of the line with a guy running in that understands gate and wattage and gain and tambre and reverb and etc, etc, etc. Guard members are so important, you need at minimum 30 kids in the guard to be successful regardless of your wind numbers. That's 30 new guard uniforms EVERY YEAR. This is just for a band that is just trying to break into the circuit. I can't imagine how much money it takes for a Broken Arrow or Carmel or Ronald Reagan HS. Don't forget about Staff. You need color guard specialists and Low Brass techs and pit people and snare techs....it goes on and on. When I started teaching, it was me. I was the music writer and the drill writer and colorguard guy etc. Those days are over. Money, Money, money. You need more than you can imagine to be successful. I didn't even talk about travel budget. The closest BOA regional was 8 hours away. Hotel, charters and meals don't come free.

Merlin Oaks: For us to go the next level, our kids need to understand what it feels like to be at that next level. We don't know what it feels like-what it means to be a consistent BOA finalist band yet. Our kids and parents have to understand that if the program wants to be at a certain place, then everyone has to work together to get to that place. It's the commitment to work toward excellence that gets you to the next level. We rehearse more in the summer. We have a June camp and a July camp and we did not do that before BOA. It is more of a continuous training cycle now.

\section{What are the observable outcomes for participation in Bands of America in relation to the musical performance quality of the marching band?}

Flora Taylor: Outcomes of participating in Bands of America has heightened our musical performance quality greatly. Before BOA, Camdenton was a very successful Missouri band program. However, since we became a part of the BOA circuit, we have become more aware that our field performance is more tied into our concert season performances than we ever realized. Brass and woodwind sounds are more related to the indoor sound production than we every focused on before. Percussion has changed greatly. The percussion department has completely changed their role in the fall outdoor performance. From individual to sections, the percussion is aware of their parts and roles and how they integrate with the wind parts. Before, that was not always the case. Overall, our fall show is more musical than anything we ever performed before the BOA circuit became a part of our season.

Karissa Snow: Through participation in BOA, the performance quality has definitely gone up. BOA puts a very positive emphasis on the music part of marching band. In past years, we came to a part in Missouri where the emphasis was not necessarily upon the music - it was upon the show - the smoking mirrors - the uniform - BOA has positively influenced the emphasis on the music.

In concert band, we use some of the same language to get the musical concepts out of the band. 
Skylar Christiansen: I feel our kids play more like a concert band on the field now than in the past. It isn't about being the largest and loudest band. It is about the quality of musicianship of the kids. It is the same for the performance side of things. This kids no longer stand with perfect posture for every set - there is body shaping while playing and performing. The guard has had to step up their quality of performance even more. They are more of the storytellers than the musicians.

Eric Benson: "The best thing we have observed in our time on the BOA circuit is a change in attitude in our students. They get a chance to see what some of the very best bands in the country can do, and many of them are eager to emulate them. We know that we have some "disadvantages" when it comes to competing with some of those top-tier groups, but that does not seem to stop our kids from wanting to be the best, or at least among them. It makes great educational sense to show kids how the most successful groups rehearse, perform, and behave. We are all glad that BOA has given our students that chance."

Jaren Taylor: The Camdenton band plays better. We are more concerned about playing musically than ever before. You can see our music scores improve from the time we began until today.

\section{How would you summarize the influence of participation in Bands of America on your band program?}

Flora Taylor: For my participation in the Camdenton Band Program and our participation in the BOA circuit, it has made me a better director for our students. Every detail, from timing a pre-show, to how equipment goes from field to truck, to how each band member contributes every note and movement, BOA has a direction. Embracing the BOA style has heightened my awareness of the percussion's role in the overall sound of the marching band. It (BOA) has also changed our design direction to a more cohesive theme with elements precisely directed to the overall theme of the entire show. Whereas, before, we were not aware of all the components necessary to make that theme "speak" to the audience. BOA is the most important thing we have done for our marching band season. Being a part of the BOA organization is one of the most positive influences we could have ever done for our students.

Karissa Snow: I think BOA has been a positive thing. It has been a positive thing for marching band because of the push for not only the music but also for the entire package. Once we figured it out, now we know what we are doing and where we are going. Once we figured how you go for it, BOA has been a positive experience.

Skylar Christiansen: I feel that participation in BOA has improved our program. We may not finish with a win at any BOA contest, but our kids are much more rounded individuals as far as musicianship, literature, and performance quality than in the past. They are making connections with their show music and themes with other disciplines of education (English literature and history). 
Eric Benson: "I would summarize the BOA influence on our band program as very positive. Our students enjoy the competitive nature of marching band, and certainly enjoy seeing other groups and what they can do. While it is not always pleasant, holding ourselves to the highest standards we know is just sound educational policy. The single drawback I would highlight would be that each year, bands are constantly trying to "outdo" themselves and each other. I think this may someday lead to the proper execution of a marching program in the BOA style cost and time prohibitive for many groups."

Jaren Taylor: BOA has made my concert band better, my jazz band better, holy cow....my pep band better, my middle school bands are better.

We have become better teachers because of Bands of America.

Merlin Oaks: Because we are a rural school, participating in BOA has broadened the horizons of our students. They are not just seeing what happens in Central Missouri, but they are seeing what is happening in Minnesota, Colorado, Ohio, or other parts of the country. They are being exposed to a broader range of marching band concepts. They get to meet kids from all over the US. Some of them have made friends and contact each other contact periodically. They compare notes. They become this larger group of common people who share common elements through marching band.

\section{Additional Comments:}

Flora Taylor: On a side note, every time we go to a BOA event, the air of positiveness is overwhelming. Everyone claps for everyone else. When there is a soloist or a great moment with the color guard, or a big musical moment with the ensemble, the audience applauds. This does not always happen in Missouri. Our state has a tendency to "look" for the mistakes, to hope for an error. I know there are rivalries and there are bands that have a deep desire to beat others in competition, but the feeling at BOA is a more "all in this together" feeling rather than "every man for himself".

Merlin Oaks: How has your participation in BOA influenced your school's band staff?

The staff communicates a lot more now-we have more collaboration. Its about drill sets - how can we fix drill problems, etc. We used to try and put the show on the field first and then go back and clean drill. Now, we try and clean up things as we go. Now, staff members will jump outside their own particular caption in order to address other issues that haven't been brought up in a meeting. It is a little more cross caption teaching. No one is afraid to step out of his or her caption and help another caption.

We have learned that from watching and talking to the Broken Arrow staff. We have someone on the field to take care of what needs to be taken care of so that others can watch from the top of the stadium or in our case the hill. 
Has your participation in BOA resulted in the necessity to begin winter color guard and winter indoor percussion festival attendance?

We have re-started winter guard. We will have three winter guards this year. We have done that to try and boost our color guard numbers. This makes u s stronger when we get into the fall.

As a guidance counselor, what challenges do you face in maintaining a schedule that allows students to stay in band? How difficult/what impact does marching band have on the students fulfilling their core requirements? Are there scheduling difficulties?

When the IB program started, there was the perspective that kids could not do band or choir. There has been a lot of educating that there is no reason why a kid cannot stay in the IB program and be in band or choir. The district has adapted to the idea that kids should have those choices to be in band and also participate in IB. We have modified the schedule in order to accommodate the kids in band.

BOA has not created retention problems. BOA has not caused any kids to drop into band. BOA has made the band more physical, so some kids can't fulfill their commitment physically, but otherwise the kids just know what their commitment expectation is.

\section{Student Responses:}

What is the main influence of BOA on you and the band and how does this influence band practice/learning drill \& music?

Competing at a higher level (Anita)

BOA brings a higher level of performance (Stewart)

Compete at a national level (Carl)

"It (BOA) affects everything-how we shape our show-the standard for which we strivewe strive for a national standard." (Kim)

We are shooting for that national level (Kim)

It shows us a new level that we have to achieve (Mark)

Competing against bands that push hard (Anita)

Pushes me to do my best (Carl)

I am striving to be a better me (Mark)

Pushes yourself to do better (Anita)

"It (BOA) challenges and motivates us so that we push ourselves more. We go out there to be the best we can be. We push ourselves to be better each time we practice and each time we perform." (Kim)

I try to work hard and do everything with greater efficiency (Trevor)

It pushes you to learn faster (Kim)

Makes me want to be better (Carl) 
It influences us to be better at what we do and to show off (Julie)

BOA pushes me very hard in our full ensemble rehearsals (Antoine)

I try harder-I focus on specific spots (Fred)

When it comes to drill, ... it makes me want to strive and find the best way to make it to my spot (Jake)

Pushes others to keep on pushing (Carl)

The work ethic with everyone is a lot better (Trevor)

Requiring a better work ethic makes them better at other things in life (Ted)

(Everyone else) wants to strive and see how far they can go and how good they can

become (Mark)

(BOA) makes you want to perform the music and musicality (Anita)

Makes me focus on how the music moves me (Antoine)

When it comes to my music, I want to sound great for these competitions-it just makes

me want to strive to do my best (Jake)

(BOA) makes you want to perform to the emotionality of the show (Antoine)

BOA just makes us a better product in general. Everything about our performancevisual or musical-is just at a better level by attending BOA (Ted)

It (BOA) makes me practice more and makes me push myself to be a better marcher and player and to show improvement at each contest (Julie)

Our practices are geared around how we are going to be judged at BOA (Sally)

"I think the BOA aspect affects Camdenton's rehearsals quite a bit. I think the director pushes us a bit harder. We require more of the students because they need to be on a different level. Rehearsals become quite rigorous." (Ted)

\section{Does BOA make Camdenton a better band?}

It's nice to compete against amazing bands. We are competing at a higher level against really great bands.(Antoine)

Yes - BOA pushes us to be better players and marchers and to just improve us as a band (Julie)

Yes because it pushes us to get better." (Sally)

Yes - BOA gives us a higher standard that we have to push ourselves to. We have to work harder and push ourselves harder and stronger-it motivates us more (Jake)

Yes because we see those high level bands and we want to achieve and strive to achieve those high levels (Mark)

"Yes it makes us better. We compare ourselves to better bands and we see what other bands do and if we need to improve." (Sherry)

"Yes-it gives us a higher standard that we have to push ourselves to. We have to work harder and push ourselves harder and stronger - it motivates us more." (Jake)

"We compete against bands that are high caliber and it pushes us to be better " (Sally)

"I think by participating in BOA it takes less emphasis on winning the awards-we see bands ...that always do well. We know we aren't going to beat them but they inspire us. It takes the stress off us and lets us concentrate on how we play the music." (Stewart) 


\section{How has BOA shaped the culture of Camdenton?}

"We see our marching band as a team sport-for what it is. BOA means that EVERYONE must be performing to his or her utmost potential. We see that every mistake we make affects all 179 other members. We also see the emotional effect of the music. BOA makes you remember-makes you think about every mistake you make and you remember that there are 179 other people who are working as good for your score as you are working for their score. It is selfish to not perform at your highest level" (Antoine)

"I think we get along. We have our bumps and struggles like very family, but we all work together for the bigger picture. We make new relationships. We help new people out." (Fred)

"We are a family-you are closer to people in your section. It is like having a ton of little sisters. If they need help, you are going to be there for them and we are always going to be together. With the instructors, you know that they are going to be there. The staff makes this what it is. They may push us, but they know us as people and they know what we need. They are extra parents-they know how far we can be pushed to be great." (Kim)

"Students can get quite a few things as a result of the band's participation in BOA. There is a greater degree of work ethic by being involved in this group and I think that helps in more than just the band aspect of your life-a work ethic is good for life-college. There is also a greater sense of family and camaraderie and I don't know if that would be the same if they weren't pushed as hard." (Ted)

I love the band-I see it as a second family. Band trips are like family vacations (Jake)

Since we are competing at a higher level, we spend a lot of time together. At BOA competitions, everyone is wishing everyone good luck (Anita)

There are two types of practice. There is the kind that you do for yourself and the kind that you do for your band (Antoine)

You are responsible to al 180 members of your band to push and correct those mistakes you make, no matter how minor (Antoine)

When I think about all those other bands practicing it makes me want to do better for my band (Antoine)

It really makes me want to do my best and to step up to the plate and help others so that they can do their best so that we can compete well in these competitions (Jake) For me-when it comes down to practice, it comes down to what you want from yourself-for you to see how far you can push your self. I do it for the other band members (Mark)

I try to be professional and I get a little snippy with everyone, but it is only because I care. I want the whole color guard to be looked at like a group (Sherry)

Each individual has to be better in order for the whole band to be better (Trevor) I can't always be perfect but I can try, and help others to be perfect too (Sherry) It focuses on unity within the whole program. We are all here to help one another (Stewart) 
We have patience with each other and the common desire to be better. (Trevor)

\section{Does BOA motivate/challenge you more than MO contests?}

Music and musicality aren't important at other contests (Anita)

With BOA I trust that my efforts will be rewarded (Antoine)

Yes-part of it is the challenge. It (BOA) is more organized. MO contests are not regulated by any national system (Stewart)

BOA is very competitive (Antoine)

BOA) is the most competitive competition and it really pushes you to feel the music music should have feeling (Anita)

"I feel a higher level of accomplishment even if we don't place-we work harder. It is more important to do better than at regular contests where we could easily place."

(Trevor)

Going to BOA is a greater challenge and a greater pool of bands (Stewart)

BOA makes me want to perform better (Antoine)

BOA gives us a very strong sense of motivation (Jake)

I would say yes again, because it's the level of strictness they have with their judging and the caliber of bands we compete against (Sally)

As a freshman, it is your wake-up call when you compete, you see these other schools and you see what you are up against (Sherry)

BOA is harder and it is a more difficult thing to accomplish-so it makes you go the extra mile (Carl)

Everyone is motivated to push further and do better. BOA pushes us more than any other contest. It gives us a sense of achievement when we push further (Trevor)

Being able to see BOA shows influences how I am going to pace myself-just seeing those bands perform at that level reminds me of what I can do (Antoine)

It (BOA) motivates me to see how far I can push myself (Antoine)

I am competing with bands that are on the national level and that have actually won grand nationals. It is making me try harder (Fred)

It motivates me to be more successful and to do better (Trevor)

We feel motivated to work hard even on the bad days (Trevor)

I think BOA is what has increased the work ethic and the motivation to work harder (Trevor)

"I definitely feel that when there are 60 bands in the competition and 12 in the finals, you want to make it in to the top 12 or 15 . In all these other competitions, we are always up there in the top, but when it comes to BOA, we all really have to work and od our best if we are going to make finals." (Jake)

"(BOA) puts us into competition with bands that we wouldn't normally be in contact with in the state. Some Missouri bands that we might otherwise compete against don't go to BOA. Part of it is an inspiration-we see a band that has won Grand Nationals so we think that we should do that-we get a level of success that we haven't attained to yet. We see how other bands do what they do and how we can get better." (Stewart) 


\section{Would you rather go to MO contests?}

No-we wouldn't strive to be the best-we wouldn't try to be our best-it is what motivates us (Kim)

If we were to just go to some of these little competitions, we might be a little more loose (Jake)

No-BOA pushes us more to be better (Carl)

No-BOA makes us become better (Julie)

No. I feel BOA makes us better (Sally)

No. They are always fun but I would much rather compete at a high level. I like the professionalism at BOA-doing the retreats and getting to meet everyone (Fred)

No (Sherry)

"No definitely not. They don't push you when you know that you are going to be at the top, and so you don't try as hard. If we went into a competition where we knew we would do well, we would only halfway play the show and not concentrate. The musicality that comes from BOA pushes us." (Anita)

"No. I think if we did that we would lose the work ethic. We have been pushed by going to BOA competitions. And it would turn the marching band program into a joke. We would just expect to go in and beat them-we would not expect a challenge. It wouldn't be like we go into this to learn the music-it would become just like a sport." (Stewart) "No-trophies aren't important to me. Working harder and being more challenged is more value rather than going to random festivals that we could easily win." (Trevor)

\section{How do others view Camdenton?}

"I feel they see Camdenton stepping up and taking the extra mile and the initiative." (Carl)

"It definitely makes them look at us higher. We have competed against bands from all over and we are comparable to them. If the tiny town of Camdenton can do it, some of them can too." (Anita)

"I think they view us as a very good band. But we don't compete where a lot of these bands compete because we mostly do actual BOA events. I think we aren't exposed, but some of the bands that do go to BOA view us as competitors. But there is also a camaraderie that goes along with BOA. Once the contest is over-you understand you are all there for the same reason-pushing yourself and communicating emotion." (Antoine) I would hope they think very high of us (Fred)

Bands that don't attend BOA are intimidated by us. We are getting stronger and it pushes them more to keep ahead of us (Jake)

I think they view us as one of the best bands in the state (Julie)

I hope they find us to be confident in that we think highly of ourselves, but not too confident (Sherry)

After this year, we have made a name for ourselves. We are in the same league as some of the highest-level bands in the state (Stewart) 
I feel they view us as a band that is really improving and that has come a long way in the last couple of years (Sally)

\section{Do you like/how do you feel about the fact that your band goes to BOA?}

Yes-I enjoy the opportunity to compete with bands at a high level and I also appreciate the opportunity to observe those bands (Antoine)

Yes, it makes the band strive to be better and we enjoy seeing the band be a success (Carl)

I love BOA — seeing other bands and meeting new people. Watching bands and seeing their routines (Sherry)

"Yes, of course I absolutely love it. You go against high-level bands and you can taste their passion-and it is a matter of passion." (Mark)

Yes, because we get to see the way the different contests work and BOA is just a high level-it makes us become better (Julie)

"I love the fact that it pushes us further; it makes us be successful and go further, and I like being successful and going further. It motivates us." (Trevor)

"Yes-its exciting knowing that at the end of the season we are going to compete against some of the best in the nation. Its incredible to know that we've come so far from where we were at the beginning of the season to now-it is awesome!" (Kim)

I think BOA is great-the level of competition-the quality of contest-the quality of judging is great (Ted)

I like the way that BOA is judged; the fact that the importance is in the musicality (Anita) "I think it is really a neat experience to be judged the way we are and to get to know the other bands that are there." (Sally)

I think it is an amazing organization to recognize bands from all across the country under one scoring system. I feel that it puts all bands on the same level and holds them to the same standard and promotes emotionality and musicianship (Antoine)

"The reward of being a BOA band is just getting to perform and doing what you do your best; to go out on the field and show people what you have spent hours trying to perfect." (Ted)

"I love it" (Fred)

I love going to BOA-it gives us a sense of where we need to go. (Trevor)

I really enjoy it (Carl)

"I feel like it is really a great experience and chance in your life. It is a great experience in your high school career." (Julie)

BOA is absolutely a good thing (Ted) 


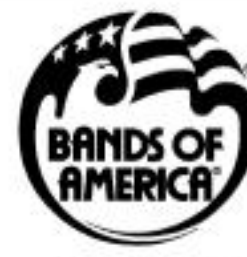

ANONPROFT EDUCATONAL ORGANIZATION
Band

Date Prelims

Finals

Music General Elfect is the utlization of al elements to bring about maximum ellectiveness $\alpha$ the musical pertormance. Evaluate each caption below besed on the criteria reference. Understand that we evaluate what is being performed at the same time we are evaluating how $\mathrm{t}$ is being performed. Since we judge achievement, we must understand that the construction and content $\alpha$ a program, h combination weth the pertormance level which is being demonstrated, will determine the achlevement level. It is impossible to consider one of these elements wthout consibering the othec.

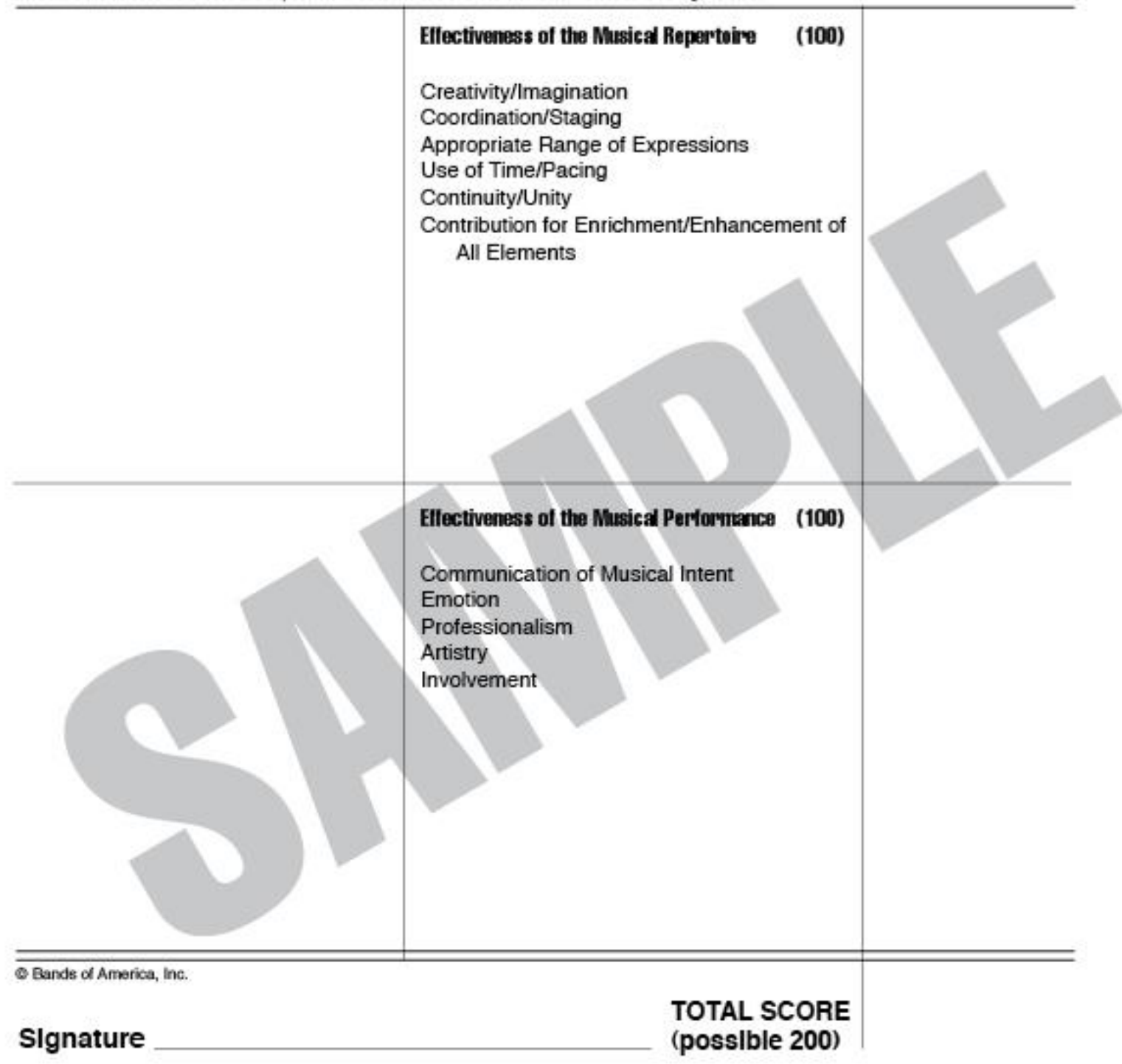

Used by permission of Music for All 

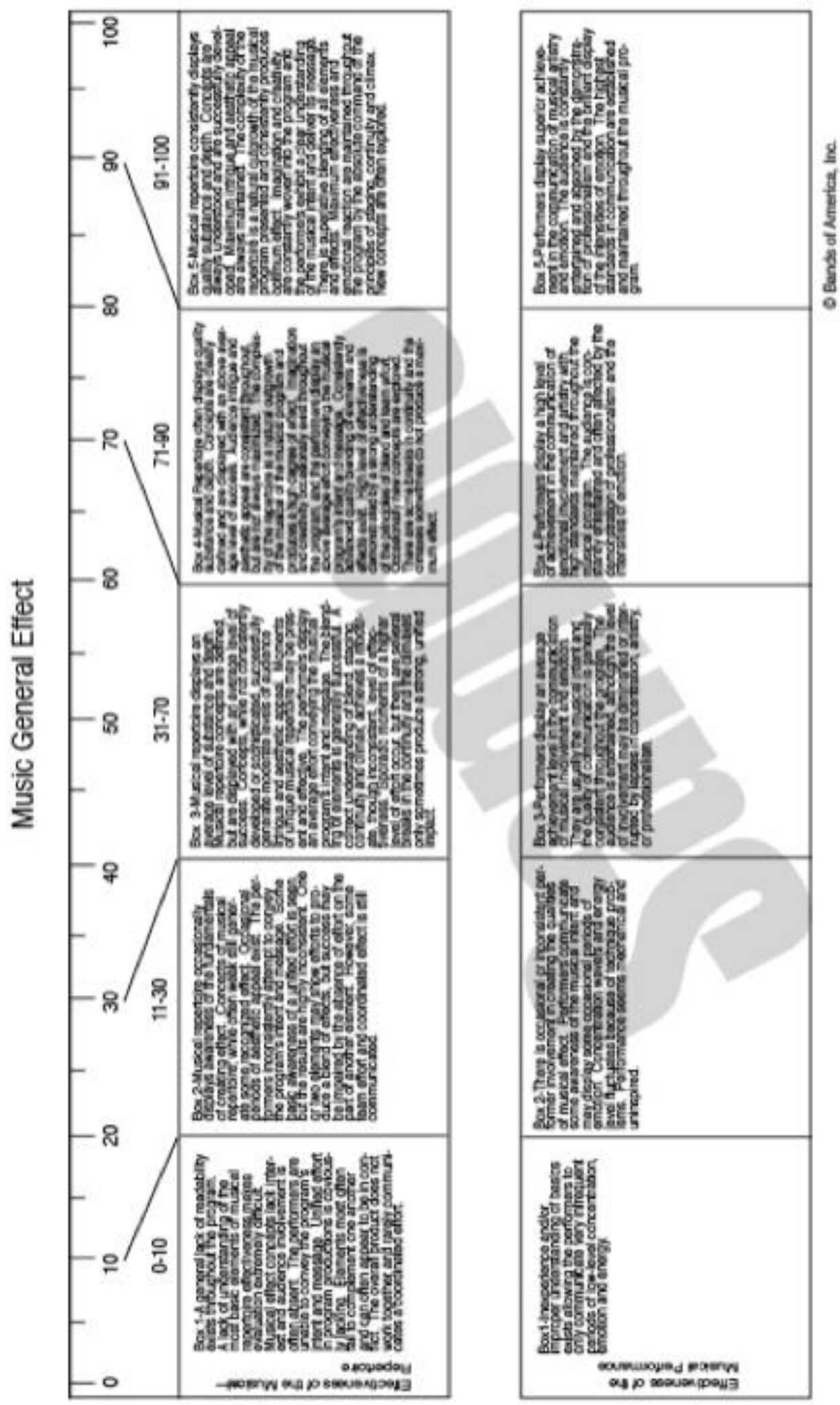

Used by permission of Music for All 
Date_

Prelims

Finals

\section{MUSIC PERFORMANCE \\ (INDIVIDUAL)}

A NON-PROFIT

EDUCATIONAL

ORGANIZATION

Evaluate each capton below based on the crterli reference. Understand that we evaluate what is being perfomed at the same time we are evaluating how It is being performed. Since we judge actievement, we must understand that the construction and contert of a program, in combinabon with the periormance level which is being demonstrated, will determine the achievement level It is impossibla to consiber one of these elements wilhout considering the ocher.

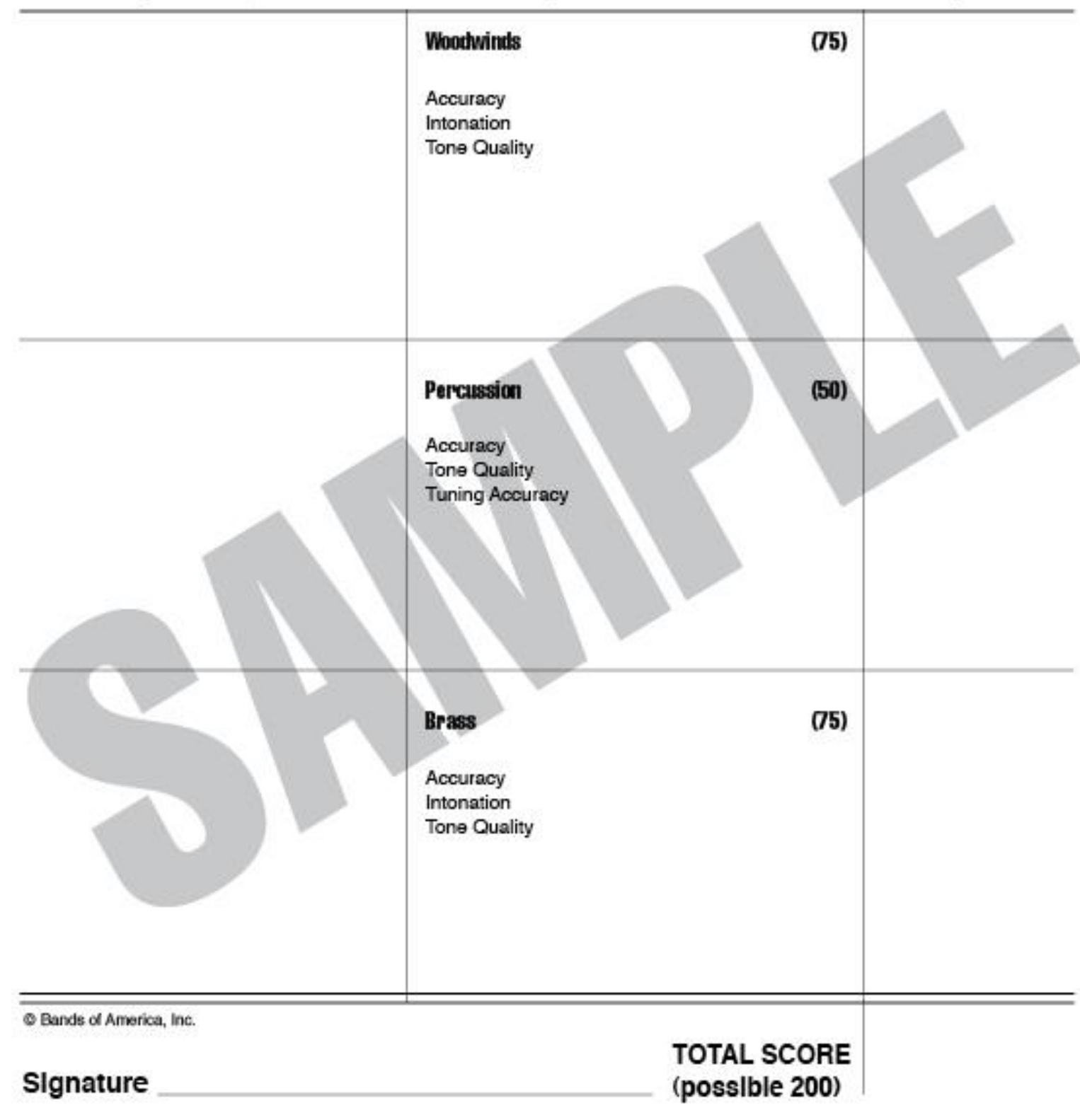

Used by permission of Music for All 


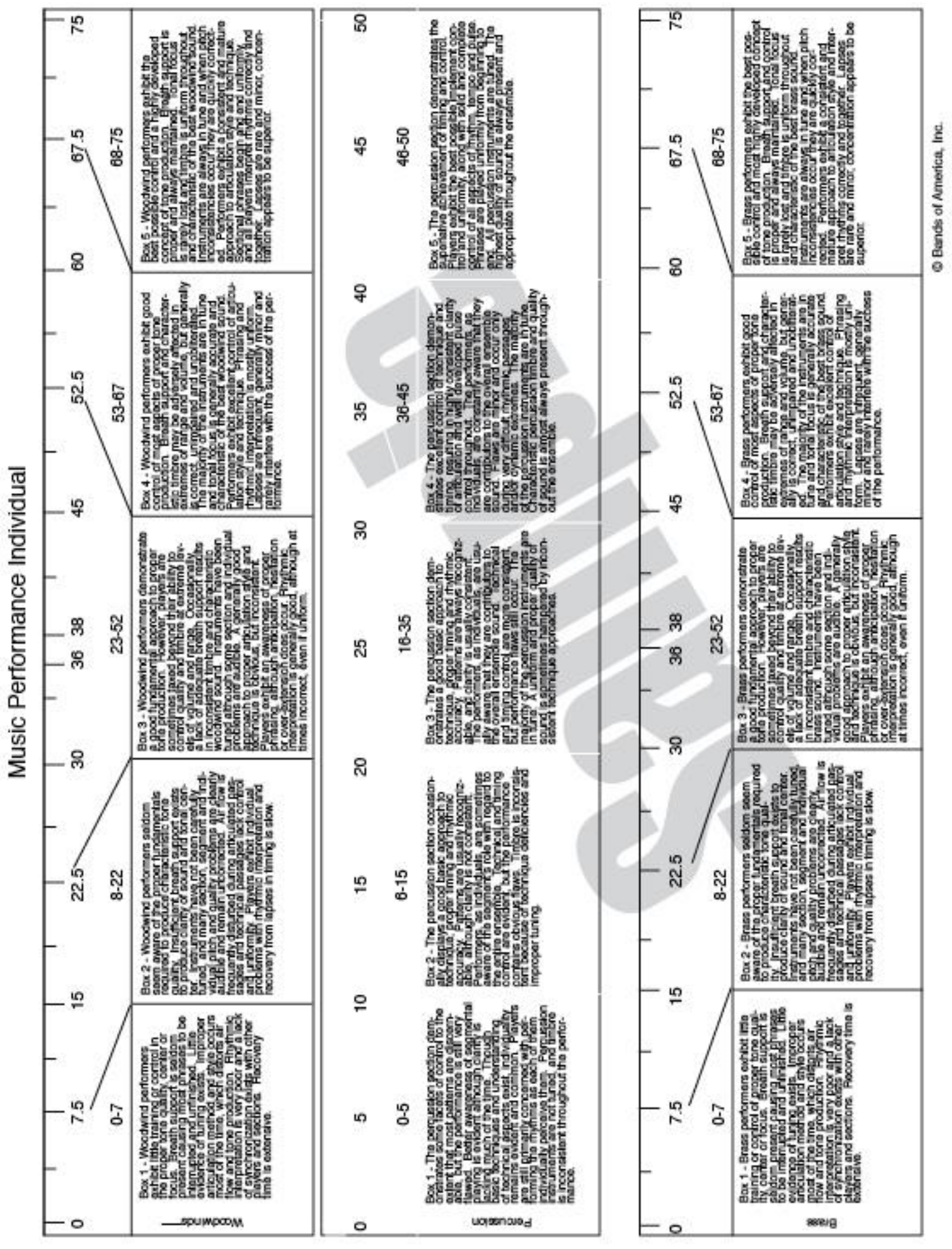

Used by permission of Music for All 
Date

Prelims

Finals

\section{MUSIC PRFORMANCE (ENSEMBLE)}

A NONPPOFIT

EDUCATIONAL

ORGANIZATION

Evaluate each capoion below based on the criteria reference. Understand that we evaluate what is being perfomed at the same trme we are evaluating how it is being performed. Since we judge actievement, we must understand that the construction and contert of a program, in combination with the pertormance level which is being demonstrated, will determine the achievemert level. It is impossible to consider one of these elements without considering the ocher.

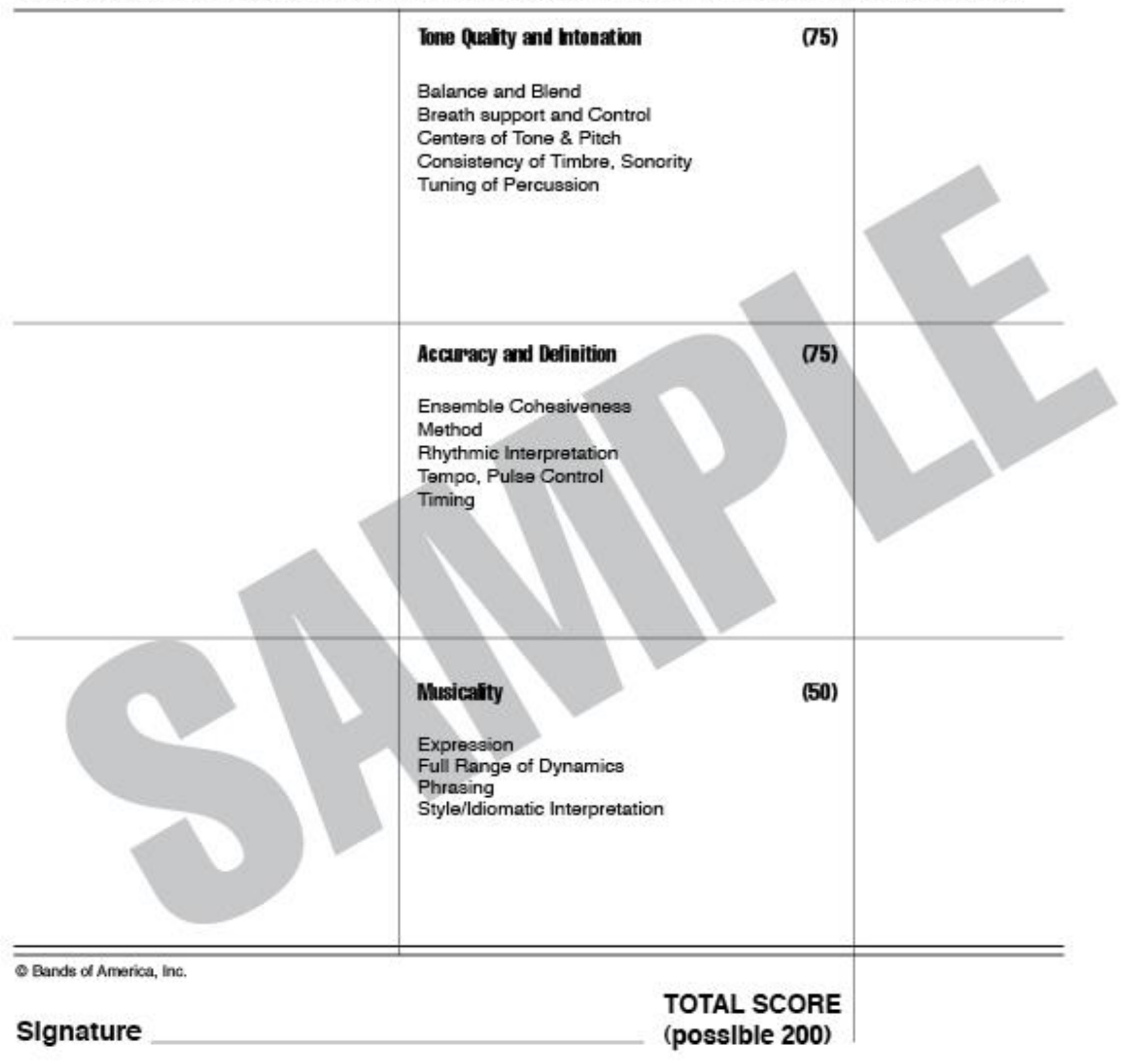

Used by permission of Music for All 


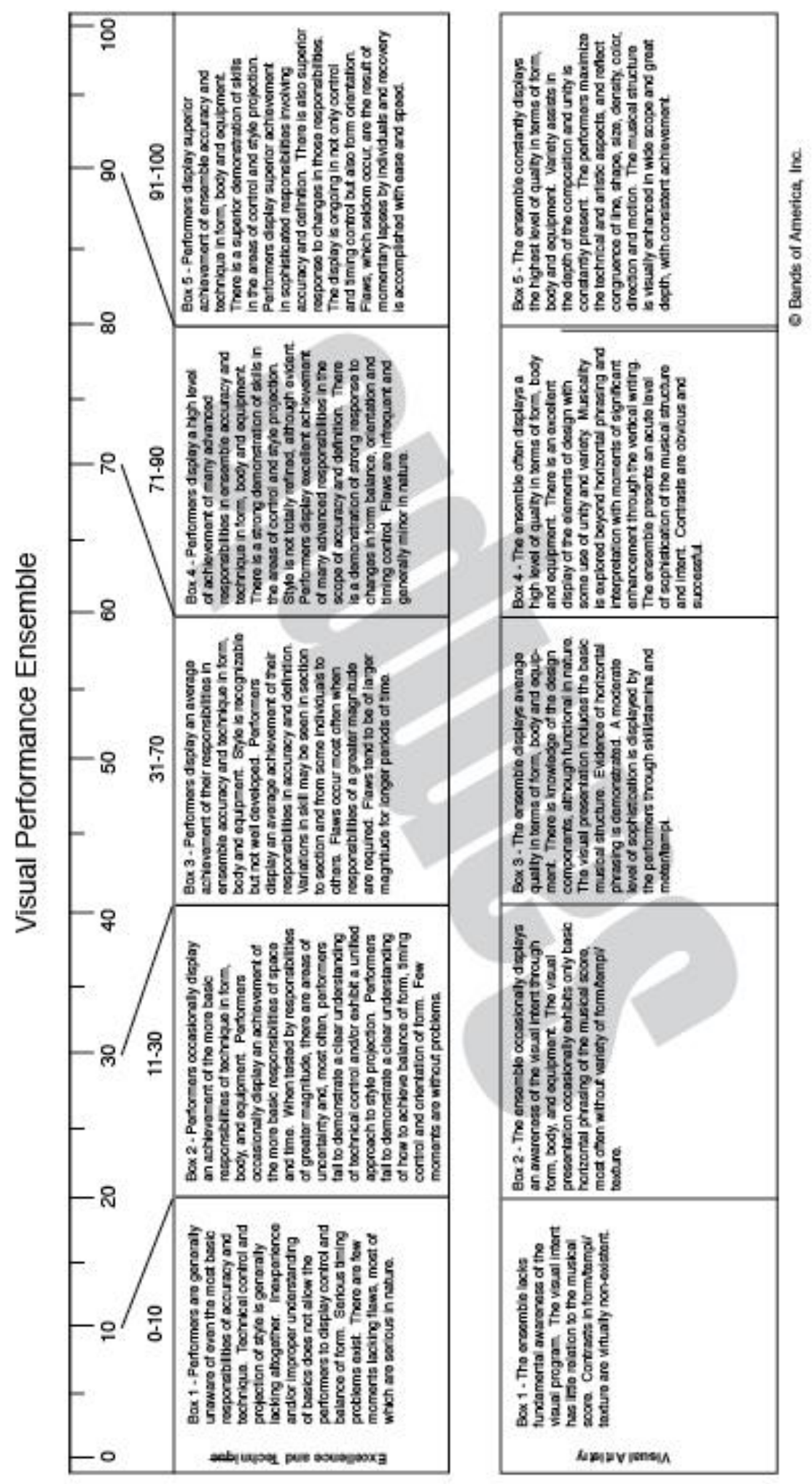

Used by permission of Music for All 
Band

BANDS OF

Date

Prelims

Finals

AMERICA

A NON-PROFT

EDUCATIONAL

ORGANIZATION

\section{VISUAL GENERAL EFECT}

Vsual General Ettect is the utlization of all elements to bring about maximum effectiveness of the visual presentation. Evaluate each caption below based on the criteria reference. Understand that we evaluate what is being performed at the same time we are evaluating how if is being performed. Since we judge achievement, we must understand that the construction and content $\alpha$ a program, in combination with the performance level which is being demonstrated, will determine the achievement level. It is impossible to consider one of these elentents without considering the othe:

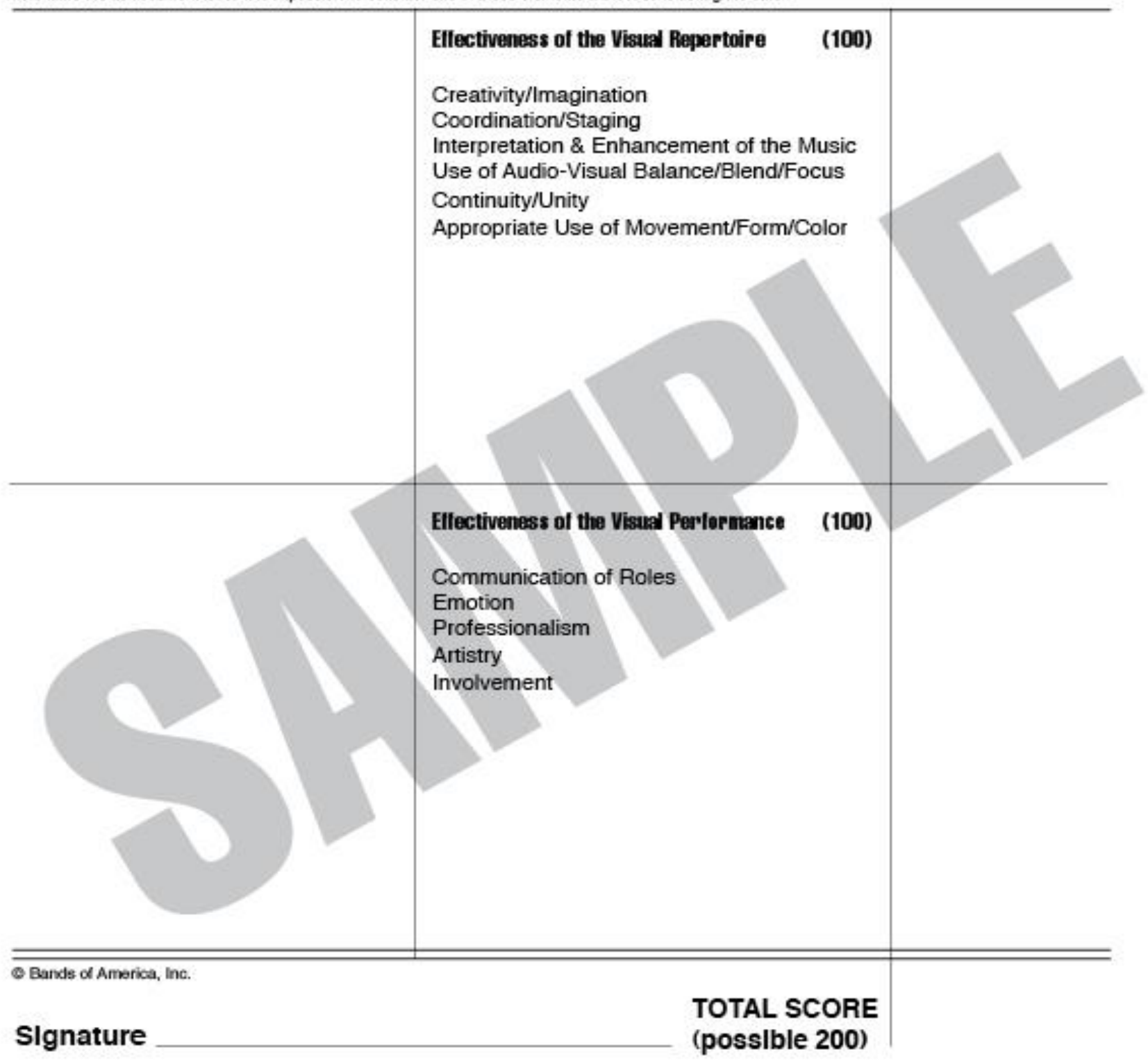

Used by permission of Music for All 

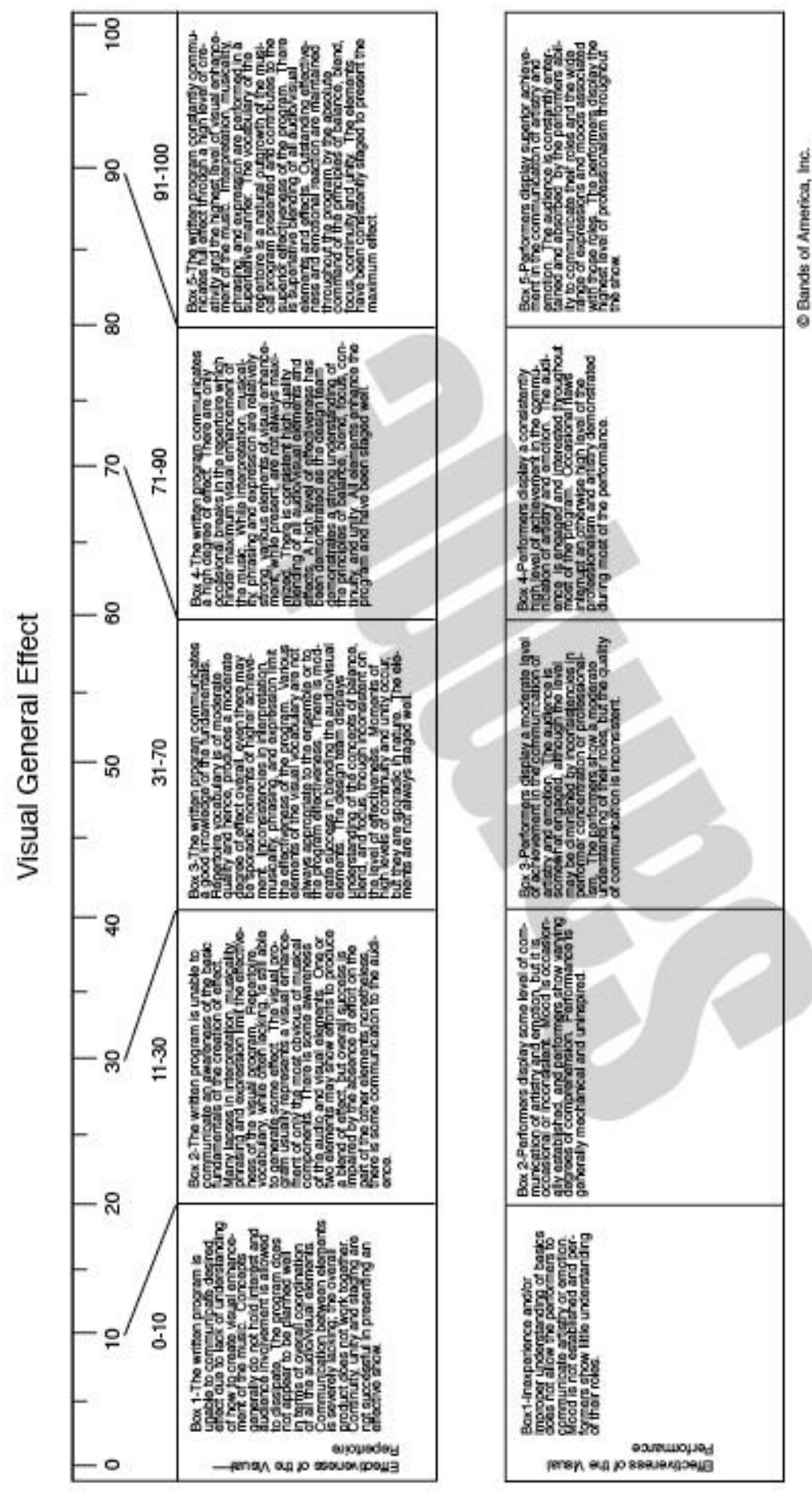

Used by permission of Music for All 


\section{VISUAL PQRFORMANCE \\ (INDIVIDUAL)}

A NON-PROFIT

EDUCATIONAL

ORGANIZATION

Be sure to comment on the relattve strengths and weaknesses of all sections (winds, percussion, atadliary). Evaluate each caption below based on the crteria reference. Understand that we evaluate what is being perfomed at the same time we are evaluating how it is being performed. Since we judge achievernent, we must understand that the construction and content of a program, in combination with the perfomance level which is being demonstrated, will deternine the achievement level. It is impossible to consider one of these elements without considering the other.

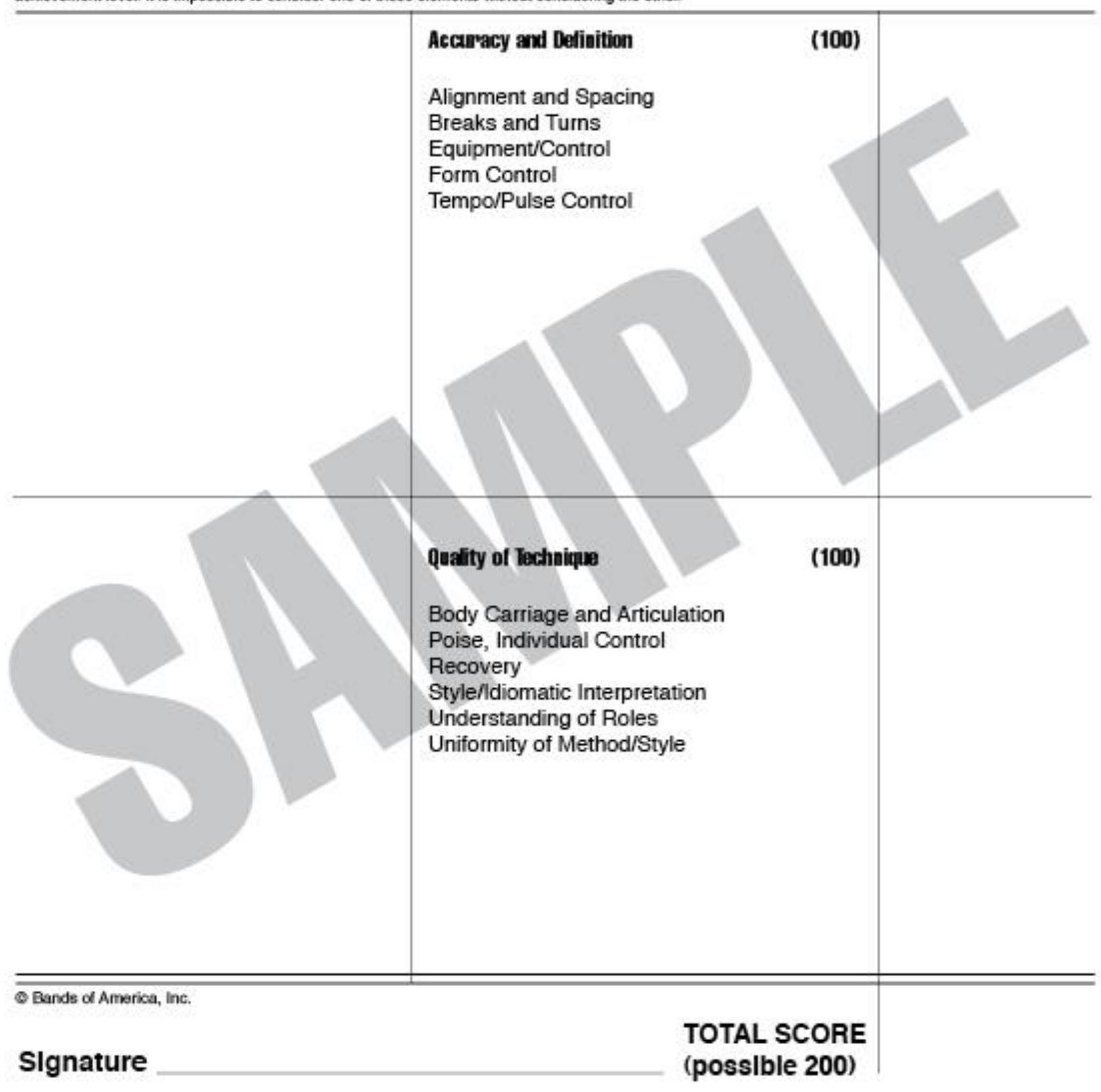

Used by permissin of Music for Al 

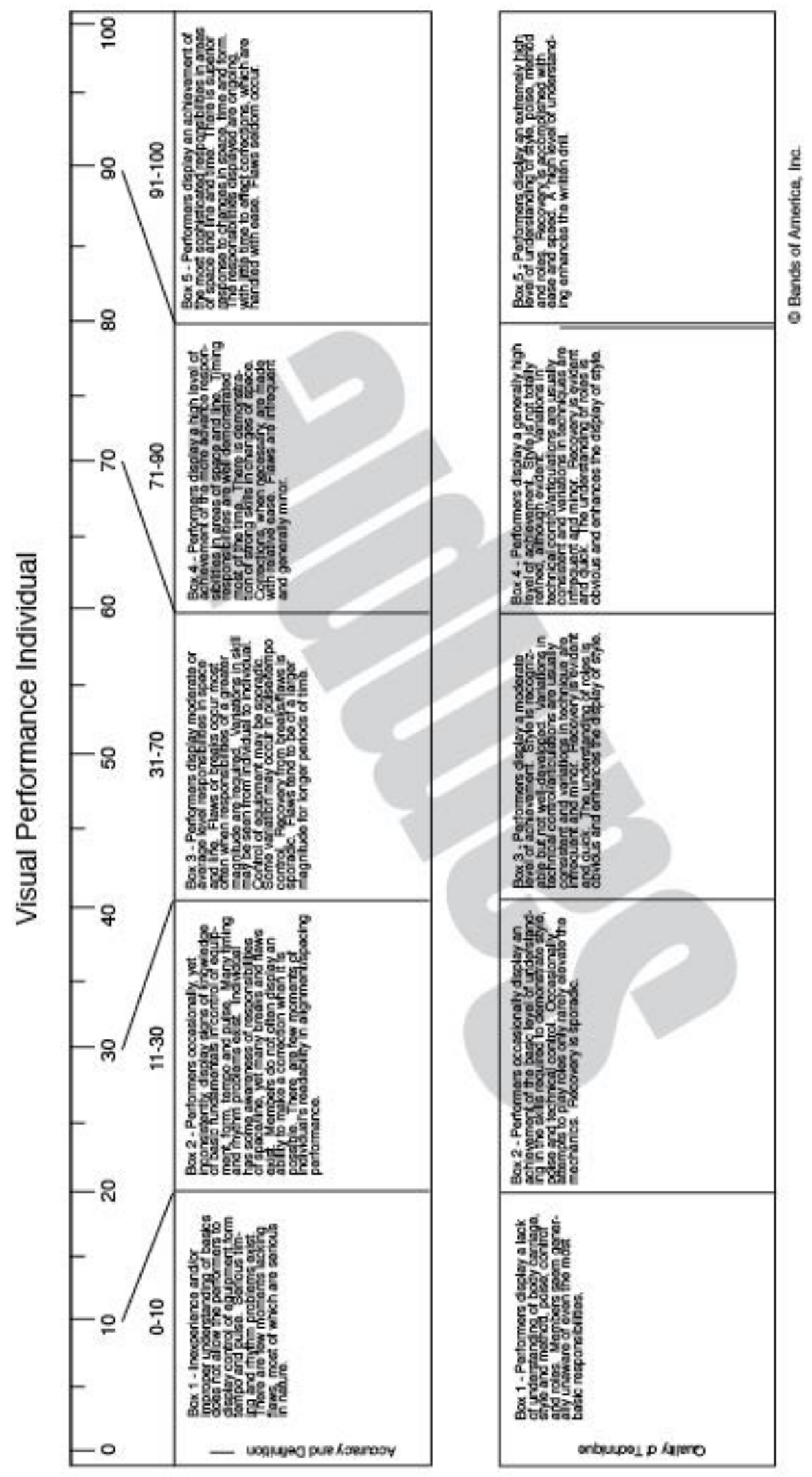

Used by permission of Music for All 


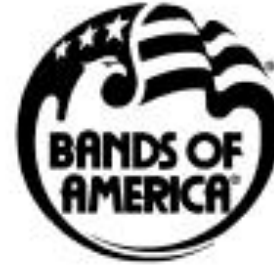

A NON-PROFIT EDUCATIONAL

ORGANIZATION

Date

Prelims

Finals

VISUAL PGRORMANCE (ENSEMBLE)

Evaluate each capton below based on the criteria reference. Understand that we evaluate what is being performed at the same time we are evaluating hos it is being performed. Since we judge achievement, we must understand that the construction and contert of a program, in combination with the pertormance level which is being demonstrated, will determine the achievement level. It is impossibla to consider one of these elements without considering the other.

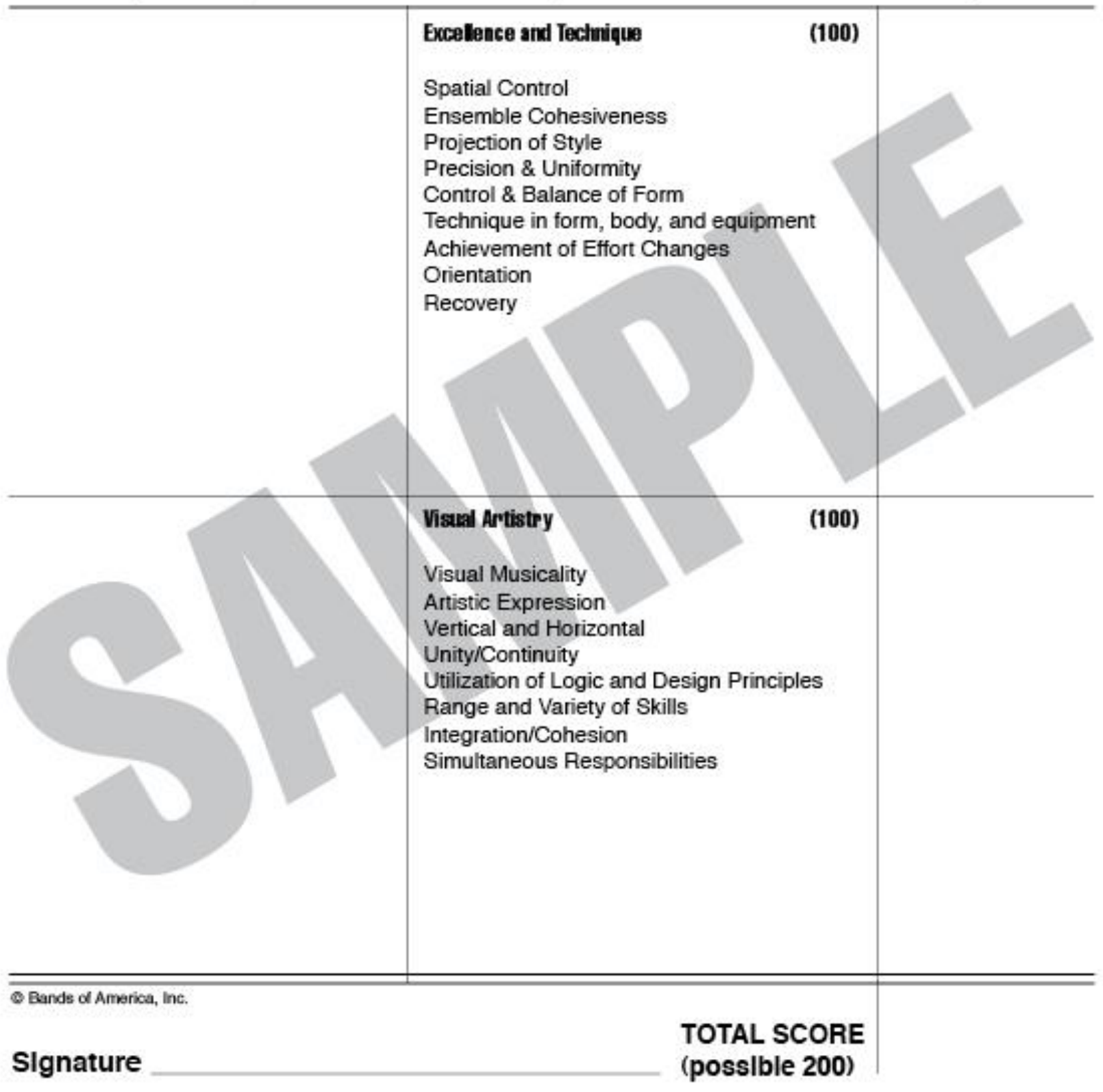

Used by permission of Music for All 


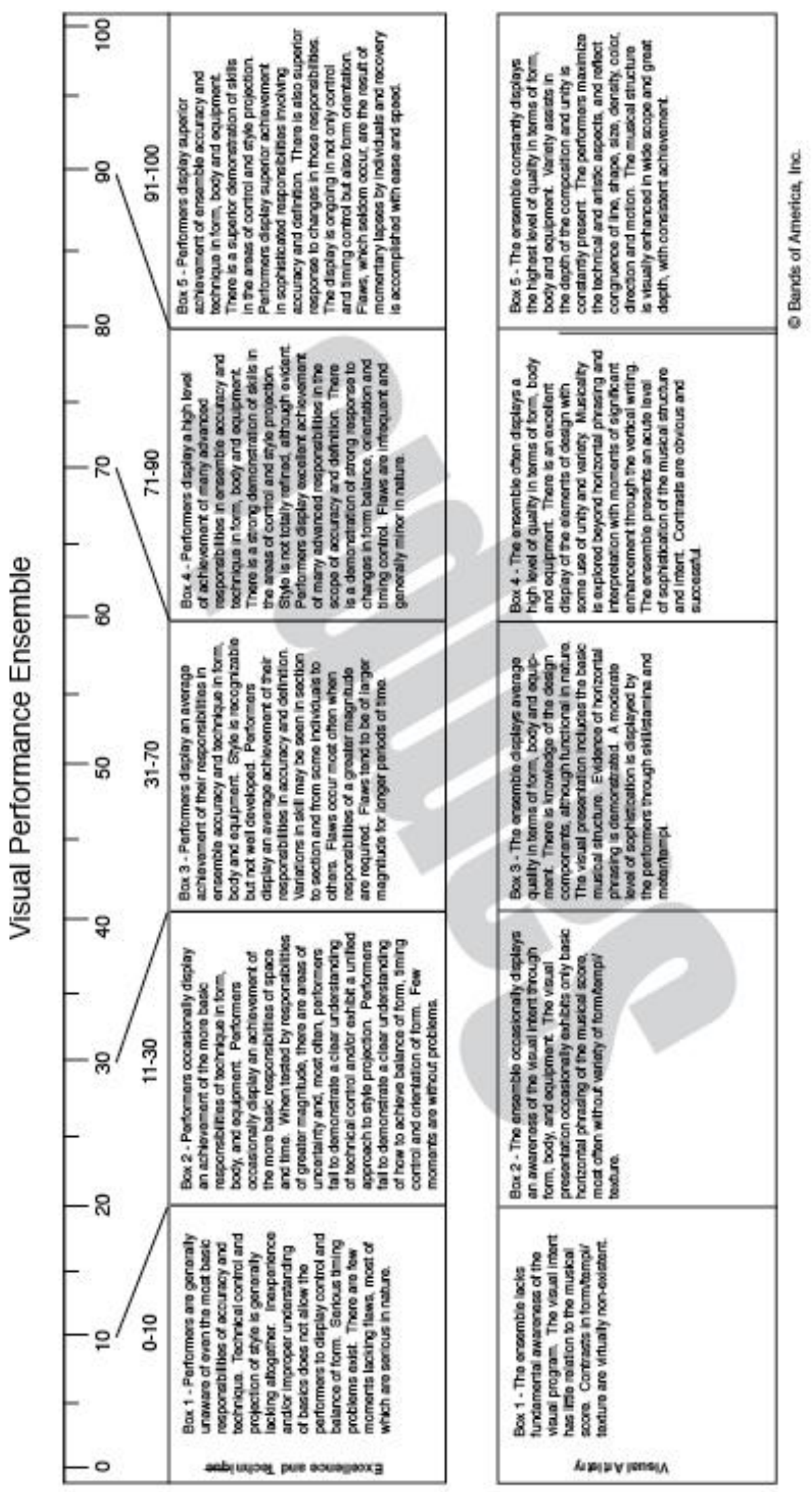

Used by permission of Music for All 
Stephen C. Eubanks attended Missouri Southern State College in Joplin, Missouri, earning a Bachelor of Music Education degree in 1979. After three years of serving as director of bands in the public schools of Alton, Missouri, he began the position of assistant director of bands for the Jefferson City public schools in 1982. He received a Master of Education in Curriculum and Instruction with a major in Music Education from the University of Missouri in 1986. In 1993, he worked as director of bands for the Carthage, Missouri public schools. In 1995, he returned to the Jefferson City public schools, where he became the director of bands and music department chairperson in 1996. He continued in this position until his retirement in 2009. In 2016, he received a Doctor of Philosophy in Learning, Teaching, and Curriculum, Music Education from the University of Missouri. As a doctoral student there, Stephen taught courses in music education, assisted in instrumental rehearsal clinic and basic conducting courses, and supervised the music student teaching seminar while attending graduate school. He assisted the band program at the University of Missouri, frequently serving as a guest conductor for ensembles in the School of Music, as well as working with Marching Mizzou. A regular clinician and adjudicator for Missouri school band programs, Dr. Eubanks will begin employment with the University of Nevada, Reno beginning in the fall of 2016 as assistant director of bands and music education lecturer. 